\title{
GirlsRead! E-Reader Curriculum
}

Natalie Jackson Hachonda

Population Council

Nicole Haberland

Population Council

Abdul-Kahad Alhassan

Beatrice Ani-Asamoah

Pamela Nyirenda

See next page for additional authors

Follow this and additional works at: https://knowledgecommons.popcouncil.org/departments_sbsr-pgy

Part of the Demography, Population, and Ecology Commons, Family, Life Course, and Society Commons, Gender and Sexuality Commons, and the International Public Health Commons How does access to this work benefit you? Let us know!

\section{Recommended Citation}

Hachonda Jackson, Natalie, Nicole Haberland, Abdul-Kahad Alhassan, Beatrice Ani-Asamoah, Pamela Nyirenda, and Barbara Mensch. 2018. "GirlsRead! E-Reader Curriculum." New York: Population Council. 


\section{Authors}

Natalie Jackson Hachonda, Nicole Haberland, Abdul-Kahad Alhassan, Beatrice Ani-Asamoah, Pamela Nyirenda, and Barbara Mensch 


\section{Ponutron \\ Poncente \\ Ideas. Evidence. Impact.}

The Population Council confronts critical health and development issues - from stopping the spread of HIV to improving reproductive health and ensuring that young people lead full and productive lives. Through biomedical, social science, and public health research in 50 countries, we work with our partners to deliver solutions that lead to more effective policies, programs, and technologies that improve lives around the world. Established in 1952 and headquartered in New York the Council is a nongovernmental, nonprofit organization governed by an international board of trustees.

Population Council

One Dag Hammarskjold Plaza

New York NY 10017

Tel: 212-339-0500

Fax: 212-775-6052

www.popcouncil.org

Email: publications@popcouncil.org

Email: info.zambia@popcouncil.org

Population Council - Zambia

Plot 3670 No. 4 Mwaleshi Road

Olympia Park

P/Bag RW 319X

Lusaka, Zambia 10101

Tel: +260211295925
This curriculum has been adapted from Worldreader's E-reader training and integration guides.

This curriculum was funded by a grant from the United States Department of State as part of the DREAMS Innovation Challenge, managed by

JSI Research \& Training Institute, Inc. (JSI). The opinions, findings, and conclusions stated here are those of the authors and do not necessarily reflect those of the United States Department of State or JSI.

Suggested citation: Jackson Hachonda, Natalie, Nicole Haberland Abdul-Kahad Alhassan, Beatrice Ani-Asamoah, Pamela Nyirenda, and Barbara Mensch (eds.). 2018. GirlsRead! E-Reader Curriculum. New York: Population Council.

(c) 2018 The Population Council, Inc

Any part of this volume may be photocopied without permission from the authors or publisher, provided that publication credit is given and copies are distributed free. Any commercial reproduction requires prior written permission from the Population Council. Please also credit any original sources as noted for selected activities. For inquiries regarding rights and permission, including translations, please contact publications@popcouncil.org.

ISBN: 0-978-87834-140-4 


\section{acknowledgments}

This curriculum was developed for the GirlsRead! project. We are grateful to Worldreader, one of the GirlsRead! implementing partners, for providing training and technical assistance on e-reader

use. Selected material from two Worldreader training resources -

GirlsRead! Zambia E-reader Training Guide: Kindle Paperwhite Model and GirlsRead! Zambia E-reading Integration Guide - was adapted for this GirlsRead! curriculum.

We are grateful to the Forum for African Women Educationalists in Zambia (FAWEZA), our other partner for GirlsRead!, for implementing the program and collecting feedback from mentors on the use of the E-reader curriculum in year one to make improvements to this revised curriculum for year two of programming.

We would like to thank the United States Department of State as the funder and JSI Research \& Training Institute, Inc. (JSI) as the grant manager for the grant under the DREAMS Innovation Challenge that has made GirlsRead! possible. 


\section{table of contents}

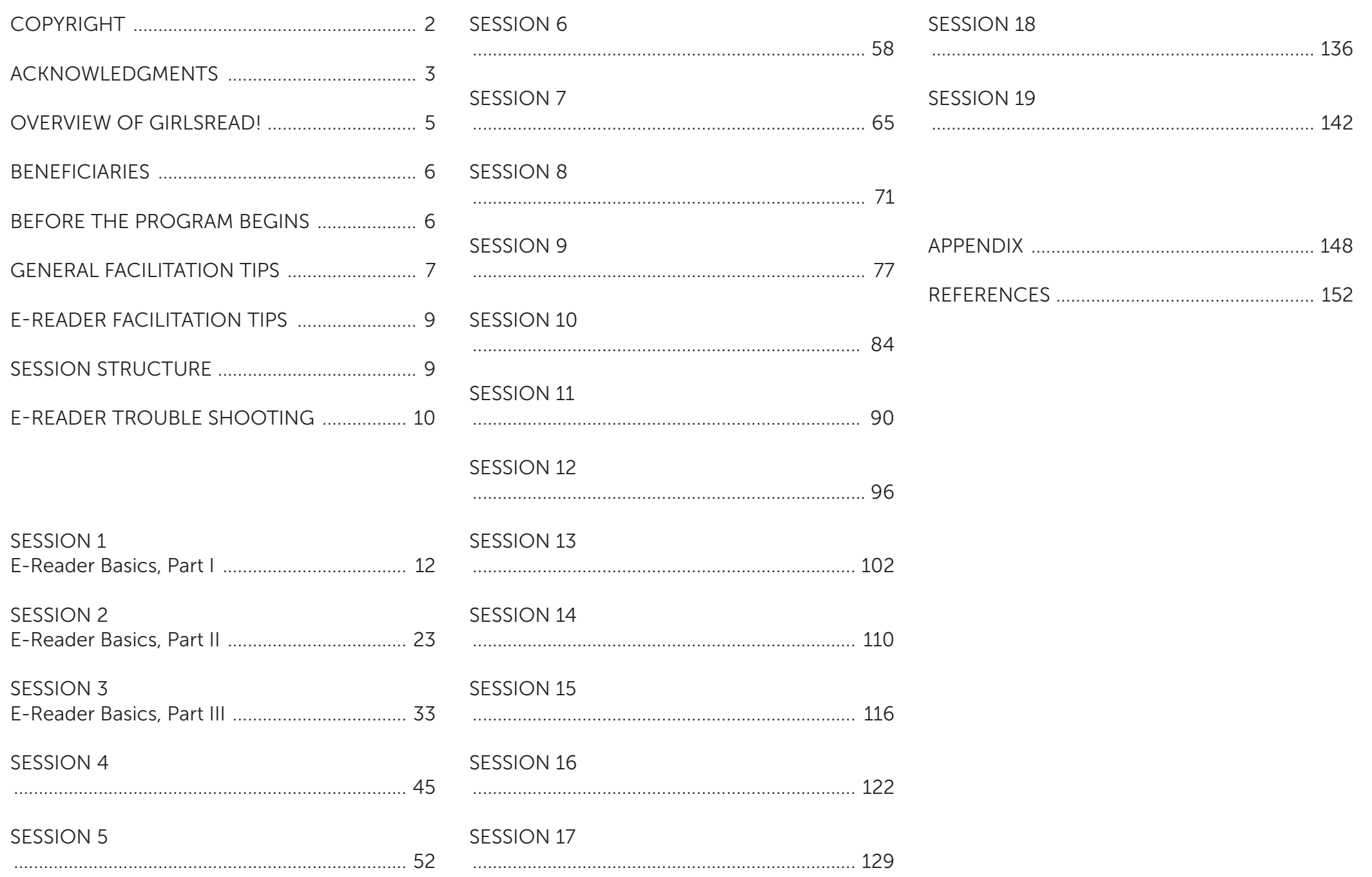




\section{introduction}

\section{OVERVIEW OF GIRLSREAD!*}

Zambian adolescent girls are at risk for premature school leaving and HIV infection due to a host of contextual factors including child marriage, early childbearing, harmful gender norms, and intimate partner violence.

The overall goal of GirlsRead! is to enhance learning and increase progression to secondary school among Zambian adolescent girls in grade 7, the last year of primary school. It works in three districts: Lusaka, Ndola, and Chingola which have been targeted by the Determined Resilient Empowered AIDS-free Mentored Safe (DREAMS) Core intervention funded by the US President's Emergency Plan for AIDS Relief (PEPFAR) to prevent HIV in adolescent girls and young women ages 10-24 in 10 countries in sub-Saharan Africa. GirlsRead! is part of the DREAMS Innovation Challenge, a US State Department funded initiative working in conjunction with DREAMS Core to test innovative initiatives in six challenge focal areas. GirlsRead! is part of the "Keeping Girls in Secondary School" focal area.

Through GirlsRead!, Population Council, together with FAWEZA and Worldreader are aiming to improve school retention by bolstering girls' learning outcomes, furthering social connections, improving critical thinking skills, increasing agency, and fostering community norms supportive of girls' schooling. GirlsRead! participants meet in groups of 15-20 girls in weekly meetings called safe spaces under the guidance of a female mentor. The safe spaces are broken up into two parts with two different curricula.

During the first part of the safe space, mentors use GirlsRead! Girls Rights: An Empowerment Curriculum to facilitate sessions that aim to:

1. Increase adolescent girls' understanding of gender equality, rights, sexual and reproductive health, and HIV.
2. Reinforce and promote attitudes and behaviors that will lead to a better quality of life for adolescent girls, including increased schooling and reducing bullying, harassment, and sexual coercion.

3. Instill skills among adolescents to enable them to overcome the challenges of growing up and becoming responsible adults including communication skills, decision-making and negotiation, goal setting, and developing healthy relationships.

During the second part of the safe space, mentors use this curriculum GirlsRead! E-reader Curriculum, to facilitate sessions that aim to:

1. Introduce the basic steps of how to use an e-reader and access the approximately 100 e-books loaded onto the e-reader.

2. Build participants' reading skills

3. Foster participants' joy of reading.

\section{GirlsRead! e-readers}

Each GirlsRead! e-reader includes approximately 100 preloaded e-books. Most of the books are fiction, though there are also nonfiction books such as a world atlas, biographies, and a dictionary. The majority of books are written by African authors. All books are in English, because English is the language of instruction and the language of the grade 7 exam that determines secondary school placement.

After girls and their parents or guardians sign a contract about e-reader care, theft, and loss, girls keep their e-readers for the duration of the program. They take the e-readers home and they keep them over school breaks. In some cases (this happens only rarely) parents may not agree to the terms of the contract and in such cases the school or mentor holds the e-reader for the girl in-between meetings.

Continued on next page 


\section{introduction (cont.)}

\author{
BENEFICIARIES \\ GirlsRead! participants are girls in grade 7 - the last year of primary \\ school - when they are at high risk of leaving school.
}

\section{Group structure}

Each group meets once a week in the afternoon after their morning classes. The sessions will last 2 hours, with the first hour focused on the empowerment curriculum and the second hour focused on the e-reader curriculum.

\section{BEFORE THE PROGRAM BEGINS}

Mentors should peruse the curriculum and thoroughly read as much of the background information as possible. This will help mentors gain a strong general sense of the sessions and books that will be covered throughout the program, and an idea of where to find answers to any questions that participants may ask. The preparation and facilitato notes for each session should be re-read just before conducting the corresponding session. Mentors should prepare any necessary materials for each session ahead of time.

\section{Know your audience}

Depending on the group, it may be necessary to change the approach to leading the sessions. It is important that mentors work with

participants according to their education/competency level.

\section{Be prepared}

Every training experience has the potential to raise challenges. The most effective way to minimize challenges is to be prepared. Mentors should know the material they will present and practice facilitating the activities on their own or with a friend.

\section{Preparing for the e-reader session (this is key!):}

Practice reading the books in advance of each session. It is much easier to read aloud, to lead a discussion, and to engage participants when one is familiar with the content of the book. Reading aloud is different than reading to oneself. Remember to use different voices for different characters in order to make the story come alive. Use expressive intonation, exaggerate, and have fun with sounds and characters. The more you do this, the more engaged the participants will be. Look up words you don't know ahead of time.

Continued on next page 


\section{introduction (cont.)}

\section{GENERAL FACILITATION TIPS}

Below are some tips and methods to help build your capacity as a facilitator.

\section{Establish a learning environment based on equality, respect, and} human rights.

1. Create a supportive learning environment. All participants should feel involved, listened to, comfortable, and safe from ridicule, especially when they take risks with new ideas. Encourage participation, particularly among those who feel alone or intimidated. (Various conditions and situations can trigger such feelings. For example, differences in social power associated with gender, social class, or age can be a factor. Participants with limited reading skills may avoid activities or joining discussions. Those living with a physical disability or other special needs may feel shy.) O course, it is also important to ensure the safety and privacy of the physical space.

2. During an early session, ask participants to work together to devise a list of guidelines for their own respectful classroom.

3. Ask participants to respect other people's privacy, and remind them not to disclose information to others that they feel should be kept private. Consider how some participants might intimidate or even abuse others after leaving a classroom in which sensitive topics have been discussed. Assure them that you, as their mentor, will keep all discussions confidential. In this way, you serve as a role model for respecting others' privacy.

4. Make certain that they understand that they have the right not to participate or share if doing so makes them uncomfortable.

5. Encourage all participants to share their thoughts. Do not judge their ideas.
Foster a process that draws on participants' experiences, integrating new information and ideas into what they already know and think about a topic.

1. Remember that all participants have knowledge and experience. Listen and ask questions to draw them out

2. Listen to their concerns and pose hypothetical problems that reflect their real lives. Engage them in solving these problems, making their own choices and developing their ideas along the way.

3. Encourage them to explore the significance of an issue in their own lives.

4. Think of your role as facilitating discussion of participants' ideas rather than as a lecturer or transmitter of information. Sometimes you may need to correct factual errors or help them recognize when a comment is disrespectful.

5. Occasionally, you may wish to share an example from your own experience that is relevant to the lesson. However, be extremely careful to maintain appropriate boundaries with the participants

\section{Build on their power to reflect, study, and think critically about their} own lives and the world around them, and to solve problems.

1. Encourage participants to question conventional wisdom. Ask them to think about their beliefs and their community's standards and norms. Invite them to explore opinions different from their own in a respectful manner.

2. Encourage creativity.

3. Encourage them to take risks in their thinking and to be unafraid of making mistakes. Be willing to demonstrate such behavior yourself.

4. Organize small groups to explore issues and engage in collective activities.

5. Encourage various perspectives in analyzing problems and suggesting possible solutions.

Continued on next page 


\section{introduction (cont.)}

Foster participants' ability to apply what they learn to their lives and communities, that is, help them to become active citizens and forces for positive change.

1. Repeatedly ask participants to relate the content to their own lives and world. Encourage them to consider the material in light of principles of fairness and social justice.

2. Be aware of the environment in which you work so that you can avoid putting participants in harm's way.

3. Keep in mind that young people often draw inspiration from their teachers and community leaders.

\section{A good facilitator}

1. Sees the participants as experts with information and skills to share, rather than seeing himself/herself as the only expert in the room.

2. Encourages participants to learn from each other, and guides this process rather than providing direct instructions and lecture-style learning.

3. Believes that we learn by doing, experiencing, practicing, and feeling, rather than by memorizing, repeating, and recording information.

4. Is organized, but flexible in changing methods based on participant needs

5. Is enthusiastic about the topic and participants.

6. Keeps promises to the group - to let participants speak, take a break, etc.

7. Is patient and a good listener.

8. Is prepared to handle strong emotions that may arise during discussions.

\section{Before each session}

1. Carefully read through all of the sessions' background notes and activities. Think about how you will perform each step and what you will add to every session.

2. Try to anticipate questions that may be asked, and know where to look for answers in the materials provided. If participants ask questions that you cannot answer right away, write them down and follow-up on them before the next session, so that you can discuss them then.
3. Adapt the activities and group discussions to make them more appropriate to the age and education level of your participants.

4. Think about and plan for any issues that may arise during more "difficult" sessions with complex material or sensitive topics.

5. Think of local examples and ways to make the activities more relevant to the participants' daily lives and concerns.

6. Have materials prepared beforehand

\section{Additional facilitation tips}

1. Have a "parking lot" for issues that arise during a session, but that are not relevant to the session objectives. You can come back to them at another time or simply explain at the end of the training that it was important, but outside of the scope of the curriculum

2. Capture important points on the chalkboard during discussions for use during the summary activities. It can be very challenging to both lead the discussion and write down all important points, so consider having one of the participants assist you in writing down key points.

3. Whenever appropriate, identify next steps or possible solutions to problems.

4. Relate the information to what has been learned in previous sessions whenever possible.

5. Check to make sure you are not speaking more than the participants. If you find that you are doing most of the talking, encourage participants to answer each other's questions. For instance, if someone asks a question, open discussion to the participants with the inquiry: "Does anyone have an answer to that question?"

6. The way you hold your body will help effectively facilitate the group. Being attentive and nodding will make them feel their contribution is important. Looking away can effectively tell the person not to talk or participate. Always face the person to whom you are speaking.

7. Have fun!

Continued on next page 


\section{introduction (cont.)}

\section{E-READER FACILITATION TIPS}

The e-reading time in the weekly safe space meetings is meant to be fun and interactive, encouraging the group to read for pleasure. Different from the standard instructional reading periods in school, the GirlsRead! E-Reader Curriculum activities should heighten participants' interest in reading and inspire them to read independently. Mentors play an important role in supporting and encouraging participants to read throughout this program. Mentors who are teachers should try to act like reading partners rather than instructors/teachers, as the activities in this curriculum should not feel like they are in a class at school.

\section{Different comfort levels with technology}

Keep in mind that participants come from different backgrounds and will have a range of familiarity with technology. Remember to give all participants the opportunity and time to use their e-readers. Some will take longer to become comfortable using their e-readers, so it is important to be patient and supportive.

\section{Handling different reading abilities}

Participants will have different reading proficiencies and as a result will read at different paces and will read different level books. It is very important to have strategies to handle these different reading abilities. Here are some strategies that can help:

- Talk to participants about the need for teamwork, support and cooperation. This should be reflected in the "rules" established for the group.

Ensure that participants understand that it is normal for people to read at different paces and levels, but the most important thing is that they help and respect each other.

- Another helpful strategy is to pair or group readers in your e-reading sessions. By effectively pairing or grouping "stronger" and "weaker"

readers, all participants will be engaged and participate in the session.

During each activity, always be mindful of the pace and vocabulary used and consider the range of reading abilities in the group.

\section{SESSION STRUCTURE}

The GirlsRead! E-Reader Curriculum has 19 sessions. Each session is outlined as follows:

Session description

Objectives

Session time

Required materials

Pre-session preparation

Facilitator notes

- Warm-up (in Sessions 4-19)

Activities

Wrap-up

\section{Session title}

The session title names the main topic covered in the session

\section{Session description}

The session description summarizes the activities undertaken in each

\section{Objectives}

The objectives provide an overview of the learning aims and purpose of each session.

\section{Session time}

A breakdown of the estimated time to be spent on each activity is provided at the beginning of each session and below each activity title. These general time frames have been assigned to aid in determining the division of time between each activity in a session so that all the material can be covered. However, participants may want to explore some issues in more depth, or at other times they may work through the material more quickly. Allow participants flexibility with the space and time allocated to each part of a session.

Continued on next page 


\section{introduction (cont.)}

\section{Required materials}

Materials needed to prepare for each session are listed. Participants will be provided with e-readers at the beginning of the program. Participants parents/caregivers must sign a contract that lays out responsibilities for keeping the e-reader safe and returning it at the end of the program. Participants should be reminded to bring their e-readers with them to each session. Chalk and a chalkboard are needed for most sessions.

When these materials are not available, adapt the session accordingly.

\section{Pre-session preparation}

Preparation activities for each session are noted. It is important for the facilitator to complete these preparations before each session. Being prepared for the learning session will make the facilitator's job much easier and help the session to run smoothly. Review this information carefully.

\section{Facilitator notes}

These notes provide details about relevant session background information for the facilitator, additional session-specific tips that may be helpful, and reminders about how to facilitate each session.

\section{Warm-up (Sessions 4-19)}

At the start of Sessions 4-19, a book board is used for the warm-up activity. The book board is a great way to allow participants to share their thoughts about the stories they read on their e-readers outside of safe space meetings, get tips from their peers on which books they might enjoy, and to show off how much they are reading in their spare time. This becomes another motivation for participants to read outside of the safe space.

\section{Activities}

Step-by-step instructions for each activity are provided to guide the facilitator in helping participants learn and work with the concepts of the session. The steps are listed in the order in which they should be implemented and it is intended that the steps be followed as outlined. While a general script for each session is provided, facilitators should feel free to use their own words to explain each point.

\section{Wrap-up}

A suggested outline to wrap-up each session normally includes instructions to ask participants to summarize what they have learned during the session, while the facilitator fills in any key points they miss, addresses any questions or comments on the activities/books read and discusses other books on the e-readers that participants hope to read between now and the next safe space meeting.

\section{E-READER TROUBLE SHOOTING}

Like any technology, e-readers can malfunction. While some of these problems can be resolved, at other times, the device may be completely damaged and beyond repair. Here are some of the common problems and how you can address them. Note that you may need internet access for some situations. Also note that device issues are not necessarily the fault of the user.

\section{Frozen screen}

Just like a mobile phone or laptop, the e-reader can freeze. When this happens, you have to restart it. To restart the e-reader, hold down the power button for 20 seconds and then release it. $80 \%$ of the time, this will fix the problem. If it doesn't, your screen may be damaged beyond repair.

\section{Change in language}

The e-reader gives you access to several language options, for example allowing you to change the language from English to French. This can happen accidentally. If it does, you will have to go back into your settings to revert to English. To switch back to English, go to settings and then Language. However, the device may be in a new language that you are not familiar with. To access your settings and then Language option, place the e-reader side by side with another e-reader which is in English. Now go through the process using the English device as a guide/reference.

Continued on next page 


\section{introduction (cont.)}

\section{Deleted books}

One can accidentally delete books from the e-reader. When this happens, you will no longer see the books on your home screen.

However, the book is still in your account and can be recovered from the "cloud." To recover a deleted book, you will need internet access (by Wi-Fi or creating a hotspot from a mobile device). Turn on the e-reader's Wi-Fi under settings and connect to the appropriate access point. Tap "ALL" on your toolbar. Here, you will see all the books in your cloud. To re-download (recover) the deleted book, tap on the title and wait as it downloads. Once the download is complete, the book will reappear on your home screen. If you are unable to fix this, contact your GirlsRead! E-reader Tech Support to address the problem.

\section{Forgotten password}

Password locks are very exciting to use. However, if the password is forgotten, the e-reader has to be completely reset to its factory settings. When this is done, the e-reader will disconnect from its Kindle account and will thus lose all the books currently on it. To fix this,

the device has to be registered again to the account and then every single book re-downloaded from the "cloud." We are thus not setting passwords for the GirlsRead! e-readers, but if this is an issue contact your GirlsRead! E-reader Tech Support to address the problem.

\section{Broken screens}

As you know, the screen of the device is the most fragile part of the device. If it is damaged in any way, you will observe it as a crack, an ink spill or part of the screen not working. This cannot be fixed. Contact your E-reader Tech Support to address the problem.

\section{Part malfunction}

Sometimes, a part of the e-reader such as the power button or battery may become faulty and not work. Contact your E-reader Tech Support to address the problem.

\section{Software problem}

Very rarely, a software problem may be indicated on your e-reader screen. This may include phrases such as "contact Amazon." This cannot be fixed. Contact your E-reader Tech Support to address the problem. 


$$
\begin{aligned}
& \text { SESSION } 1 \\
& \text { E-READER BASICS, PART I }
\end{aligned}
$$




\section{session 1 / e-reader basics, part I’}

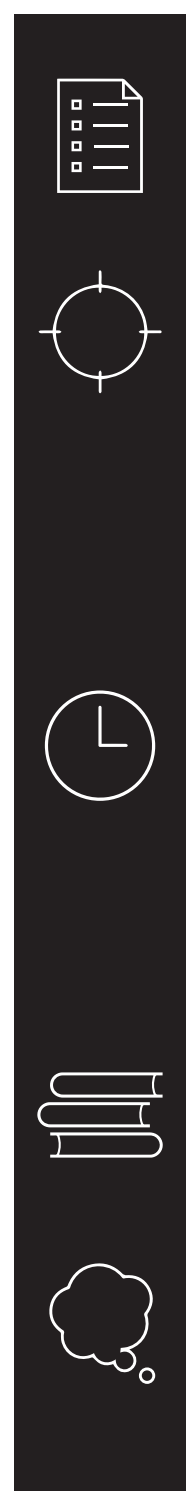

\section{SESSION DESCRIPTION}

Part one of an introduction to e-readers and how to use them.

\section{OBJECTIVES}

By the end of the session, participants will:

Be able to explain the difference between an e-reader and an e-book

know how to care for their e-readers to avoid damage

Be able to turn an e-reader on and off

- Be able to swipe to view different books and turn pages

Know the name and function of each icon on the home screen

During this session, participants will also receive and read the e-reader

policy forms that they will bring home for their parent/guardian's signature.

\section{SESSION TIME}

1 hour

Activity 1: What is an e-reader and what is an e-book? 5 minutes

Activity 2: Caring for an e-reader, 5 minutes

Activity 3: E-reader usage and policy, 10 minutes

Activity 4: Turning on your e-reader and learning to swipe, 15 minutes

Activity 5: Understanding the home screen, 20 minutes

Wrap-up: 5 minutes

\section{REQUIRED MATERIALS}

Devices (e-readers)

Chalkboard, chalk, and eraser

\section{PRE-SESSION PREPARATION}

Read through the entire session and, if necessary, practice presenting

the activities. Prepare all materials needed.

Draw a large e-reader toolbar with parts labeled on the chalkboard. 


\section{session 1 / e-reader basics, part I (cont.)}

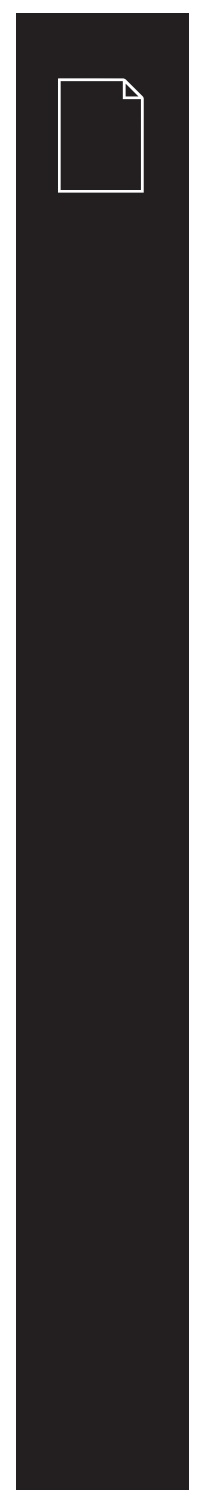

FACILITATOR NOTES

Even though participants will have access to

their own e-readers, have them sit in pairs to

work together during the first session to make

them feel more comfortable. Remember

that this is the first time most, if not all, of the

participants will hold e-readers, and they may

feel intimidated by the technology. 


\section{activity 1}

\section{WHAT IS AN E-READER AND WHAT IS AN E-BOOK?}

[5 MINUTES]

1. Hold up an e-reader for everyone to see.

2. Ask: What do you think this is?

3. Explain: This is an e-reader or an

electronic reader. An e-reader is a device

or machine that contains e-books, which

are electronic books. An e-book is similar

to a physical book in that it has pages filled

with words and/or pictures.

This e-reader has about 100 books already pre-loaded inside. This e-reader can hold up to 1400 different books. Imagine filling your school bag with that many books! Each e-reader is like a library of books. As a GirlsRead! participant, each one of you will have an e-reader assigned to you for the duration of the program. 


\section{activity 2}

\section{CARING FOR AN E-READER [5 MINUTES]}

1. Explain: E-readers must be handled with care. They are as fragile as a mirror or glass

2. Discuss with participants how to care for their e-readers to prevent them from breaking or getting damaged:

- Glass Screen: The front area of the e-reader is made of a very thin sheet of glass that can easily be broken. Some common ways the glass is broken include: dropping the e-reader, setting something heavy on the case or screen, carrying the e-reader in a bag with heavy objects, or sitting on the e-reader.

Case: The e-reader has a case to protect it and keep the e-reader clean. Always leave the e-reader in the case. The case will protect the e-reader. Zip the case closed when not using the e-reader. Do not keep other objects (pen, pencil, keys, etc.) inside the e-reader case. These objects will break the screen.
Desk: Care should be used when placing e-readers on desks. Participants should hold the e-readers in their hands when standing up or changing desks, to prevent e-readers from falling off the edge.

Never place the e-reader on the floor, as someone might step on it and break the screen.

Dropping: Dropping e-readers can result in permanently damaging the e-reader. Remind participants to be careful not to drop their devices.

Fingers ONLY! Use your fingers only to tap the touch screen. Do not touch the screen with a pen or pencil.

- Hands: Ensure that your hands are clean before using the e-reader. Dirty hands can damage the e-reader. Be sure to wipe any chalk from your hands before handling the e-reader if you are using a chalkboard.
Weather: Avoid exposing your e-reader to strong sun or to rain. Strong sun can damage the screen, the battery, or can cause your e-reader to malfunction. Rain like water, can damage your e-reader.

Cleaning: Clean your e-reader by wiping it gently with a dry cloth. No water should be used to clean an e-reader.

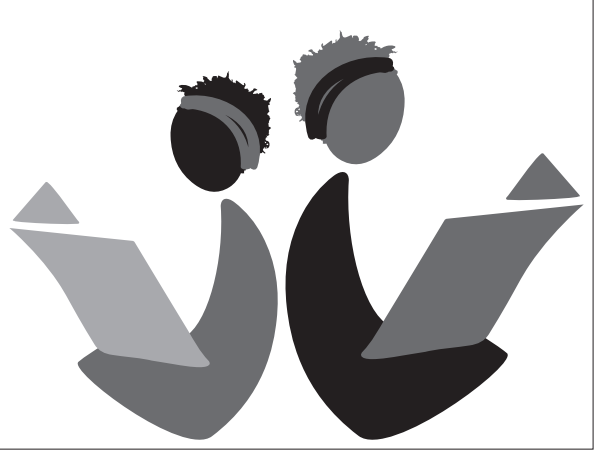




\section{activity 3}

\section{E-READER USAGE AND POLICY \\ [10 MINUTES]}

1. Hand out the e-readers to participants, explaining that today they will use the e-readers during the session and you will collect them again at the end of the session. They will get to take them home at the end of the second session.

2. Hand out copies of the e-reader usage and policy form. Explain that all participants should take the form home to their parent guardian to read and sign, then return it to the mentor before or at the next safe space meeting. Without a signed policy form, participants are not allowed to take an e-reader home next week. If participants have a signed contract, an e-reader will be assigned to them, they will sign for the designated e-reader with a unique serial number and account number, and that e-reader will be their responsibility for the duration of the program.

3. Read the contract aloud to the participants. Ask if there are any questions.

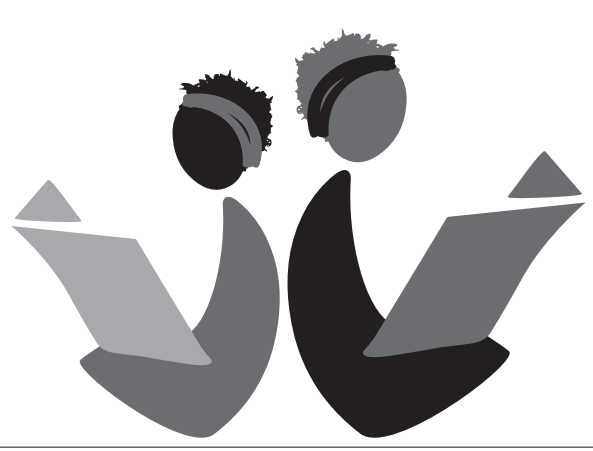




\section{activity 4}

\section{TURNING ON THE E-READER AND LEARNING TO SWIPE \\ [15 MINUTES]}

1. Explain: Throughout GirlsRead! and our time using e-readers, you will hear me say "Check." When I say "Check," it means we should all turn our open e-readers to the front of the room and put them above our heads. Let's practice. "Check." [Wait for everyone to hold their e-readers over their heads with their e-readers open to the ront of the room so you can see them.

Other ways to check in that everyone is following along are "Give me Ten!" and "Voices."

For "Give me Ten": If participants are distracted, playing with e-readers, and/ or not following the session say, "Give me Ten" then participants put down their e-readers on the desk or their lap and put up their hands showing ten fingers.

For "Voices": Say, "I can hear voices," and participants respond: "Shhhh."

Practice each of these methods quickly with the group.
2. Explain: Now we will learn how to turn on our e-readers. If you look at your e-reader you will notice that there is only one button, located at the bottom right edge. This is the power button. The reason that our e-readers do not have other buttons is because they have what is called a touch screen. A touch screen allows us to tap directly on icons (symbols) or certain areas of the screen to accomplish different tasks. This touch screen also allows us to swipe our finger across the screen to accomplish other types of tasks. We will learn more about these tasks later.

Turn on the e-reader by pressing the power button. The image will change to the "Home" screen view - you should see a list of book titles. Practice turning the e-reader on and off three times. When you turn off the device this way, it goes into SLEEP MODE. This means you are putting the device to sleep. Now turn the e-reader back on again.

If you look at the top, you will see "All Items" and a number listed which represents the number of books in that e-reader. How many items are in your e-reader?
3. Explain: Now we will learn how to swipe, or turn "pages." This e-reader only shows a certain number of books on each page. In order to get to the next page of a book, we will need to swipe our index finger from the right side of the screen to the left side of the screen. When you are swiping, do not press down hard on the screen as the touch screen will interpret this as a tap and this might cause something unexpected to happen.

Show participants how to swipe. Allow them time to practice swiping. Walk around and help participants who are not able to swipe correctly.

Continued on next page 


\section{activity 4 (cont.)}

4. Explain: To go back to the previous page, we will need to swipe our index finger from the left side of the screen to the

right side of the screen. Practice swiping left and right to go to the next page and previous page five times. [Note that while swiping, participants may accidentally open a book. You will have to guide them on how to return to the home screen. Monitor progress and help participants along the way.]

5. Explain: Now we are going to practice turning the e-reader off completely. To do

this you have to hold the power button for seven seconds and tap 'screen off.' Both options - sleep mode and turning the e-reader off completely - will help conserve your battery life. Let's try! [Have all participants turn their screens off. Walk around and help participants as needed. When it seems that everyone has turned off their screen, call out, "Check" to verify that all screens are off.] 


\section{activity 5}

\section{UNDERSTANDING THE HOME SCREEN \\ [20 MINUTES]}

1. Ask participants to look at the top of their home screen. What do you see? You should see some icons and options. This is the Toolbar (show participants the enlarged Toolbar on page 151). The Toolbar is always visible from the home screen.

2. Explain: Let's learn more about the different parts of the Toolbar.

3. Point to each icon and let the participants try to guess its function based on the name/picture.

4. Say: The top black bar includes:

- The Device Name: This is the account number associated with your e-reader.

- The Connection icon: This indicates either a Wi-Fi connection or that the device is in "Airplane Mode." Airplane Mode means that the wireless is off and no data can be downloaded. Airplane mode also extends battery life.

- The Battery icon: This shows how much battery life remains in the device.

- The Current Time

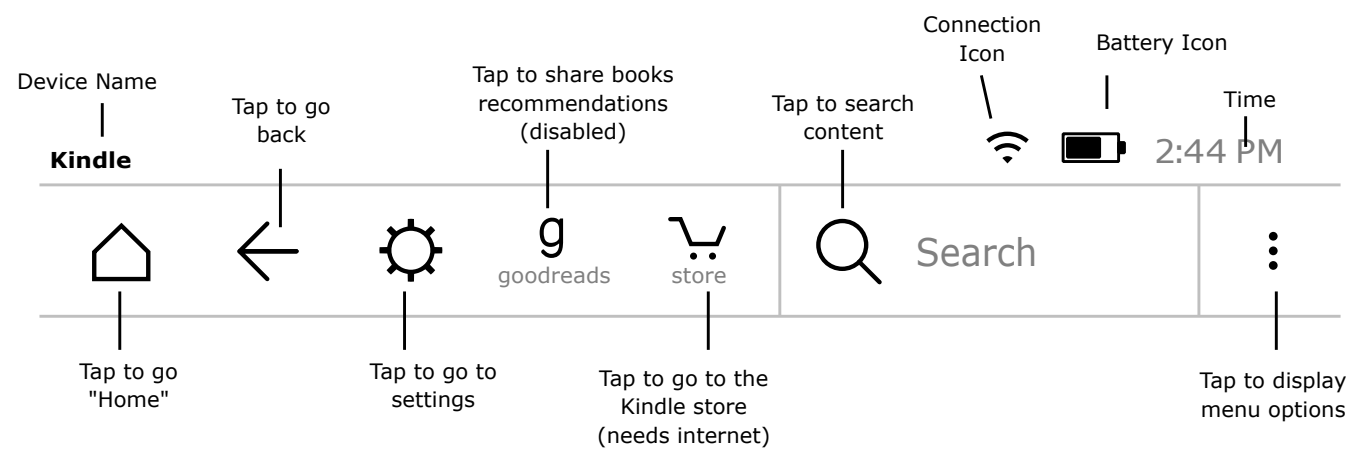

5. Say: Below the top black bar, there is a line with the following icons:

Back: Tapping this icon takes you back one step to the previous screen.

Home: Tapping this icon will take you to your home screen. This is a very important icon, so let's practice using this a few times. Please swipe from right to left

twice to get to page 3 (you will see 3 of $X$ on the bottom of your screen). Now, tap the "Home" icon. This will take you back

to page 1. Tapping "Home" will always take you to the same place: Page 1 of $X$. The home icon is an important one to remember. To help us remember what this one does, think about how when you're lost or cannot find what you're looking for, you probably want to go home.
Continued on next page

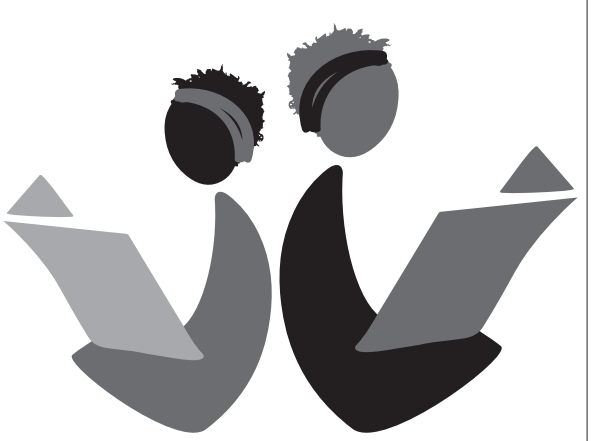




\section{activity 5 (cont.)}

Settings Menu. Tapping this icon gives you a shortcut to these important features:

Airplane mode: Turning airplane mode on turns off $\mathrm{Wi}-\mathrm{Fi}$ access and extends battery life. We recommend always keeping your device on Airplane mode (unless you are downloading new books).

Sync my Kindle. This icon updates your Kindle if you have bought new books and are connected to Wi-Fi. You will rarely use this.

Screen brightness: When you go to settings, a bar will pop-up at the top of your screen allowing you to adjust the brightness of your screen. Remember to reduce the brightness if you are reading at night or in a dark room.

Keeping the brightness low helps to conserve battery life.

All Settings. This icon takes you to additional settings that we will cover later.

Shopping Cart: Tapping this icon takes you to the Amazon store. However, we are not using this function so you can ignore it.
Search: Tapping this icon allows you to search through your device for a word, book, or collection. This is a very useful icon and we will discuss it at length later.

Menu: Tapping this icon will give you menu options. We will also discuss this icon in greater detail later.

Practice saying the names of the icons aloud as a group, or have participants quiz each other.

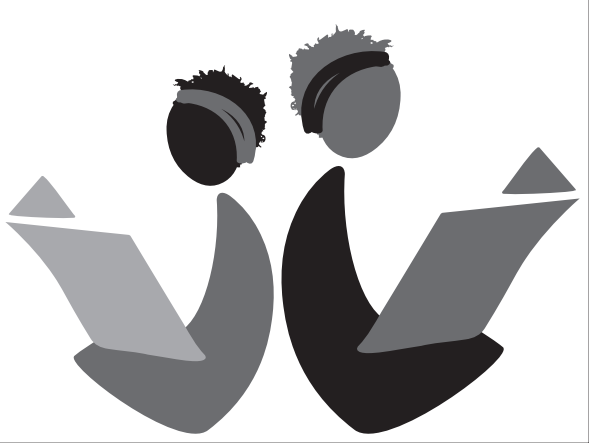




\section{wrap-up}

\section{WRAP-UP \\ [5 MINUTES]}

Collect the e-readers from participants one by one. Count the e-readers to verify that you have them all back and put them in the storage box. Remind participants that this week they are returning the e-readers, but if they come with signed e-reader usage and policy forms before or at the next safe space meeting then they will go home with the e-readers to use for the rest of the GirlsRead! program.

While collecting the e-readers, ask participants:

\section{What do you think of the e-readers? \\ - What did you learn today? \\ - How do you feel?}

Thank them for their participation and remind them of the meeting time and place for next week.

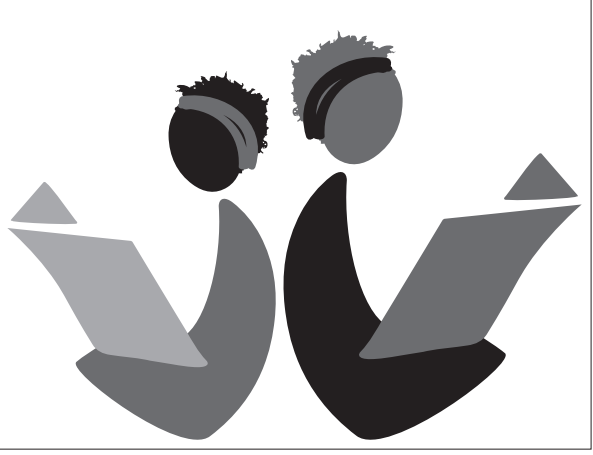




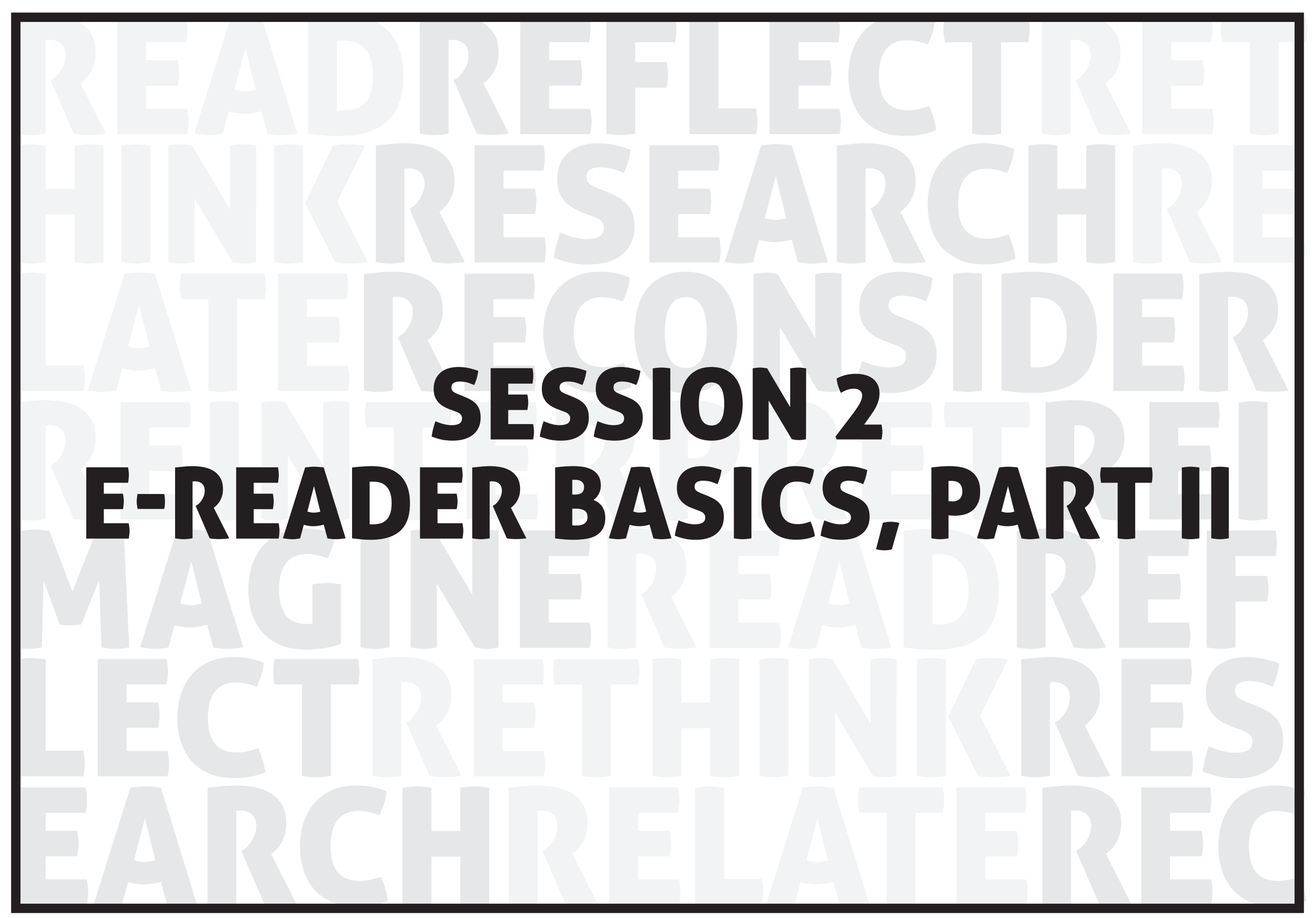




\section{session 2 / e-reader basics, part II}
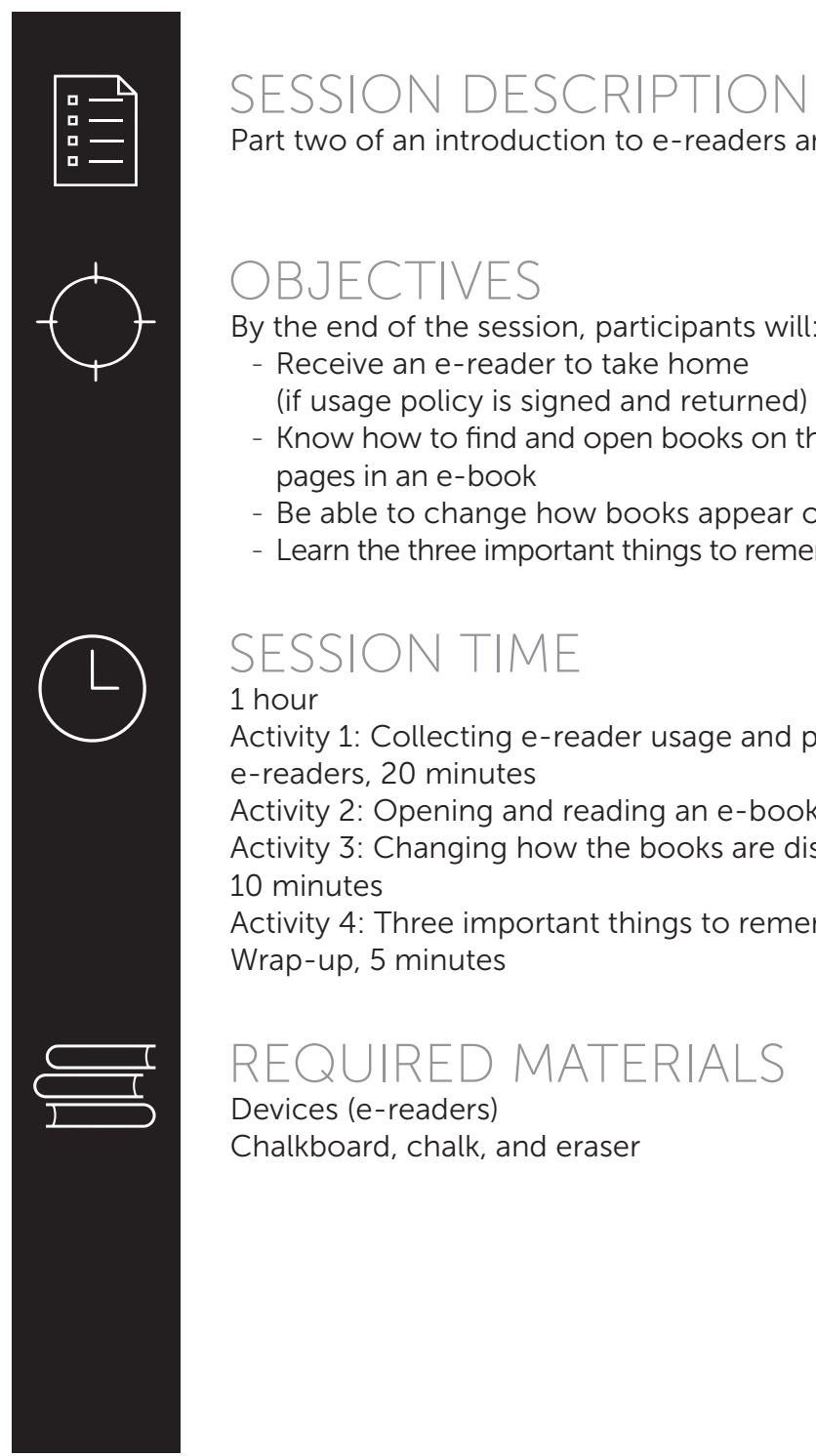

SESSION DESCRIPTION

Part two of an introduction to e-readers and how to use them.

\section{OBJECTIVES}

By the end of the session, participants will:

Receive an e-reader to take home

(if usage policy is signed and returned)

- Know how to find and open books on the e-reader and flip through

pages in an e-book

Be able to change how books appear on the e-reader

- Learn the three important things to remember when using the e-reader

\section{SESSION TIME}

1 hour

Activity 1: Collecting e-reader usage and policy forms and distributing e-readers, 20 minutes

Activity 2: Opening and reading an e-book, 15 minutes

Activity 3: Changing how the books are displayed on your home page,

10 minutes

Activity 4: Three important things to remember, 10 minutes

Wrap-up, 5 minutes

\section{REQUIRED MATERIALS}

Devices (e-readers)

Chalkboard, chalk, and eraser 


\section{session 2 / e-reader basics, part II (cont.)}

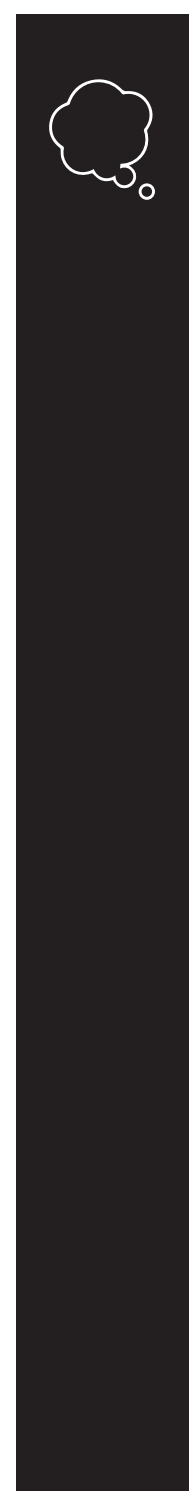

PRE-SESSION PREPARATION

Read through the entire session and, if necessary, practice presenting

the activities. Prepare all materials needed.

Copy the zone diagram below onto the board before the session

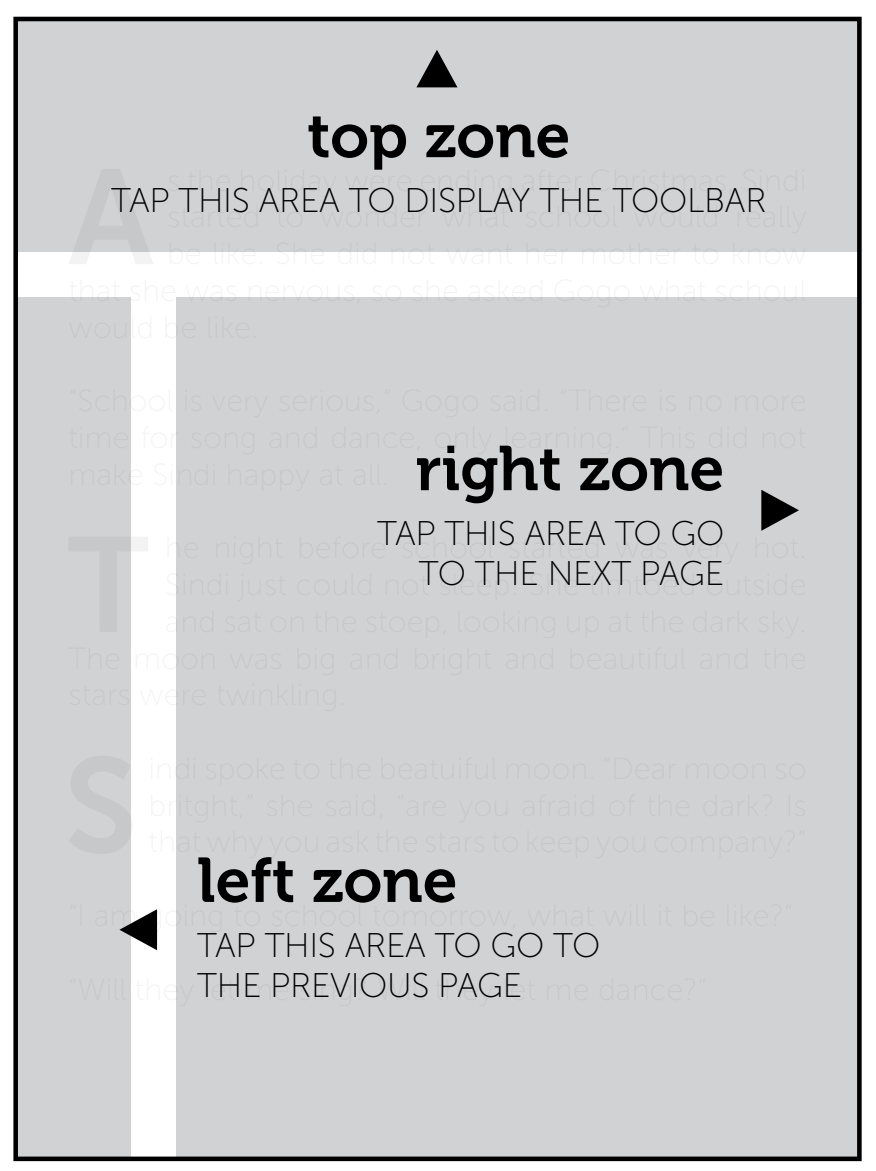




\section{activity 1}

\section{COLLECTING E-READER USAGE AND POLICY FORMS AND ASSIGNING E-READERS [20 MINUTES]}

1. Collect signed e-reader usage and policy forms from participants. Those who brought back a signed form will get to take home their e-readers today. For those who forgot to bring their signed forms, explain that they will get to use an e-reader during the session, but they will not take it home. Once they bring the signed form, ideally next week, they can take the e-reader home with them. If their parent/guardian has not agreed to sign the form, then the participant will use the

e-reader during sessions but will not bring it home.

2. Hand out the e-readers one by one, verifying that the name listed on the GirlsRead! distribution sheet matches the serial and account numbers printed on the e-reader. Once verified, ask the participant to sign next to her name and e-reader number before handing her the e-reader. Repeat these steps for each participant.
3. Once all participants have their e-readers, tell them how each e-reader has

been labeled with a serial number and account number that is unique for their device. Show them where the numbers are on their e-readers and explain the importance of using the same e-reader at all times and not exchanging e-readers with friends.

4. Tell the participants that today, they are taking the e-readers HOME! For the duration of the program, the participants will be responsible for their e-readers. At the end of the program, they will return the e-readers and the school will keep them. 


\section{activity 2}

\section{OPENING AND READING AN E-BOOK \\ [15 MINUTES]}

1. Explain: Now we are going to open and read part of a book.

2. Tap "Home" to be sure you are on your Home screen. You should see a list of the book titles on your e-reader. [Do a "Check" to make sure everyone is on the home page.]

3. Let's find the book The Adventures of Jack Lime. If the title that you are looking for is not visible on the first screen, just swipe your finger across the screen from right to left or the opposite direction to find it. Once you have found this book, let's "Check" together. [Verify that everyone is on the right book; help those who have not found it.]

4. Now let's open the book. To open it, tap the book title. "Check." [Verify that everyone has opened the book.]

5. When you first open an e-book, it may open to the cover just like an actual book. Usually there are several pages to move through before you arrive at the main text
6. Before we proceed, we need to learn about the different parts of our touch screen when we are inside of a book. There are three basic areas of the touch screen called Tap Zones. [Refer to the diagram to the right which should be drawn on the chalkboard before the beginning of the session.]

7. Top Zone: Tap this area to display the toolbar

8. Right Zone: Tap this area to go to the next page.

9. Left Zone: Tap this area to go to the previous page. Notice that the Left Zone is much narrower than the Right Zone.

10. Let's all practice going to the next page by tapping the Right Zone five times. "Check." [Verify that everyone has gone to the next page; help those who have not been able to do it correctly.]

Continued on next page
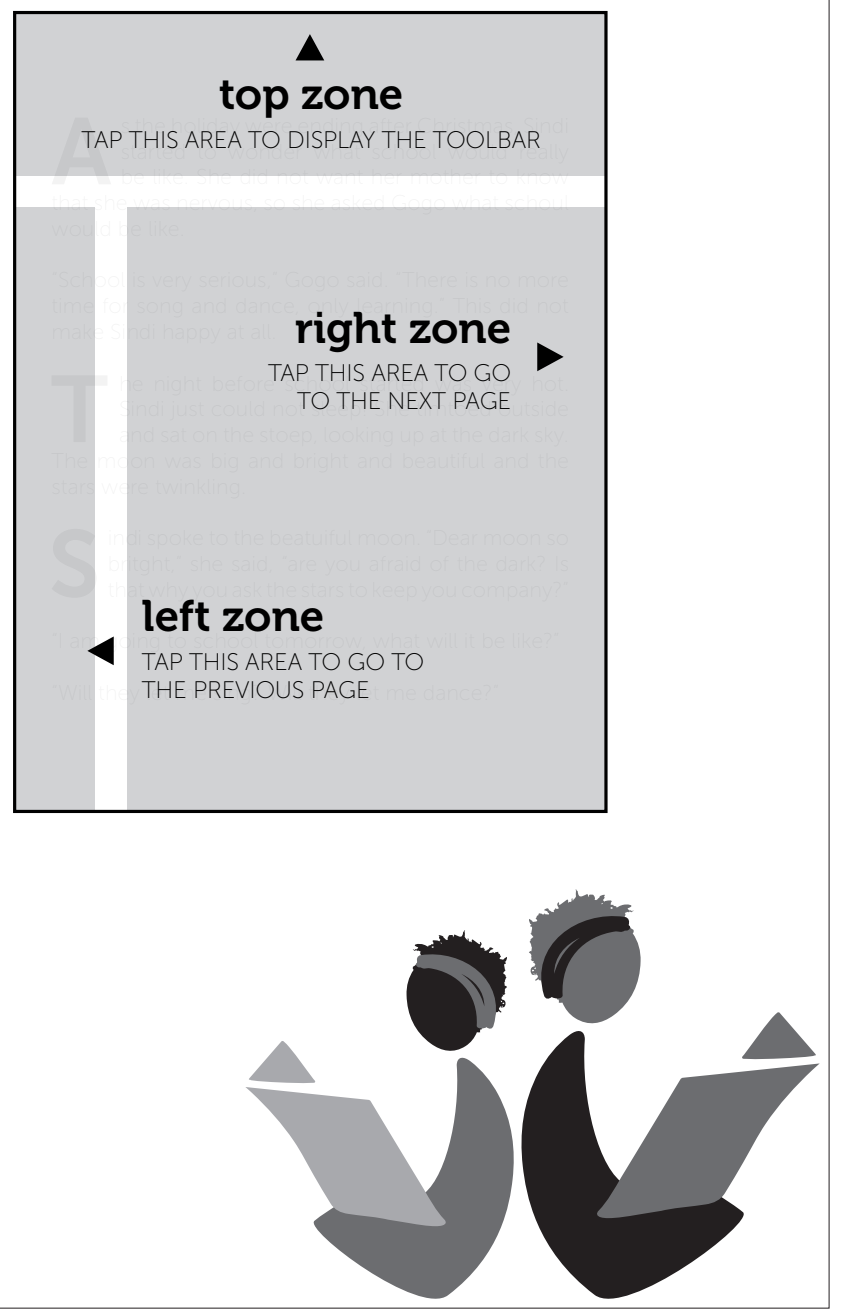


\section{activity 2 (cont.)}

11. Now let's practice going to the previous page by tapping the Left Zone two times. "Check." [Verify that everyone has gone to the previous page; help those who have not been able to do it correctly.]

12. Now, let's see what happens if we turn our e-reader off. Let's press the power button "Check." [Verify that everyone's e-readers are off; help those who have not been able to turn them off.]

13. Ask: Where do you think we will be if we turn our e-reader back on? Let's press the power button. Where are we? We should be just where we left off. Your e-reader will always bring you back to the last screen you were on.

14. Now, let's continue tapping the Right Zone and the Left Zone until you fee comfortable "turning pages."

15. Ask: If at any point we want to go "Back" or "Home," what should we do? We can tap the Top Zone to display the toolbar. From the toolbar, we can tap the "Home" icon or the "Back" icon. Let's try this.
16. Ask: As you turn the pages, what do you see at the bottom of the page? Can you guess what the percentages mean? [If it says $1 \%$ it means you are at the front of the book. If it says $99 \%$ or $100 \%$, you've finished the book. If it says $50 \%$, then you are half-way through the book.]

17. Ask everyone to return to the first paragraph of the book selected (same as above: The Adventures of Jack Lime). Ask for a volunteer to read the first paragraph of the book.

18. Ask: Does reading from the e-reader feel any different from reading from an actual book? If so, how?

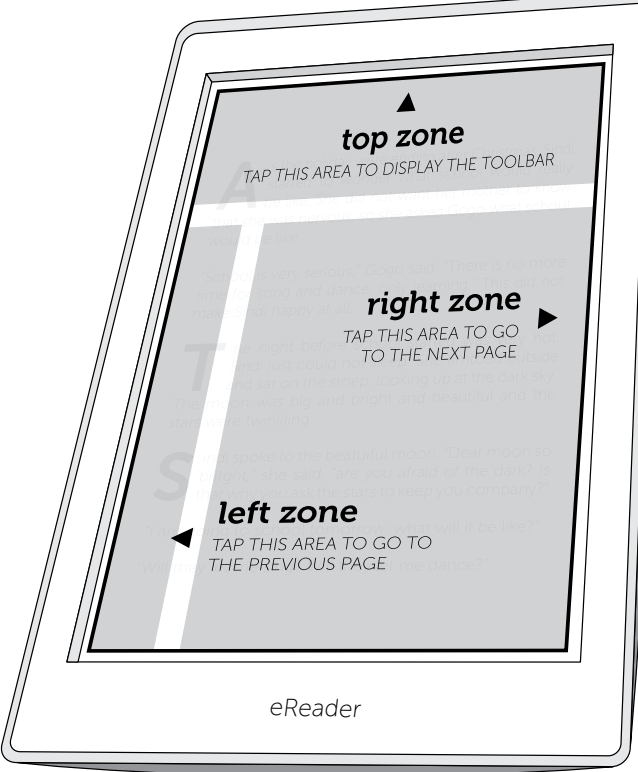

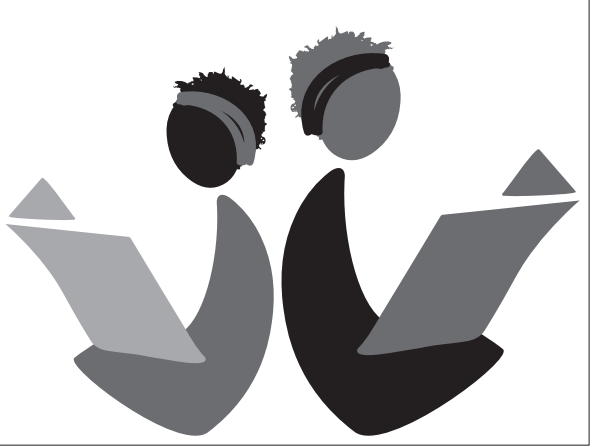




\section{activity 3}

\section{CHANGING HOW THE BOOKS ARE DISPLAYED ON YOUR HOME PAGE \\ [10 MINUTES]}

1. Ask: How will we find the book we want to open? Have you noticed how the books are listed?

2. Explain: If you look at the Home screen of your e-reader, you should see many book covers with titles on them. This is called "Grid View."

3. The e-reader also allows you to view just the titles of the books. To do this, let's tap on "All Items" near the top on the right with an arrow next to it.

4. You should see a list of options. Find the option labeled "List View" and tap it. You should now see a list of book titles on your screen. "Check." This is another way to view your books. [Have participants switch back and forth between the List View and the Grid View.]

5. Now if you look toward the top right of your e-reader, you will see "Recent" followed by a down arrow. What do you think this means?

6. This means that our e-reader is ordering the books based on how recently we opened them.
7. If we tap on "Recent," there are other options to change the way that our e-reader displays the e-books that it contains. "Check."

8. Now go back to "All Items," find "Title" and click on it. Your books should now be in alphabetical order by title, meaning from $A$ to Z. "Check."

9. If we look through our list of titles, we will see that some books have titles that start with "A," "An," or "The" and might appear to be out of place. A, An, and The are called articles, and they are not considered when alphabetizing the titles. For example, a book like "The Magic Mango" would be found under "M" for "Magic," not " $T$ " for "The."

10. Choose at least one book that has a title starting with A, An, or The and ask girls to find and open this book.

11. Explain that sorting only has to be done once, not every time the device is turned on. The e-reader will remember how you sorted the books last time. You can change how they are sorted whenever you wish.

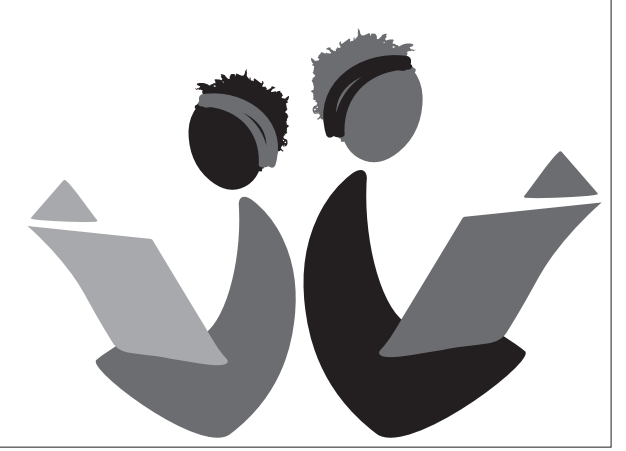




\section{activity 4}

\section{THREE IMPORTANT THINGS TO REMEMBER [10 MINUTES]}

1. Explain: There are three important things you should always remember when using an e-reader:

A. Conserve the battery using airplane mode

B. Conserve the battery by reducing screen brightness

C. Be careful not to delete a book

A. Conserve the battery using airplane mode

1. Explain: Your e-reader uses electricity, but there are ways to conserve your battery and minimize power use.

2. Tap "Home." Do you see a battery on the top right corner? Is it full, half-way full, or empty?

3. The battery should last up to 2 weeks with normal use or four hours of reading a day. Also, if your e-reader is on, and you put it down, the e-reader will shut itself off after a while. That's the e-reader's way of helping you conserve the battery.

4. However, there is something that would deplete the battery very quickly. That's if the e-reader tries to connect to the wireless network
5. Unless you are using the wireless network, the wireless should always be off.

6. Now let's try something. Tap the "Settings" icon from the toolbar bar on the top of your screen. Do you see a picture of an airplane?

7. Another way to check is to look next to the battery. Do you see a symbol of an airplane? This means your device is on airplane mode. Being on airplane mode helps to conserve your battery.

8. Turn off airplane mode by tapping the icon so there is a line drawn across the airplane. "Check." Do you see that the airplane symbol has changed to something resembling the bars that show network strength on a cell phone? That indicates the wireless is on. Whenever the airplane mode is off, the wireless is on, and vice versa.

9. Turn the airplane mode back on. "Check."

10. To conserve your battery, remember to always check that the wireless bars are not there, meaning airplane mode should always be on. If you forget to turn the wireless off, even when the e-reader is switched off, the battery depletes much faster. 


\section{activity 4 (cont.)}

\section{B. Conserve your battery by keeping your} screen brightness low

This e-reader has an internal source of light that helps us read in the dark. You can change the brightness of the screen to read more easily depending on your needs.

1. Tap Home. Tap Settings. Do you see the light bar pop up? "Check."

2. What do you see there? The device is recommending different brightness levels depending upon where we are. If you are somewhere bright, like in the sun, you will need a higher setting in order to be able to read books. If you are somewhere dark, you can keep your brightness at a low level.

3. Swipe your finger up and down on the scale to practice. You can also tap the larger sun icon on the right to increase the brightness or the smaller sun icon on the left to decrease the brightness.

4. Let's turn the brightness down to the lowest possible level. "Check."

5. When you are satisfied with the brightness of your e-reader screen, tap anywhere outside of the current window.
6. Remember that the light uses up your battery, so make sure to keep the brightness as low as possible while still being able to read comfortably.

7. Also, before you turn your device off, it is wise to turn the brightness to the lowest setting. This helps to preserve the battery.

\section{Be careful not to delete a book}

1. Tap "Home." Then tap and hold your finger on a book title and stop there. What do you see? "Check."

2. At the bottom of the list it says "Remove from Device." We do NOT want to do that

3. Tap the sign " $X$ " in the top right corner of the window that you see. Or alternatively, you can also tap the "Home" or the "Back" icon instead.

4. Let's try again. Tap "Home." Then tap and hold your finger on a book title or book cover and stop there. Can you see the option "Remove from Device?"

5. We don't want to remove the title from the device. So we tap on the "X." You can also tap the "Home" or the "Back" icon instead.
6. Remember that the "Home" and the "Back" icons are your friends. Whenever you want to get out of a situation, tap "Home" or

"Back." The "Back" icon takes you back one step to the previous screen and the "Home" icon always takes you to the "Home" screen, page 1 of $X$

7. If you delete a book, let your mentor know immediately. Unfortunately, if a book or books are deleted they will have to be sent back to the program team who will download the books again to the device.

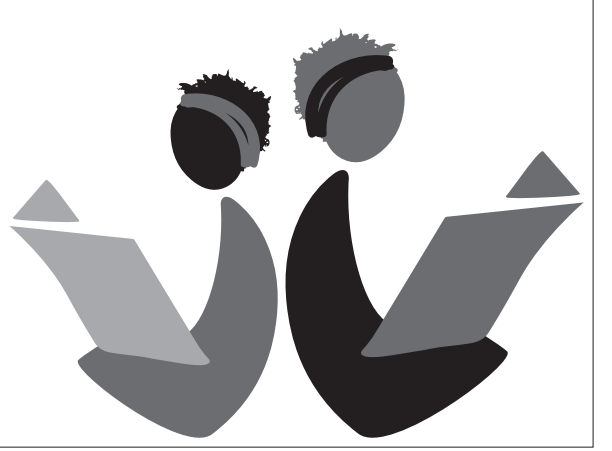




\section{wrap-up}

\section{WRAP-UP \\ [5 MINUTES]}

Ask participants:

Do you have any questions from today's session?

- How do you feel about taking your e-readers home today?

Explain: In next week's session, we will read

Tom the Banana Seller for Activity 5. For those of you taking e-readers home today, please try to read the book in advance of next week's session. Also, try to read as much as possible between now and the next session, whether on your own, with a parent/guardian, sibling, friend, or neighbor. The more you read, the better readers you will become.

Remind participants who did not get their e-readers today to return their signed

e-reader usage and policy forms before or at the next safe space meeting so that they can go home with the e-readers next week.

Thank the group for their participation and remind them of the meeting time and place for next week.

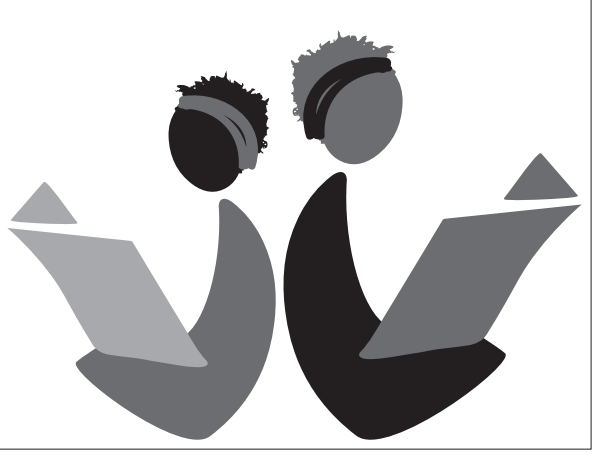




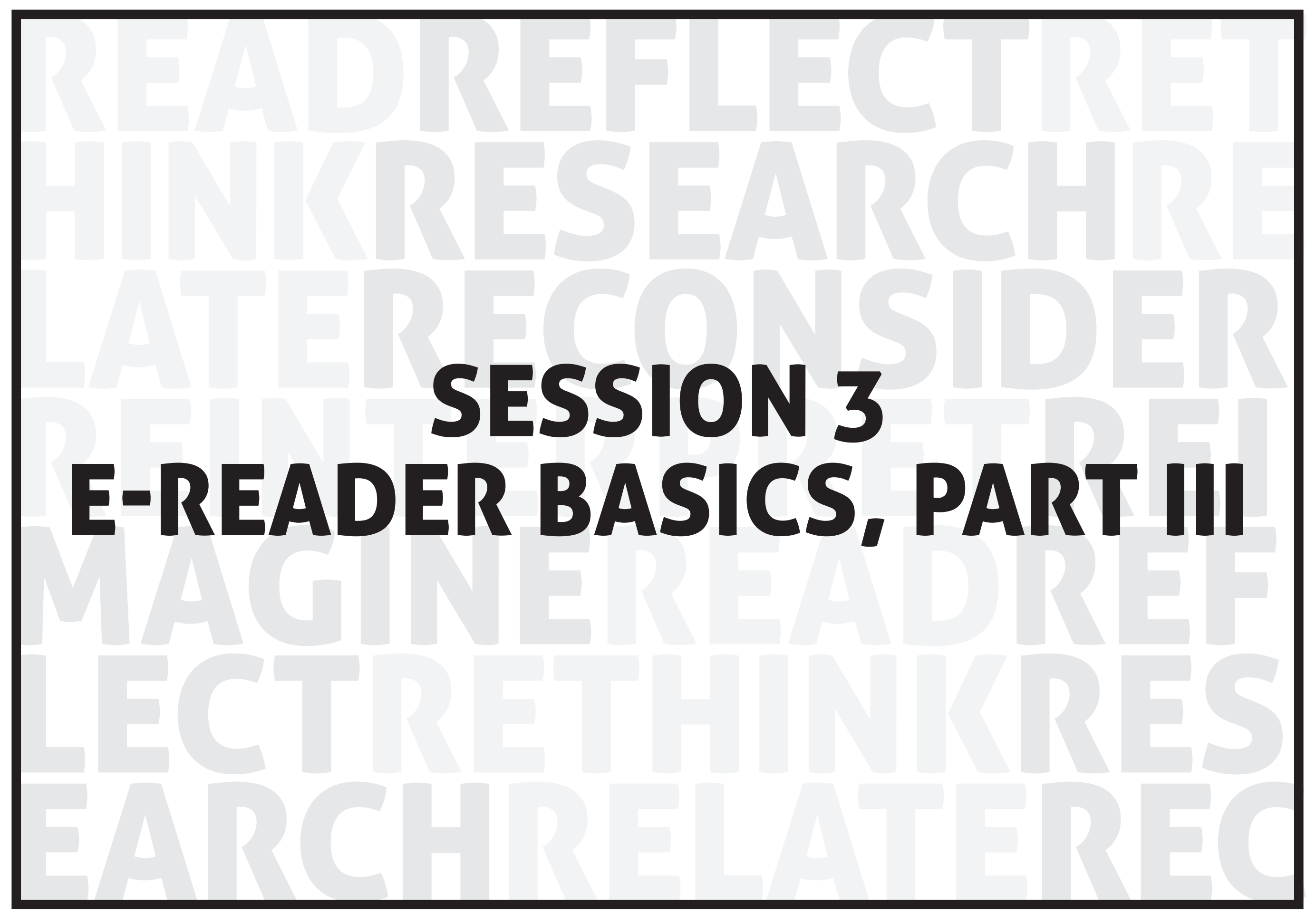




\section{session 3 / e-reader basics, part III}
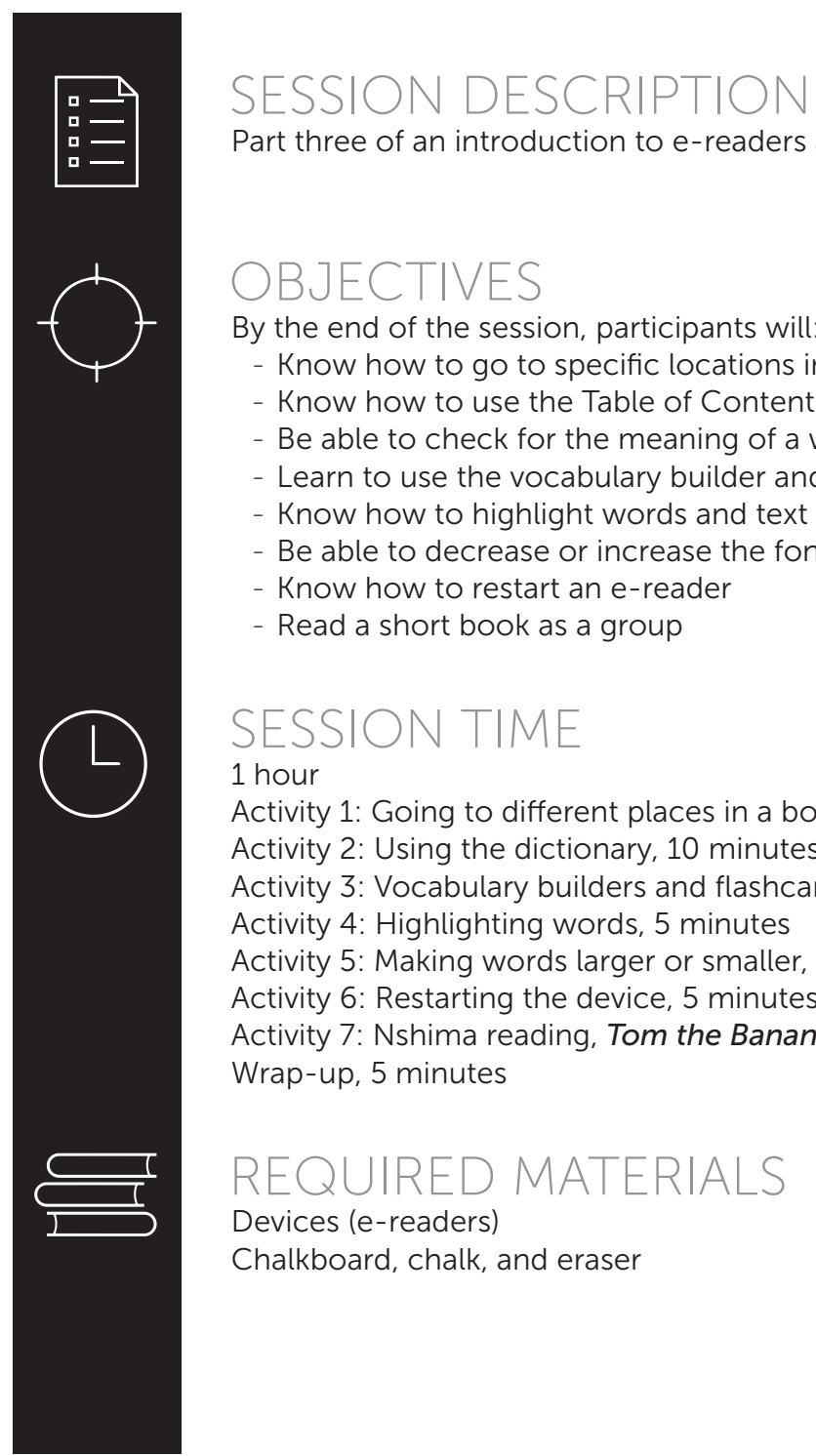

SESSION DESCRIPTION

Part three of an introduction to e-readers and how to use them.

\section{OBJECTIVES}

By the end of the session, participants will:

Know how to go to specific locations in a book

Know how to use the Table of Contents

Be able to check for the meaning of a word with the e-reader

- Learn to use the vocabulary builder and create flashcards

Know how to highlight words and text in e-books

Be able to decrease or increase the font size of words in e-books

- Know how to restart an e-reader

Read a short book as a group

\section{SESSION TIME}

1 hour

Activity 1: Going to different places in a book, 10 minutes

Activity 2: Using the dictionary, 10 minutes

Activity 3: Vocabulary builders and flashcards, 10 minutes

Activity 4: Highlighting words, 5 minutes

Activity 5: Making words larger or smaller, 5 minutes

Activity 6: Restarting the device, 5 minutes

Activity 7: Nshima reading, Tom the Banana Seller, 10 minutes

Wrap-up, 5 minutes

\section{REQUIRED MATERIALS}

Devices (e-readers)

Chalkboard, chalk, and eraser 
session 3 / e-reader basics, part III (cont.)

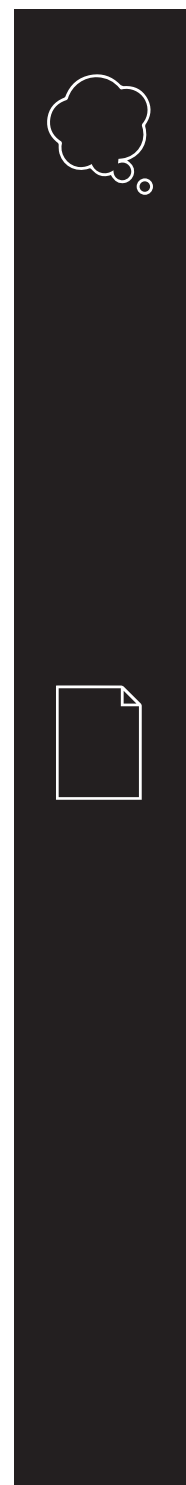

PRE-SESSION PREPARATION

Read through the entire session and, if

For Activity 2, be sure to look at the book and necessary, practice presenting the activities. word selected and get comfortable using the Prepare all materials needed. dictionary function before the session.

For Activity 1, draw a picture of two e-readers (rectangles) side by side on the chalkboard. On the left one, write "Once upon a time" in small letters inside the rectangle that depicts the screen. On the second one, write "Once Upon" in larger letters inside the rectangle. This will be used to demonstrate how fewer words will show up on the e-reader screen if we increase the font size.

\section{FACILITATOR NOTES}

There are five reading activity types that will be used in this curriculum in Sessions 3-19, as follows:

\section{Nshima reading}

In nshima reading, participants trade off reading a story. One participant starts reading a story to a point and calls out "Nshima" before selecting another participant in the group to carry on reading. They cannot choose participants sitting next to them This will help to include more people, not just the participants sitting closest to the first reader who are likely their closest friends.

\section{Choral reading}

Choral reading is reading aloud in unison with a whole group meaning the mentor and the participants. Choral reading helps build participants' fluency, self-confidence, and motivation. Because they are reading aloud together, participants who may feel self-conscious or nervous about reading aloud will have built-in support. Doing choral reading repeatedly will help struggling participants become better readers. It is also more fun since participants get excited

when they hear their own voices while reading.

\section{Echo reading}

The facilitator will read a

sentence, few lines, or a

paragraph and the participants will repeat or "echo" it back.

\section{Paired reading}

With paired reading, ask participants to pair off. If there is an uneven number, have one person pair with you, the mentor. Pair the weaker readers with the stronger readers, then have each pair read aloud to each other Encourage participants to help each other pronounce words correctly.

\section{Mentor read aloud}

Mentor read aloud allows

mentors to model reading for participants and provides for more exposure to English. Also, it allows for higher level books to be shared with the group that participants may not be able to read on their own. Before the mentor read aloud activity, the mentor must practice reading the selected book out loud and look up the meaning of any words that may be unfamiliar. While reading, the mentor should model good reading by being audible, clear, and expressive. 


\section{activity 1}

\section{GOING TO DIFFERENT PLACES IN A BOOK \\ [10 MINUTES]}

1. Explain: Moving from page to page in a book on your e-reader can be tedious.

So now you will learn an easier way of going to different places in your book. For example, you will be able to go to the beginning of the book, or to a specific chapter, without flipping through page by page.

2. First, we're going to open the book Blue Wings to learn how to go to different places in a book by using the table of contents. Like your hardcopy textbooks, most e-books also have a table of contents.

3. Ask: Could someone tell me what the table of contents is used for in a book?

[To see the chapter titles, find the page numbers for chapters, and see contents of the book.]

4. Here are the steps to access the table of contents:

Go to your Home screen. Find Blue Wings and open it.

- Tap the Top Zone, then tap "Go to."

\section{Now what do you see?}

You should see the table of contents, labeled Contents. "Check."

Now we are going to find the section of the table of contents: Chapter 16. Swipe your finger across the display from the bottom up or top down to find Chapter 16. "Check."

5. Let the participants spend a few minutes reading the selected chapter.

6. Ask if there are any questions on how to access the table of contents.

Continued on next page 


\section{activity 1 (cont.)}

7. Explain: Now we are going to learn how to go to 'locations.' Sometimes books may not have a table of contents, but we still need to go to a specific passage together. Or the chapters may be long and we need to go to a specific passage in the middle of the chapter. To do that we go to a location which refers to a specific word in a book. The reason that we use locations instead of pages is because the e-reader allows us to change the font size, which we will learn about later. The number of words in a book does not change, but if you make the font bigger or smaller, there will either be more pages or fewer pages, as we can see from this example I drew on the board [Point to the two e-readers (rectangles) you drew side by side on the chalkboard.] If we use locations, everyone will get to the right word, regardless of the page number.

8. Here are the steps to find a location:

Find the book Finders Keepers and open it.

Tap the Top Zone, and then tap "Go to." "Check."

Now tap Page or Location. You should see a box that says, "Enter a location" and a keyboard at the bottom of your display. "Check."
Insert a number by tapping the keyboard displayed at the bottom of the display. Key in the number 50 .

If you make a mistake choose the

backspace symbol (the one with the " $\mathrm{X}$ " on it). "Check.

Now tap where it says "Location" or the "Enter" key on the keyboard.

What do you see? We should all be at location 50. Tap the Top Zone then look to the bottom of the screen to see the location number, indicated as "Loc \#." The number will be right around 50 depending on the font size setting on your e-reader.

- The location function is the e-reader's best guess to get everyone to approximately the same place. It will not always lead to the same page exactly, but looking at the first two sentences or perhaps by going back one page and reading the last sentence on that page, everyone should be able to find the exact sentence you would like them to start with. 


\section{activity 2}

\section{USING THE DICTIONARY [10 MINUTES]}

1. Explain: The e-reader has a dictionary feature that allows you to look up words. There are different ways to do this. The first way is perhaps the most common. While you are reading, you may come across a new word. Your e-reader lets you see the definition of the new word easily.

2. Here are the steps:

- Go to the "Home" screen. Let's open the book Ayisha.

- Tap the Top Zone, then tap "Go To."

Select "Page or Location." "Check."

Key in 75. Then tap Location.

Go to the paragraph that starts with "Ayisha took a plastic bucket from the kitchen." Depending on the font size setting of your e-reader, this could be on the page(s) before or after the page that first comes up after selecting location 75 .

- After finding the paragraph, look for the word "fetch" in the next sentence. Tap and hold your finger for a moment on the word. When you release your finger, a window pops up.
You should see a definition for the word fetch. "Check."

3. Ask a volunteer to read the definition for fetch [go for and then bring back

(someone or something) for someone: he ran to fetch help.]

4. To go back to the text, tap "Back."

5. Explain: Another way to use the dictionary is to look up a word in the dictionary directly, not by highlighting a word in a book.

6. Here are the steps:

- Tap the Top Zone and tap "Home." "Check."

- Tap the Search icon (looks like a magnifying glass). You should see a search bar appear at the top of your screen. "Check."

- Use the keyboard at the bottom of your screen to type in the word you want to look up (for example, "mango").

Find the right arrow to the right of the search bar, where your text has appeared. Tap on the arrow.
At the bottom of the screen that appears, do you see the option for "Dictionary?" "Check."

- Tap on the dictionary option.

You should see a full definition of the word you looked up. "Check."

Ask a volunteer to read the first definition of mango. [1. a fleshy, oval, yellowish-red tropical fruit which is eaten ripe or used green for pickles or chutneys.] 


\section{activity 3}

\section{VOCABULARY BUILDER AND FLASHCARDS \\ [10 MINUTES]}

1. Explain: Now, we are going to learn another feature that will help us learn new words and expand our vocabulary.

2. Here are the steps:

- Let's open Afro: The Girl with the Magical Hair and go to location 50. This location should bring you to the beginning of

Chapter 2. Could someone read the first paragraph of Chapter 2 for me?

- Thank you! Now, let's pretend like we don't know the word "largest" in the first sentence.

- Please select the word "largest" by placing your finger on the word, holding it down and then releasing. As you can see, the dictionary box appears. Tap on the bottom of the screen to close the dictionary.

Now, please go to the Home screen

Go to the Menu button in the right corner (three dots). Next, tap on "Vocabulary Builder." "Check."

-What do you see? You should see the word that you 'highlighted.' Each time you highlight a word (hold it down and release), that word appears in your Vocabulary Builder.
Try tapping on the word "largest," and you should see the definition come up.

Next, look at the bottom of the screen. You should see a button that says

"Flashcards." Tap that.

- This is another feature that creates a "flashcard" for all the words that you have highlighted. You can use this to help test your familiarity with a word. On the flashcard, you will see the word on top of the line. Under the line, you will see the word used in a sentence to help you remember the meaning.

- Tap on "See Definition" in the top lefthand corner. This will take you back to the definition.

- Tap on the forward or backward arrow to see other flashcards.

To exit, either tap the "Exit Flashcards" in the top left-hand corner or tap the back button from the top navigation bar.

3. Let the group practice using the vocabulary builder and flashcard functions for two minutes.

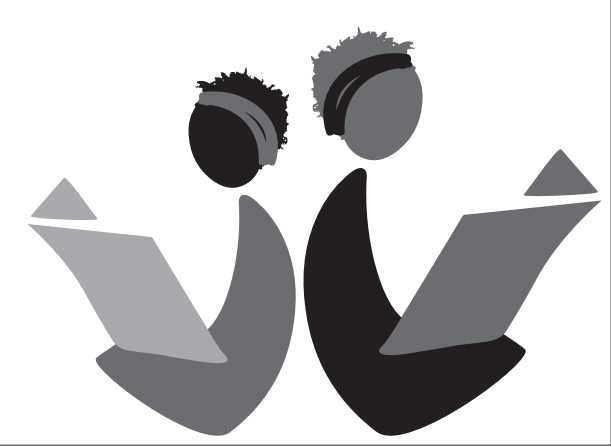




\section{activity 4}

\section{HIGHLIGHTING WORDS \\ [5 MINUTES]}

1. Explain: Now we are going to learn how to highlight words. Here are the steps to highlighting a word:

- Let's open Afro: The Girl with the Magical Hair again and go to location 150. Look for the paragraph that starts with "Prince perked up..." "Check."

- Could someone read that paragraph please?

- Now, let's pretend like we don't know the word "voice."

- Please select that word by placing your finger on the word, hold it down then

release. As we saw in the last activity, the dictionary box appears. There are also additional options that appear in the boxes below the word.

Could someone please read these options out loud? [The options are: highlight, note, share, search, and menu.]

- Please tap on "Highlight." This will highlight that word on this page, but it will also

highlight the word wherever it appears in the book. This is a great feature to use if you are learning a new word.
Once you have learned a word, you may want to un-highlight the word. Let us practice that.

Please tap on the top navigation bar and then tap on "Go To."

Next, tap on "Notes."

You will see the full list of words that have been highlighted. To remove the highlighting, tap on "delete." Then that word should no longer appear in the notes list. 


\section{activity 5}

\section{MAKING WORDS LARGER OR SMALLER [5 MINUTES]}

1. Explain: Now we are going to learn how to make the words on your e-reader larger or smaller.

2. Here are the steps:

Go to the "Home" screen. Open any book and look for a page with text.

- Tap the Top Zone and tap the "Aa" icon.

Choose the font size that suits your needs by pressing the minus (-) or plus (+) signs at the bottom where it says size. Then tap on the " $X$ " on the top right corner of the window. "Check."

3. Explain: Remember that you need to be within a book to do this. Once you change the text size, it is changed for all the books on your e-reader, not just the book you are reading. Also, remember that if the text sizes are different, the number of words on each page will be different.

4. Note: To make group reading activities easier, it is best to have the whole group set their e-readers at the same font size. Before starting a reading activity, walk the group through setting the font size on the fifth "Aa" from the left.

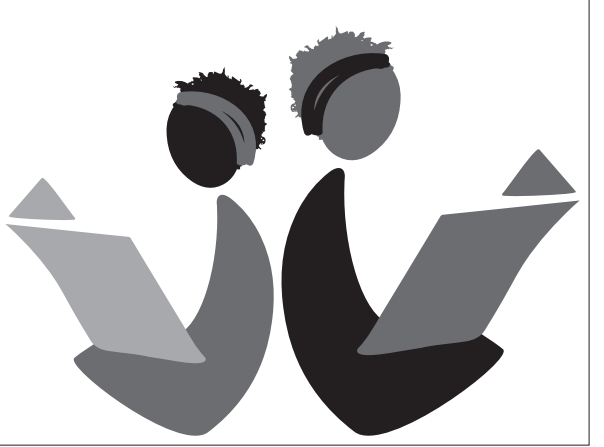




\section{activity 6}

\section{RESTARTING THE DEVICE [5 MINUTES]}

1. Explain: When your e-reader seems to "freeze" or stop working, for example if the screen stays the same even when tapping the screen, then you may need to restart the device.

2. Here are the steps; let's do them together:

Hold down the power button for 20

seconds. Your screen will go blank but keep holding the button until you count to 20 .

As the device restarts, you should see an image of someone reading a book under a tree with "Kindle" written above it. The progress bar will appear. "Check."

3. Assist anyone who was not able to restart their device. 


\section{activity 7}

\section{NSHIMA READING, TOM THE BANANA SELLER BY HUMPHREYS ODUNGA [10 MINUTES]}

1. Explain: We are going to read a short book together before we end today's session using a technique called nshima reading. In nshima reading, participants take turns reading a story. One person starts reading a story to a point and calls out "nshima" before selecting another person in the group to carry on reading. However, you are not allowed to choose a person sitting next to you to be the next reader.

2. Please open the e-book Tom the Banana Seller. Remember that you can search for a book by tapping the search icon on the home screen top bar then typing in the first word or words of the book title. Then select the book from the list that appears below where you typed the word/words. "Check." [Verify that everyone is on the right book. Help anyone who is not able to find the book.]

3. Ask: Who would like to begin reading? [Choose a volunteer.] Please begin.

Remember to read a short bit then call out nshima when selecting someone new to read.
4. After reading the book, ask the following questions:

- What did you enjoy about the book?

- What have you learned from the story?

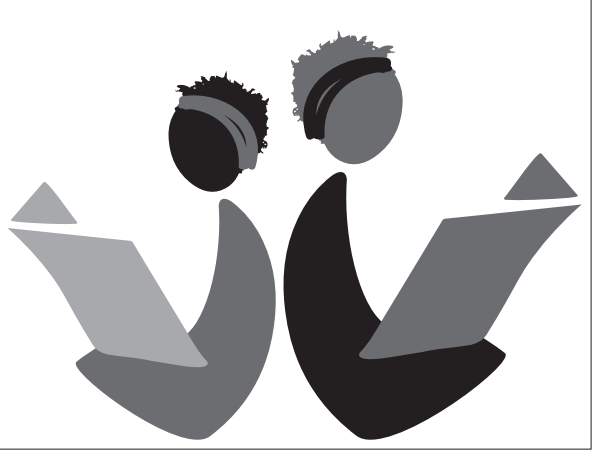




\section{wrap-up}

\section{WRAP-UP \\ [5 MINUTES]}

Explain: In next week's session, we will read I am a person, I am Me! for Activity 1 and Chapters 1-5 of Afro: The Girl with the Magical Hair for Activity 2. Please try to read these books in advance of next week's

session.

Ask: Are there any other books on the

e-readers that you hope to read between now

and our next safe space meeting? [Allow time for sharing.]

Ask: Is there anything you would like to

discuss about today's session? Did you learn anything new? What are you looking forward to at next week's session?

Thank the group for their participation.

Encourage them to read as much as possible between now and the next session, whether on their own, with a parent/guardian, sibling friend, or neighbor. The more they read, the better readers they will become.

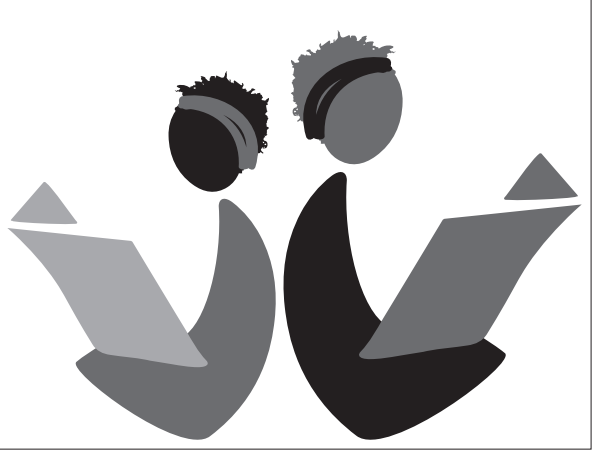




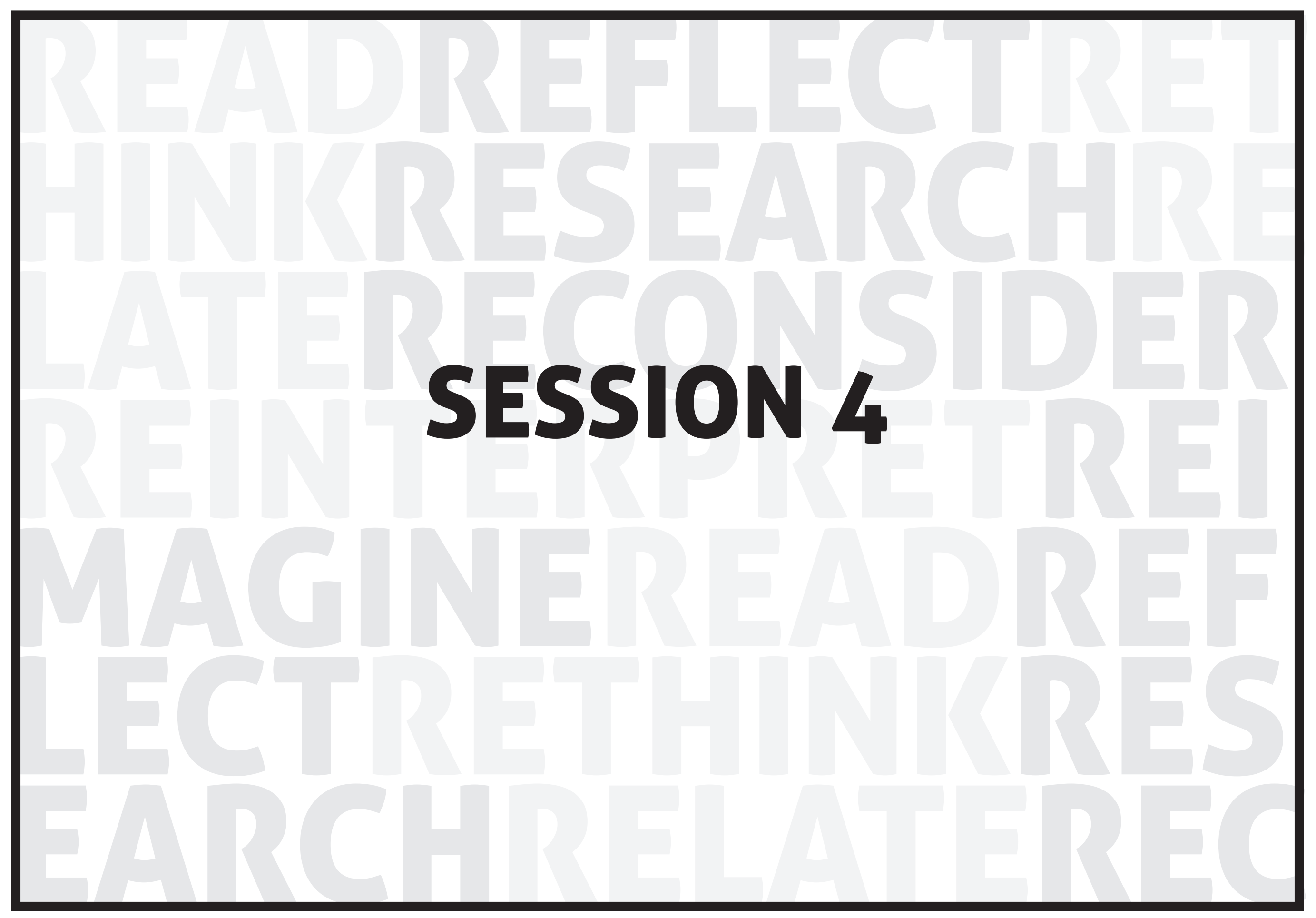




\section{session 4}

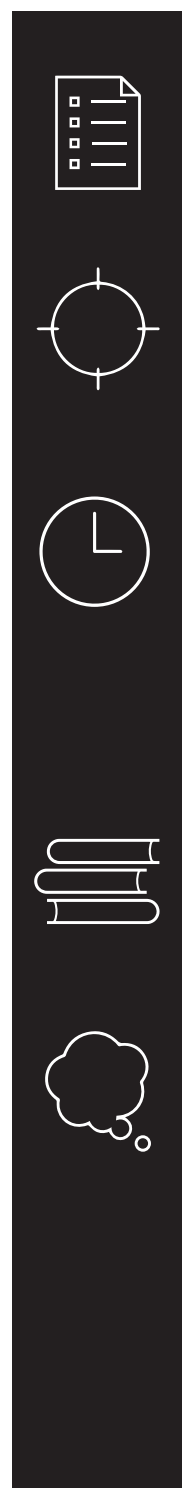

SESSION DESCRIPTION

Share books read the previous week and practice reading as a group.

\section{OBJECTIVES}

In this session, participants will:

Practice reading

Follow along while the mentor reads aloud

SESSION TIME

1 hour

Warm-up: Book board, 5 minutes

Activity 1: Choral reading, I am a Person, I am Me! 15 minutes

Activity 2: Mentor read aloud, Afro: The Girl with the Magical Hair (part 1).

35 minutes

Wrap-up, 5 minutes

\section{REQUIRED MATERIALS}

Devices (e-readers)

Chalkboard, chalk, and eraser

\section{PRE-SESSION PREPARATION}

Read through the entire session and, if necessary, practice presenting the activities. Prepare all materials needed.

Read the e-books for Activities 1 and 2 in advance. 


\section{session 4 (cont.)}

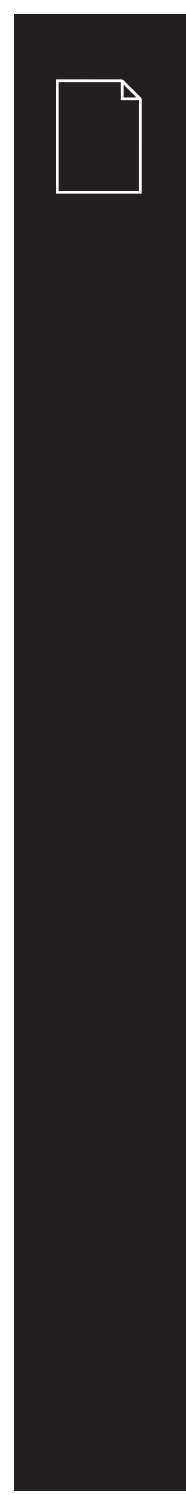

\section{FACILITATOR NOTES}

Be sure to work to keep the atmosphere informal. Ask participants to sit together on the floor or bring desks together so that everyone is sitting in a large circle. The girls should not be sitting individually at school desks. As the facilitator, you need to be able to see the participants' e-reader screens to be sure that they are on the right page/passage during the e-reader activities.

For today's Activity 2, here is a summary of the book (you'll read Chapters 1-5 in this session (4) and Chapters 6-8 in the next session (5).

\section{Afro: The Girl with the Magical Hair} by Okechukwu Ofili

\section{Summary, for the mentor's information:} This story, written by a Nigerian author, puts fun twists on the usual "evil queen vs. good/helpless princess" story. Yackiland is ruled by an evil, straight-hair obsessed queen. Everyone follows her fashion choice and uses weaves and relaxers to also have straight hair. Except one girl,

OhMyGoodnessDidYouSeeThatGirlsAfro, or "Afro" for short. Afro's hair is fantastic and it is magical. When the queen finds out she captures Afro and tries to keep her magic to herself. A handsome young man named Prince (not a real prince) stumbles upon the hole where the queen keeps Afro. Adventure (and a happy ending) follow. Afro is brave smart, creative, and values herself. Themes include "be yourself," and the plot/characters resist gender stereotypes (for example, it is Afro who saves Prince's life; not the prince who saves the princess). Afro is also a

voracious reader.

\section{Instructions:}

This is a medium length book, it will take two sessions to read the full book. 


\section{warm-up}

\section{$\mathrm{BOOK} \mathrm{BOARD*}$ \\ [5 MINUTES]}

1. The book board is a great way to allow participants to share their thoughts about the stories they read on their e-readers outside of safe space meetings, get tips from their peers on which books they might enjoy, and to show off how much they are reading in their spare time.

2. Before the e-reader component of each safe space, create a simple book board chart on the chalkboard similar to the table shown here.

3. Before the start of the session, ask participants to write the name of the book(s) they have read since the last safe space meeting and rate the book(s) with a smiley face (-) if they liked it or a frown face 6 if they did not like it. This helps girls advertise good books to their peers and encourages a culture of reading.

4. Point out the books that are listed on the book board and encourage the group to keep sharing book titles they have read each week.

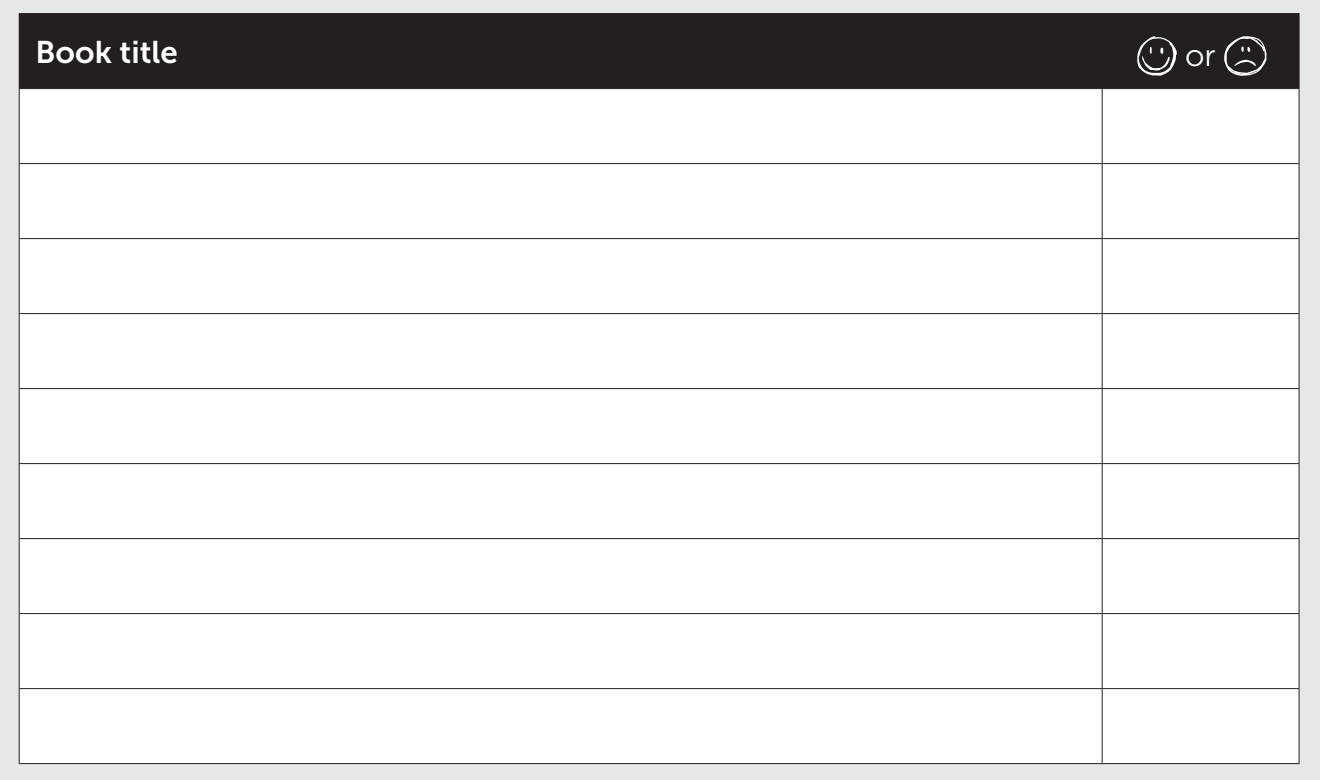

5. Ask if anyone would like to summarize the book they read, and what they liked or didn't like about it. Take one to two volunteers depending on time. The activity should not take more than five minutes.

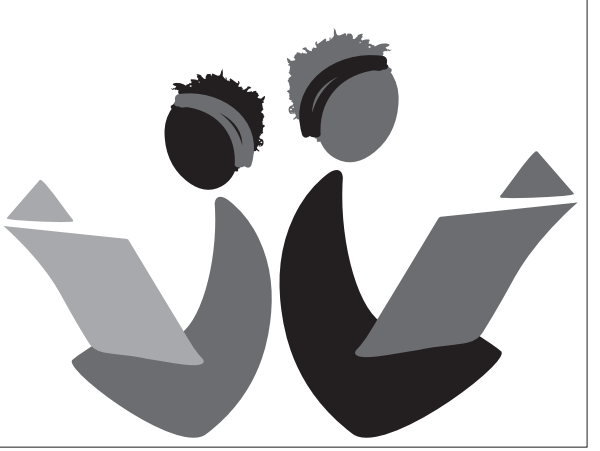




\section{activity 1}

\section{CHORAL READING, I AM A PERSON, I AM ME! BY LEONIE ARNOLD}

[15 MINUTES]

1. Explain: Today we are going to use a technique called choral reading. With choral reading, we all read out loud together as a group.

2. Say: Please open the e-book, I am a Person, I am Me! to the cover, location 1. "Check." [Verify that everyone is on the right book and on the first page of text. Help anyone who is not able to find the book.] Now let's go to the page that says, "I can see." At location 12.

3. Ask: Is everyone there? On location 12 ? "Check." Let's begin reading together, "I can see...".

4. After finishing the book, ask:

How did this book make you feel?

-What did you like about this book? 


\section{activity 2}

\section{MENTOR READ ALOUD, AFRO: THE GIRL WITH THE MAGICAL HAIR (PART 1) \\ BY OKECHUKWU OFILI [35 MINUTES]}

1. Note for mentor: Remember, you should practice reading the selected book aloud when preparing your session and look up the meaning of potentially unfamiliar words.

2. Explain: Now I am going to read to you all while you listen and follow along on your e-readers. This reading activity is called

'mentor read aloud.' Please open the e-book, Afro: The Girl with the Magical Hair. "Check." [Verify that everyone is on the right book and it is open to Chapter 1. Help anyone who is not able to find the book.]

3. Read Chapters 1-5. While reading demonstrate good reading by being audible, clear, and expressive.

4. After you are done reading Chapters 1-5 of Afro: The Girl with the Magical Hair, ask:

What has happened so far in the story?

What do you think will happen next? Why?

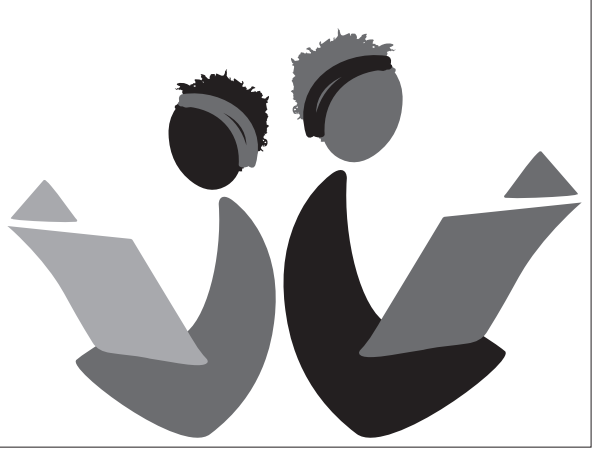




\section{wrap-up}

\section{WRAP-UP \\ [5 MINUTES]}

Explain: In next week's session, we will read Amazing Daisy! for Activity 1 and Chapters

6-8 of Afro: The Girl with the Magical Hair for

Activity 2. Please try to read these books in

advance of next week's session.

Ask: Are there any other books on the

e-readers that you hope to read between now and our next safe space meeting? [Allow time

for sharing.]

Ask: Is there anything you would like to

discuss about today's session? Did you learn anything new? What are you looking forward to for next week's session?

Thank the group for their participation.

Encourage them to read as much as possible between now and the next session, whether on their own, with a parent/guardian, sibling friend, or neighbor. The more they read, the better readers they will become. 


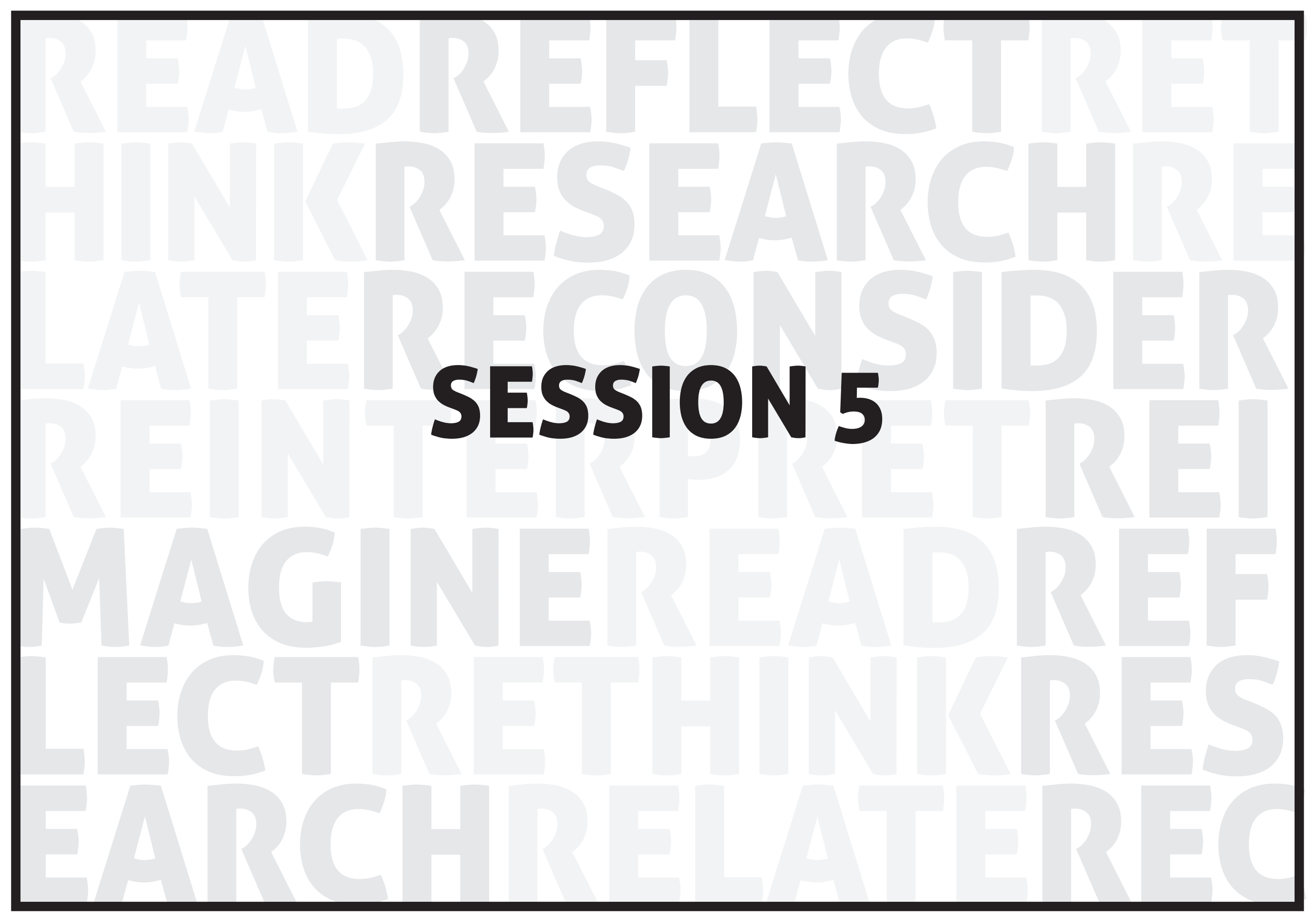




\section{session 5}

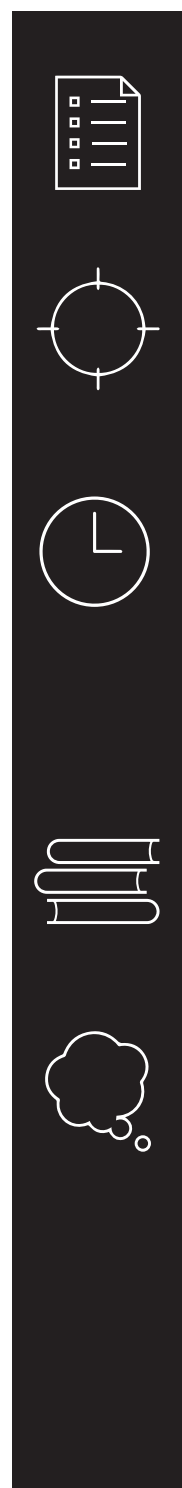

SESSION DESCRIPTION

Share books read the previous week and practice reading as a group.

OBJECTIVES

In this session, participants will:

Practice reading

Follow along while the mentor reads aloud

SESSION TIME

1 hour

Warm-up: Book board, 5 minutes

Activity 1: Echo reading, Amazing Daisy, 15 minutes

Activity 2: Mentor read aloud, Afro: The Girl with the Magical Hair (part 2),

35 minutes

Wrap-up, 5 minutes

REQUIRED MATERIALS

Devices (e-readers)

Chalkboard, chalk, and eraser

PRE-SESSION PREPARATION

Read through the entire session and, if necessary, practice presenting the activities. Prepare all materials needed.

Read the e-book for Activities 1 and 2 in advance. 


\section{warm-up}

\section{$\mathrm{BOOK} \mathrm{BOARD}$}

[5 MINUTES]

1. As in the previous session, create a simple book board chart on the chalkboard.

2. Before the start of the session, ask participants to write the name of the

book(s) they have read since the last safe space meeting and rate the book(s) with a smiley face (-) if they liked it or a frown face $(1)$ if they did not like it.

3. Point out the books that are listed on the book board and encourage the group to keep sharing book titles they have read each week.

4. Ask if anyone would like to summarize the book they read, and what they liked or didn't like about it. Take one to two volunteers depending on time. The activity should not take more than five minutes.

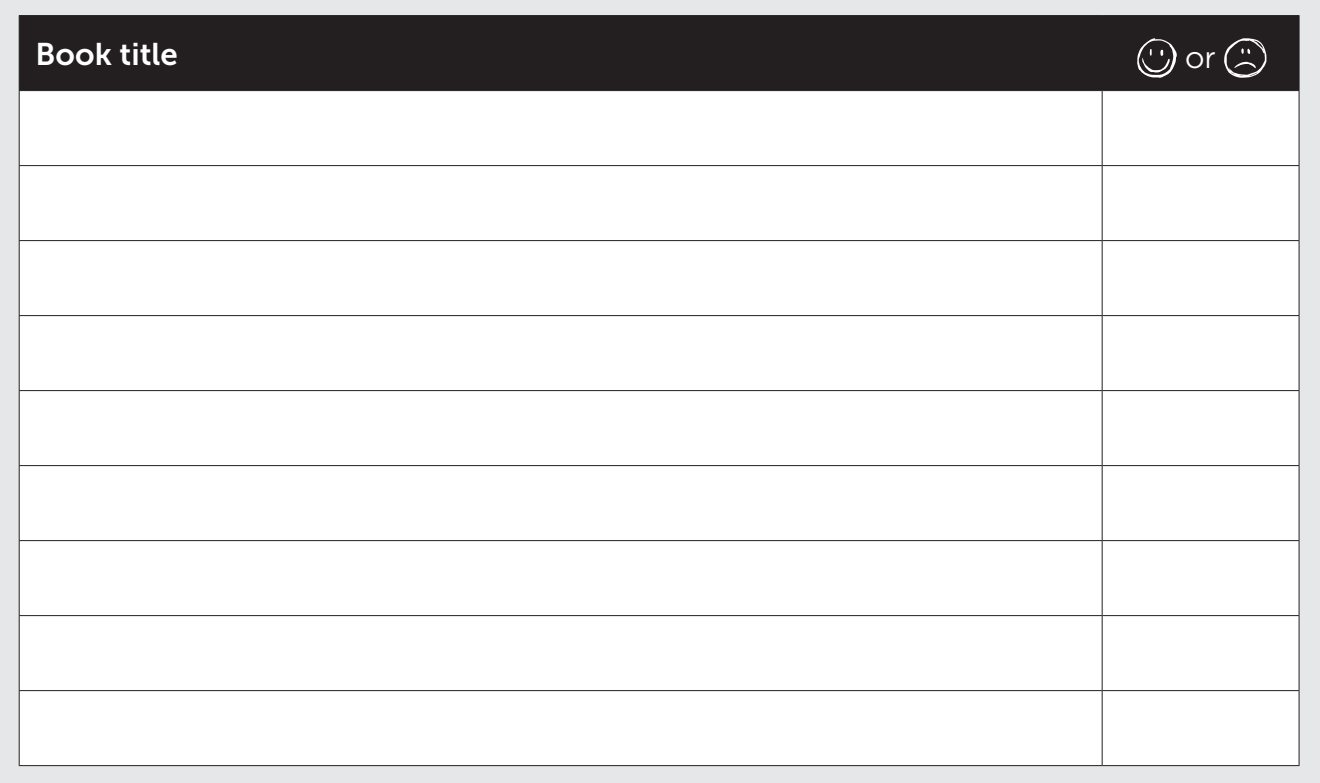




\section{activity 1}

\section{ECHO READING, AMAZING DAISY! BY NOZIZWE HERERO, SIYA MASUKU, AND LEONA INGRAM [15 MINUTES]}

1. Explain: Today we are going to use a

technique called echo reading. With echo

reading, I will read a sentence, few lines, or a paragraph, then when I stop and point at the group, you will repeat or "echo" what I

read. Let's try it!

2. Say: Please open the e-book Amazing Daisy! "Check." [Verify that everyone is on

the right book. Help anyone who is not

able to find the book.] I will begin reading

now. [Begin reading, then stop periodically

and point at the group for them to repeat what you just read.]

3. After reading the book, ask the following questions:

- What have you learned from this story?

- If you could give the book another title, what would it be?

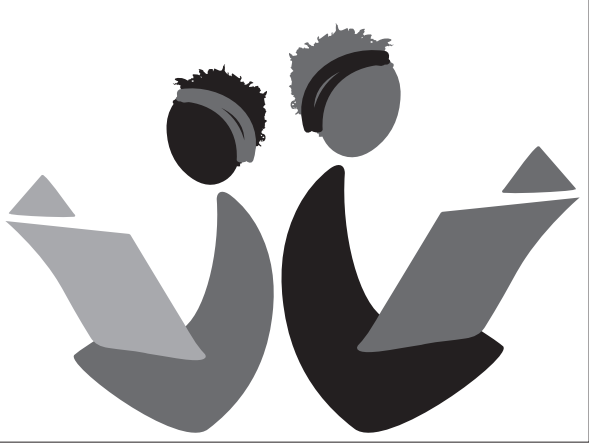




\section{activity 2}

\section{MENTOR READ ALOUD, AFRO: THE GIRL WITH THE MAGICAL HAIR (PART 2) \\ BY OKECHUKWU OFILI [35 MINUTES]}

1. Note for mentor: As in the previous sessions, you should practice reading the selected book aloud when preparing your session and look up the meaning of potentially unfamiliar words.

2. Explain: Like the last session, I am going to read to you all while you listen and follow along on your e-readers.

3. Say: We are going to finish the book we started last week, Afro: The Girl with the Magical Hair. Please open the e-book to Chapter 6: Love at First Fright. "Check." [Verify that everyone is on the right book and it is open to Chapter 6 . Help anyone who is not able to find the book/chapter.]

4. Read Chapters 6-8 (the end of the book) While reading, demonstrate good reading by being audible, clear, and expressive.

5. After you are done reading the book ask:

What did you enjoy about the book?

What do you wish was different about the ending?

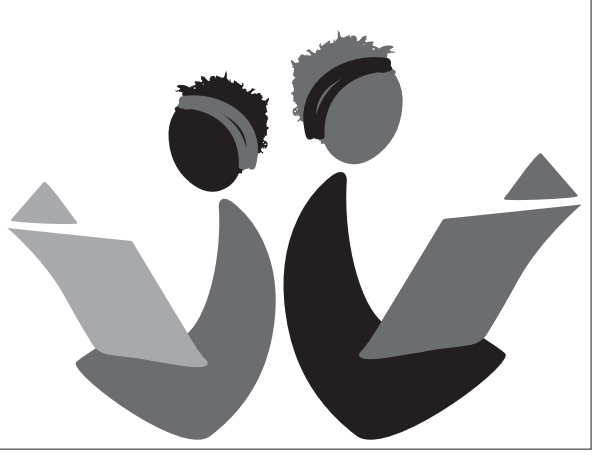




\section{wrap-up}

\section{WRAP-UP \\ [5 MINUTES]}

Explain: In next week's session, we will read Malaika's Magical Kiosk for Activity 1 and the beginning of The Girl with the Magic Hands for Activity 2. Please try to read these books in advance of next week's session.

Ask: Are there any other books on the

e-readers that you hope to read between now and our next safe space meeting? [Allow time

for sharing.]

Ask: Is there anything you would like to

discuss about today's session? Did you learn anything new? What are you looking forward to for next week's session?

Thank the group for their participation.

Encourage them to read as much as possible between now and the next session, whether on their own, with a parent/guardian, sibling friend, or neighbor. The more they read, the better readers they will become.

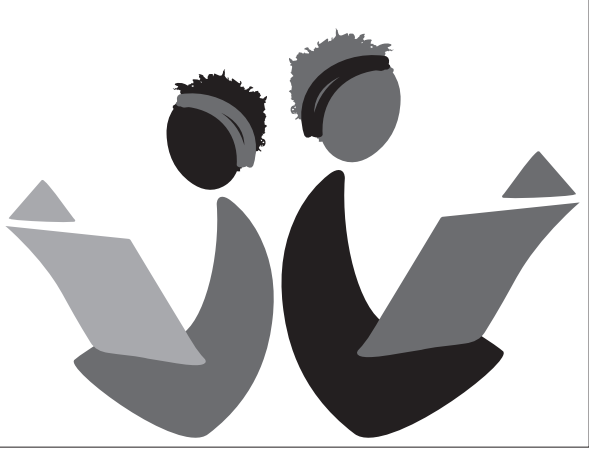




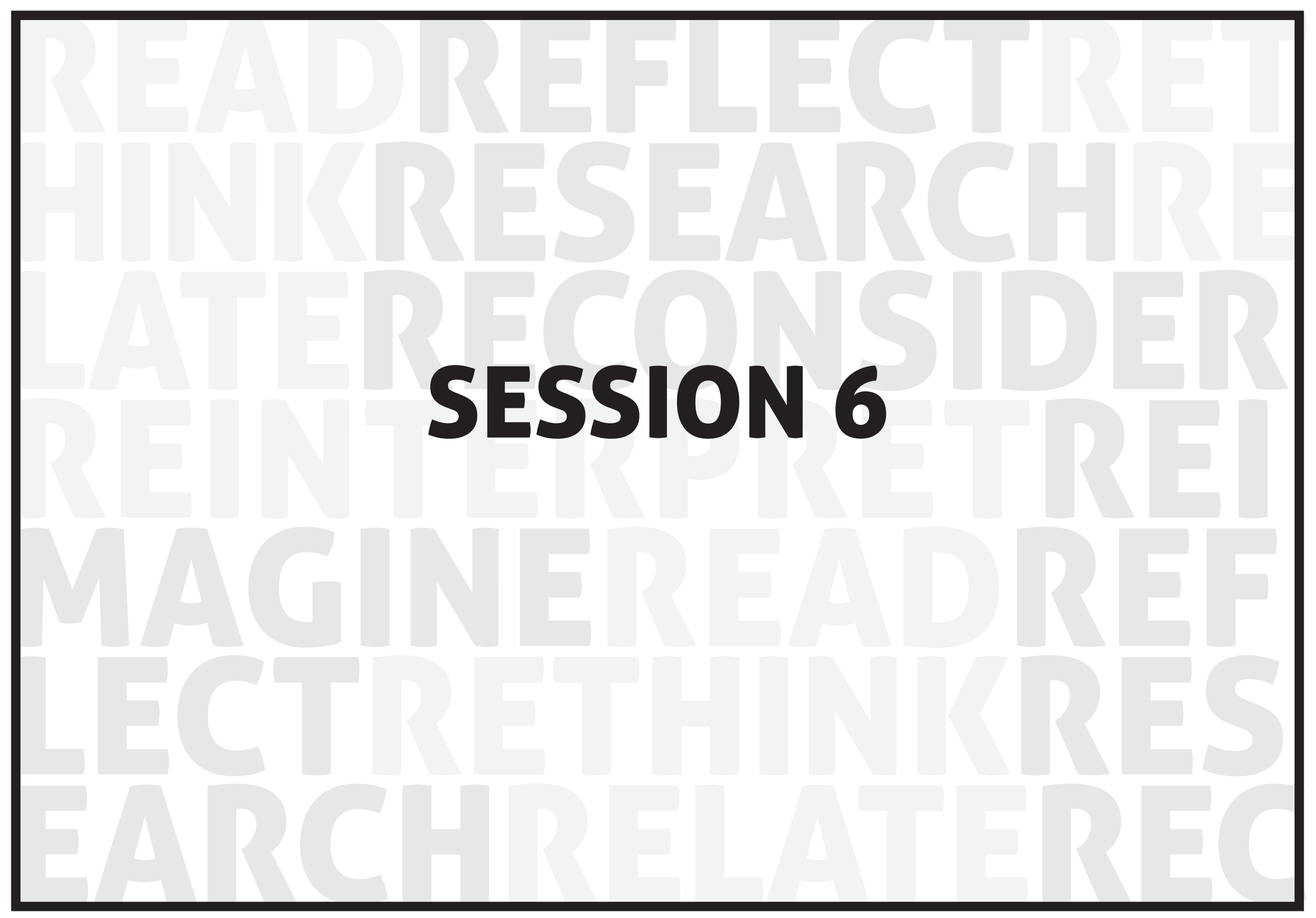




\section{session 6}

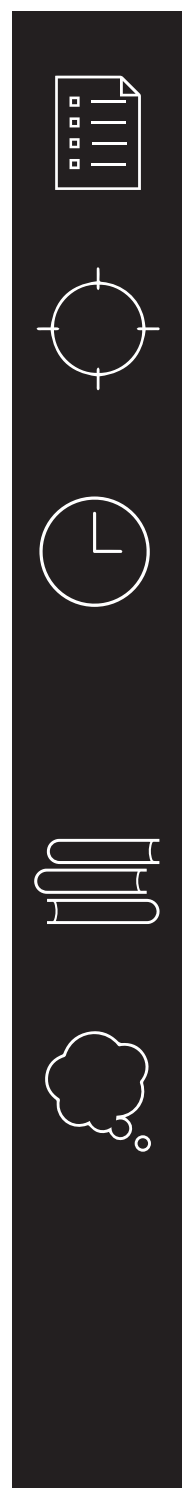

SESSION DESCRIPTION

Share books read the previous week and practice reading as a group.

\section{OBJECTIVES}

In this session, participants will:

Practice reading

Follow along while the mentor reads aloud

\section{SESSION TIME}

1 hour

Warm-up: Book board, 5 minutes

Activity 1: Nshima reading, Malaika's Magical Kiosk, 15 minutes

Activity 2: Mentor read aloud, The Girl with the Magic Hands (part 1)

35 minutes

Wrap-up, 5 minutes

\section{REQUIRED MATERIALS}

Devices (e-readers)

Chalkboard, chalk, and eraser

\section{PRE-SESSION PREPARATION}

Read through the entire session and, if necessary, practice presenting the activities. Prepare all materials needed.

Read the e-book for Activities 1 and 2 in advance. 


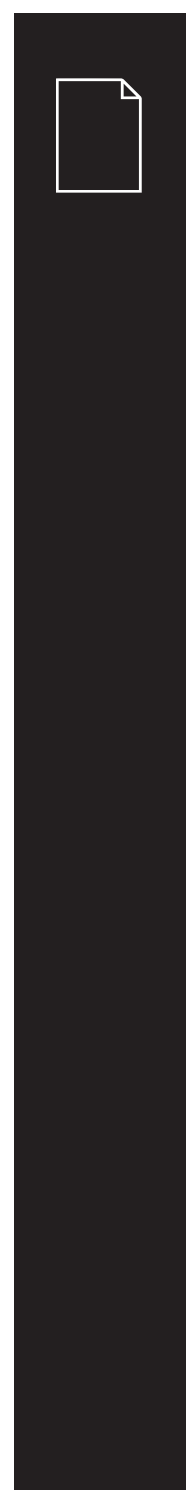

\section{FACILITATOR NOTES}

For Activity 2, here is a summary of the book and a preview of instructions for how you will break it up over the next 3 sessions:

\section{The Girl with the Magic Hands}

by Nnedi Okorafor

Summary, for the mentor's information:

From the Prologue of The Girl with the

Magic Hands, "It's a tragedy for a mere girl to

experience such deep sorrow. But things were

about to change for this girl. Oh yes. When

things are meant to be, they will. The world

always turns and the candle always burns. And

Chidera was about to learn that one can get

the very things one yearns."

Chidera, a young school girl, comes upon

spirits in the forest who help her discover her talent for drawing/painting. Chidera practices and pursues drawing/painting, which gives her joy, and increasingly brings happiness to her family and others in the community. There are messages about the worth of girls; the power and beauty of art and nature. The writing is

beautiful and descriptive.

\section{Preview of how you will use this book during} safe spaces:

This is a longer book and you won't have time to read it in its entirety. This is okay, because once you get through Chapter 2, the happy ending has already started and continues on in the same trajectory for the remainder of the book. It's a lovely read if you want to read the rest yourself - and girls can finish it on their own time if they want. Here is how you will break up the story over the next 3 sessions:

Session 6: You will read the Prologue (starting at $2 \%$, around location 18 ) and half of Chapter 1 - up to $20 \%$, around location 146 . You can end where Chidera says "I... I don't know..."

Session 7: You'll continue where you left off (half-way through Chapter 1, at 20\%, around location 146). Finish Chapter 1 and read half of Chapter 2 - up to 43\%, around location 309 .

You can end with the paragraph that starts,

"She didn't really want it to, but she could not help testing its durability."
Session 8: For the last read-aloud with this book, you'll continue where you left off (half-way through Chapter 2, at 43\%, around location 309) and finish Chapter 2. After finishing Chapter 2, you'll ask the girls to predict what they think will happen next. After discussing, you can read the first several paragraphs of Chapter 3 to give the girls a sense of the continuing happy ending. (The remainder of the book continues on in this upward path for Chidera.

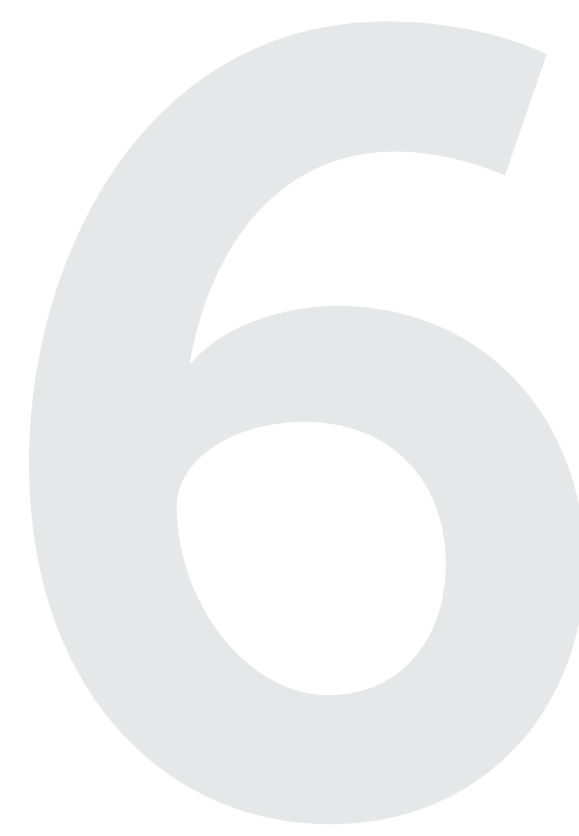




\section{warm-up}

\section{$\mathrm{BOOK} \mathrm{BOARD}$}

[5 MINUTES]

1. As in the previous session, create a simple book board chart on the chalkboard.

2. Before the start of the session, ask participants to write the name of the

book(s) they have read since the last safe space meeting and rate the book(s) with a smiley face (-) if they liked it or a frown face $(1)$ if they did not like it.

3. Point out the books that are listed on the book board and encourage the group to keep sharing book titles they have read each week.

4. Ask if anyone would like to summarize the book they read, and what they liked or didn't like about it. Take one to two volunteers depending on time. The activity should not take more than five minutes.

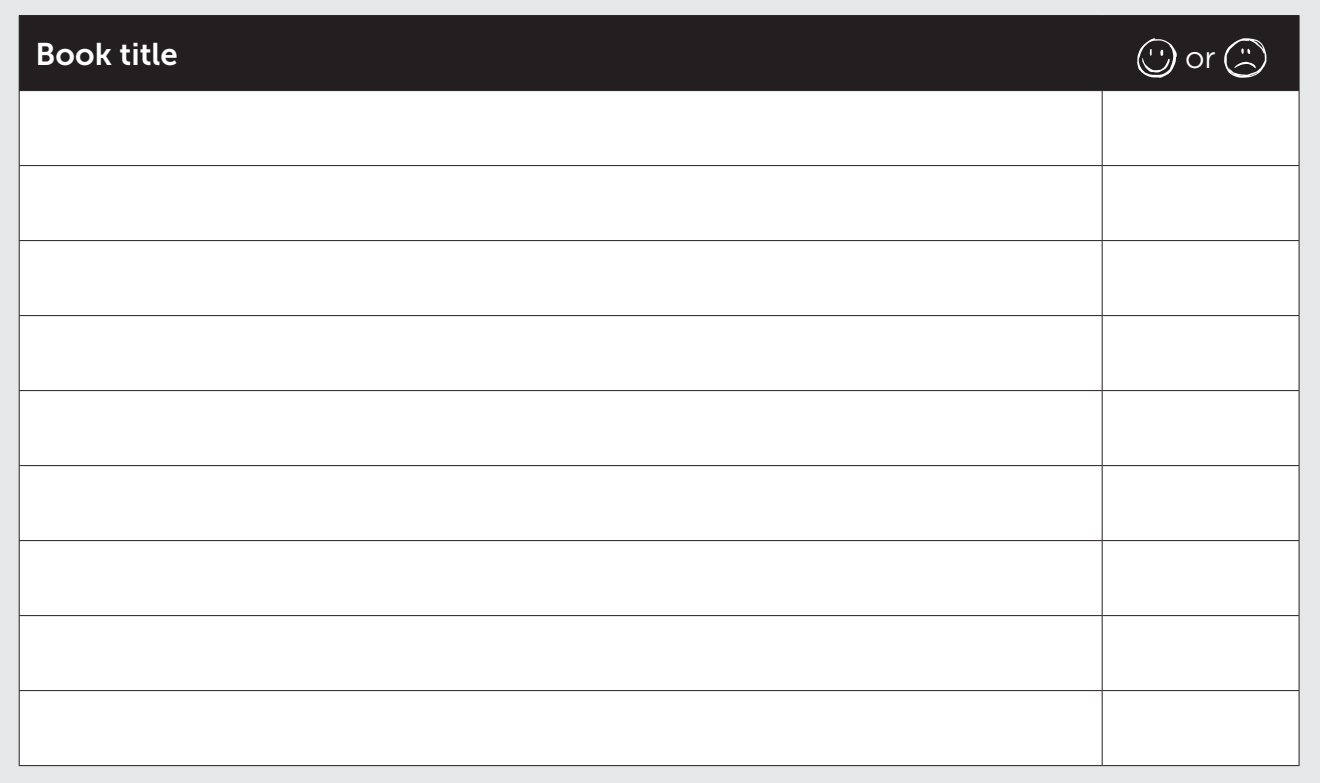




\section{activity 1}

\section{NSHIMA READING, MALAIKA'S MAGICAL KIOSK BY SHALEEN KESHAVJEE-GULAM [15 MINUTES]}

1. Ask: Does anyone remember what nshima reading is? [Let participants respond and describe nshima reading. If they don't remember, remind them that in nshima reading participants take turns reading a story. One person starts reading a story to a point then calls out "nshima" before selecting another person in the group to continue reading. Remind them that they are not allowed to choose a person sitting next to them.

2. Please open the e-book Malaika's Magical Kiosk. "Check." [Verify that everyone is on the right book. Help anyone who is not able to find the book.

3. Ask: Who would like to begin reading? [Choose a volunteer.] Please begin.

4. After reading the book, ask the following questions:

What is the main message from this story?

Which of the characters did you like best? Why?

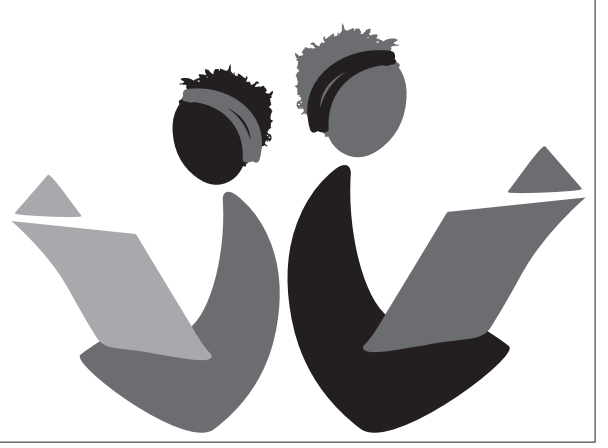




\section{activity 2}

\section{MENTOR READ ALOUD, THE GIRL WITH THE MAGIC HANDS (PART 1) \\ BY NNEDI OKORAFOR [35 MINUTES]}

1. Note for mentor: As in the previous sessions, you should practice reading the selected book aloud when preparing your session and look up the meaning of potentially unfamiliar words.

2. Explain: Like the last session, I am going to read to you all while you listen and follow along on your e-readers.

3. Say: We are going to begin a new book this week. Please open the e-book, The Girl with the Magic Hands and go to the prologue around location 18. "Check." [Verify that everyone is on the right book and it is open to the prologue. Help

anyone who is not able to find the book.]

4. Read the prologue up to half way through Chapter 1 (around location 146). While reading, demonstrate good reading by being audible, clear, and expressive.
5. After you are done reading up to location 146 where Chidera says, "I... I don't know..." ask:

- As you've been listening and reading along, what do the character and setting look like in your mind?

- What do you think will happen next? Why?

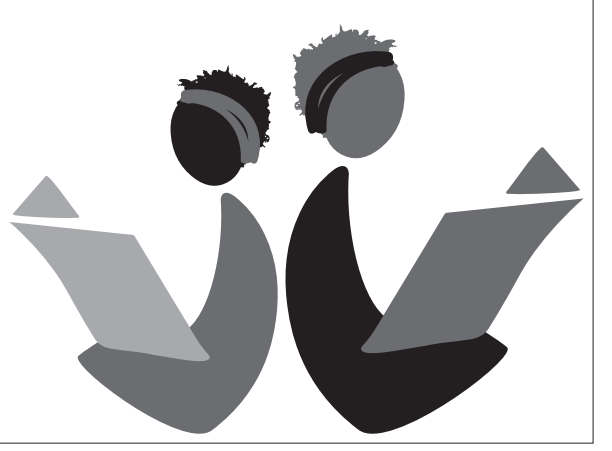




\title{
wrap-up
}

\author{
WRAP-UP \\ [5 MINUTES]
}

1. Explain: In next week's session, we will read Sakima's Song for Activity 1, and then more of The Girl with the Magic Hands for Activity 2. Please try to read these books in advance of next week's session.

2. Ask: Are there any other books on the e-readers that you hope to read between now and our next safe space meeting?

[Allow time for sharing.]

3. Ask: Is there anything you would like to discuss about today's session? Did you learn anything new? What are you looking forward to for next week's session?

4. Thank the group for their participation Encourage them to read as much as possible between now and the next session, whether on their own, with a parent/guardian, sibling, friend, or neighbor. The more they read, the better readers they will become.

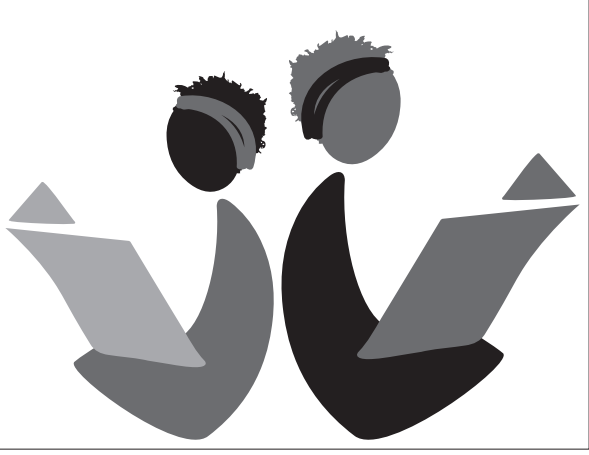




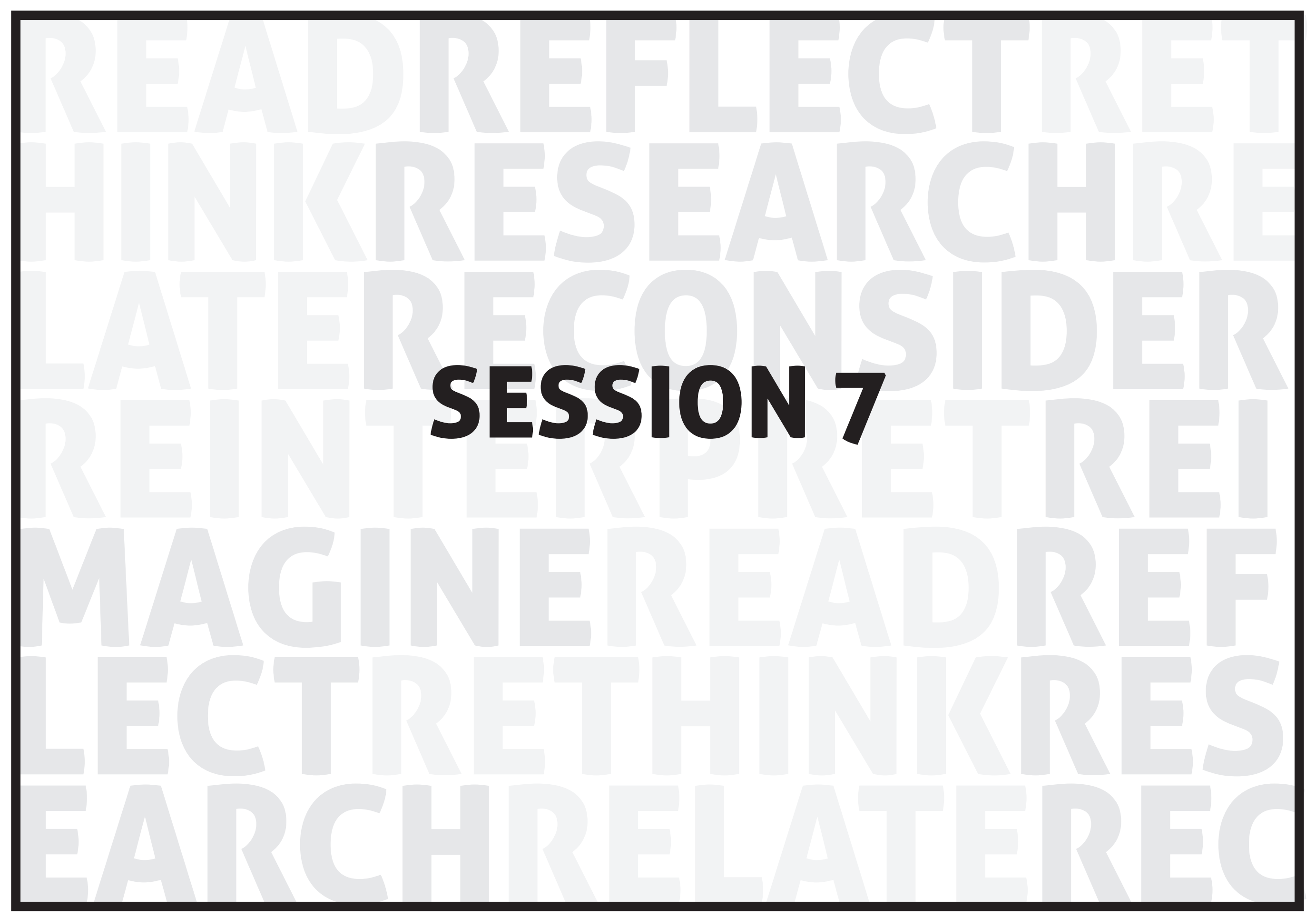




\section{session 7}

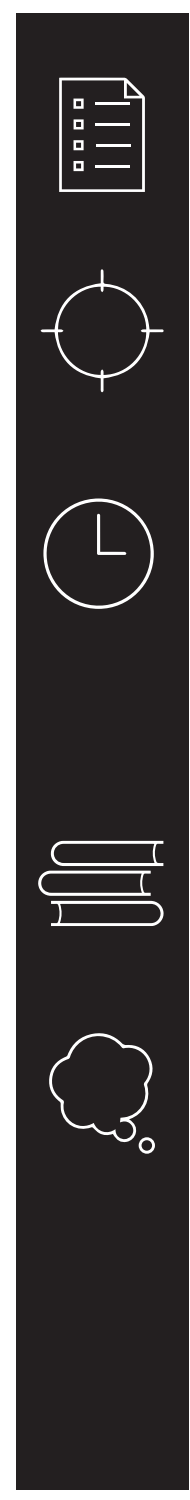

SESSION DESCRIPTION

Share books read the previous week and practice reading as a group.

\section{OBJECTIVES}

In this session, participants will:

Practice reading

Follow along while the mentor reads aloud

SESSION TIME

1 hour

Warm-up: Book board, 5 minutes

Activity 1: Paired reading, Sakima's Song, 15 minutes

Activity 2: Mentor read aloud, The Girl with the Magic Hands (part 2).

35 minutes

Wrap-up, 5 minutes

\section{REQUIRED MATERIALS}

Devices (e-readers)

Chalkboard, chalk, and eraser

\section{PRE-SESSION PREPARATION}

Read through the entire session and, if necessary, practice presenting the activities. Prepare all materials needed.

Read the e-book for Activities 1 and 2 in advance. 


\section{warm-up}

\section{$\mathrm{BOOK} \mathrm{BOARD}$}

[5 MINUTES]

1. As in the previous session, create a simple book board chart on the chalkboard.

2. Before the start of the session, ask participants to write the name of the

book(s) they have read since the last safe space meeting and rate the book(s) with a smiley face (-) if they liked it or a frown face $(1)$ if they did not like it.

3. Point out the books that are listed on the book board and encourage the group to keep sharing book titles they have read each week.

4. Ask if anyone would like to summarize the book they read, and what they liked or didn't like about it. Take one to two volunteers depending on time. The activity should not take more than five minutes.

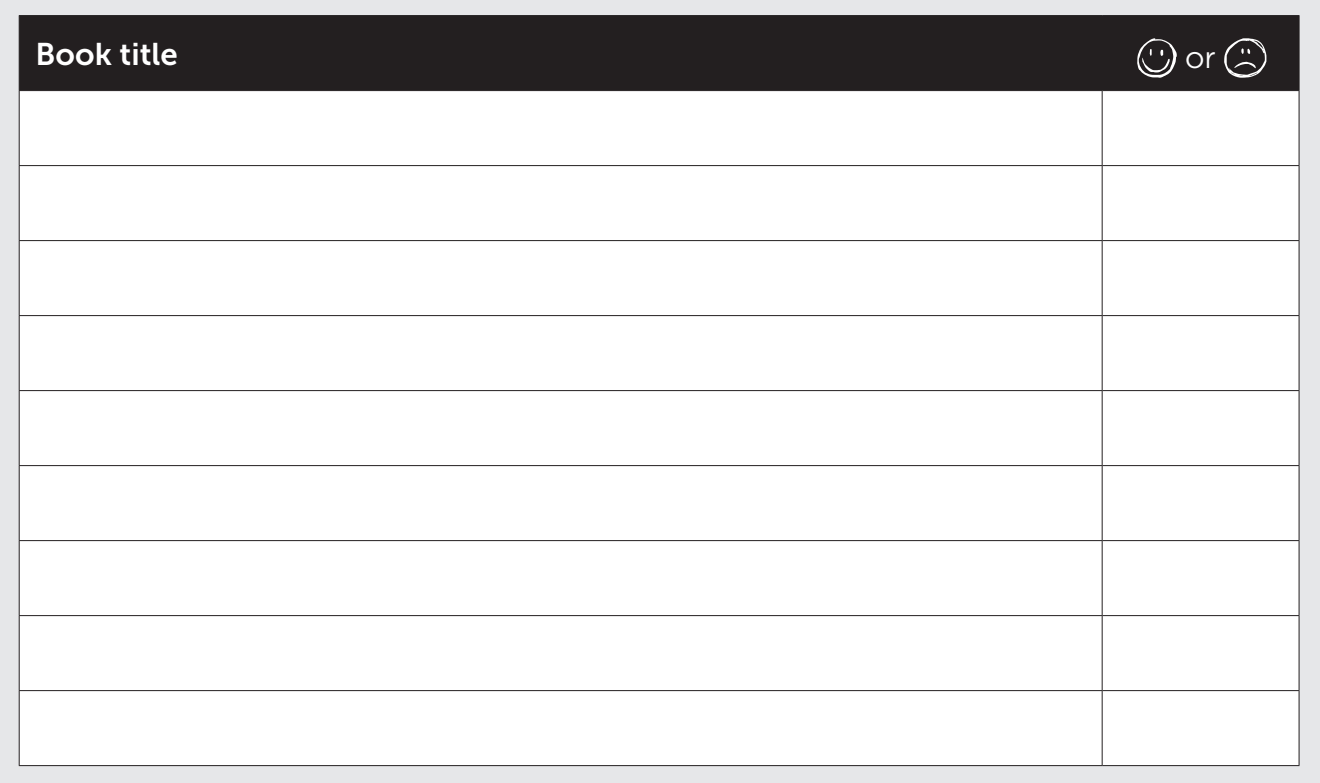




\section{activity 1}

\section{PAIRED READING, SAKIMA'S SONG BY URSULA NAFULA [15 MINUTES]}

1. Explain: Today we are going to do paired reading. In this activity you will be paired with one other participant and will read aloud to each other, taking turns so that there is one person reading at a time. If there is an uneven number, one person will pair with a mentor. Remember to help each other pronounce words correctly. [Note: Pair the weaker readers with the stronger readers.]

2. Say: Please open the e-book Sakima's Song. "Check." [Verify that everyone is on the right book. Help anyone who is not able to find the book.]

3. After all pairs have finished reading the story, ask everyone to come back to the main circle.

4. Ask the following questions:

- What do you think would happen next if the story continued?

If you could give the book another title, what would it be?

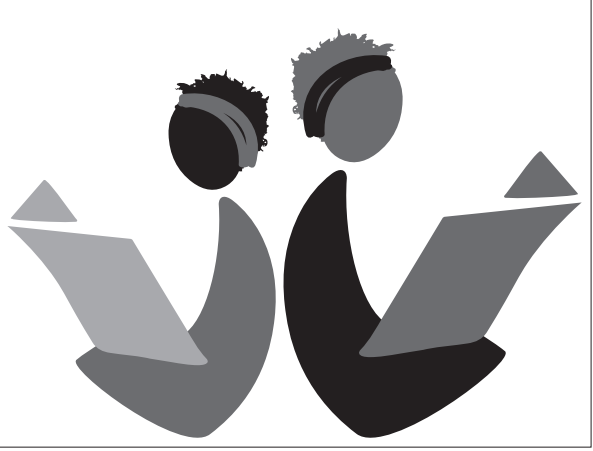




\section{activity 2}

\section{MENTOR READ ALOUD, THE GIRL WITH THE MAGIC HANDS (PART 2) \\ BY NNEDI OKORAFOR [35 MINUTES]}

1. Note for mentor: As in the previous sessions, you should practice reading the selected book aloud when preparing your session and look up the meaning of potentially unfamiliar words.

2. Explain: Like the last session, I am going to read to you all while you listen and follow along on your e-readers.

3. Say: We are going to read another part of the book we started last week. Please open the e-book, The Girl with the Magic Hands and go to Chapter 1 around location 146. "Check." [Verify that everyone is on the right book and it is open to location 146 Help anyone who is not able to find the book or location.]

4. Read the second half of Chapter 1 from around location 146 up through the first half of Chapter 2 around location 309. While reading, demonstrate good reading by being audible, clear, and expressive.
5. Read up to the paragraph around location 309 that starts, "She didn't really want it to, but she could not help testing its durability."

- What has happened in the story so far?

What do you think Chidera will do next? 


\section{wrap-up}

\section{WRAP-UP \\ [5 MINUTES]}

Explain: In next week's session, we will read Oh! and Ah! for Activity 1 and more of The

Girl with the Magic Hands for Activity 2.

Please try to read these books in advance of next week's session.

Ask: Are there any other books on the

e-readers that you hope to read between now and our next safe space meeting? [Allow time

for sharing.]

Ask: Is there anything you would like to

discuss about today's session? Did you learn anything new? What are you looking forward to for next week's session?

Thank the group for their participation.

Encourage them to read as much as possible between now and the next session, whether on their own, with a parent/guardian, sibling. friend, or neighbor. The more they read, the better readers they will become.

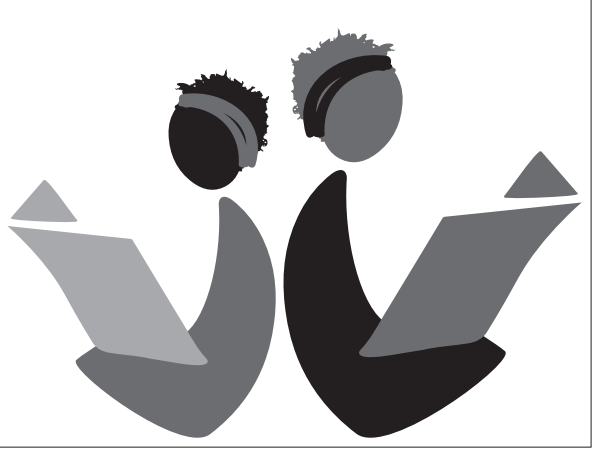




\section{SESSION 8}




\section{session 8}

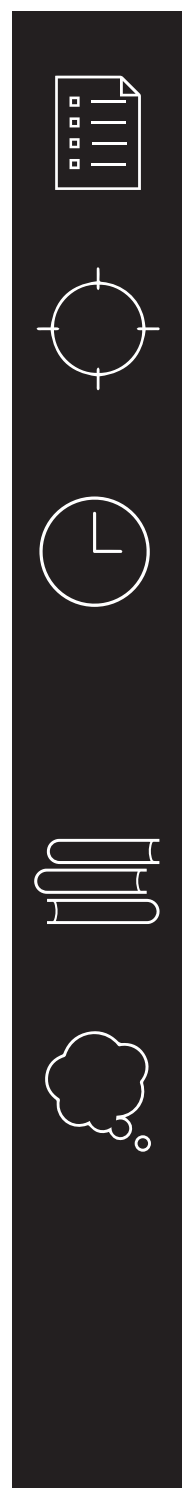

SESSION DESCRIPTION

Share books read the previous week and practice reading as a group.

\section{OBJECTIVES}

In this session, participants will:

Practice reading

Follow along while the mentor reads aloud

SESSION TIME

1 hour

Warm-up: Book board, 5 minutes

Activity 1: Nshima reading, Oh! and $A h ! 15$ minutes

Activity 2: Mentor read aloud, The Girl with the Magic Hands (part 3).

35 minutes

Wrap-up, 5 minutes

\section{REQUIRED MATERIALS}

Devices (e-readers)

Chalkboard, chalk, and eraser

\section{PRE-SESSION PREPARATION}

Read through the entire session and, if necessary, practice presenting the activities. Prepare all materials needed.

Read the e-book for Activities 1 and 2 in advance. 


\section{warm-up}

\section{$\mathrm{BOOK} \mathrm{BOARD}$}

[5 MINUTES]

1. As in the previous session, create a simple book board chart on the chalkboard.

2. Before the start of the session, ask participants to write the name of the

book(s) they have read since the last safe space meeting and rate the book(s) with a smiley face (-) if they liked it or a frown face $(1)$ if they did not like it.

3. Point out the books that are listed on the book board and encourage the group to keep sharing book titles they have read each week.

4. Ask if anyone would like to summarize the book they read, and what they liked or didn't like about it. Take one to two volunteers depending on time. The activity should not take more than five minutes.

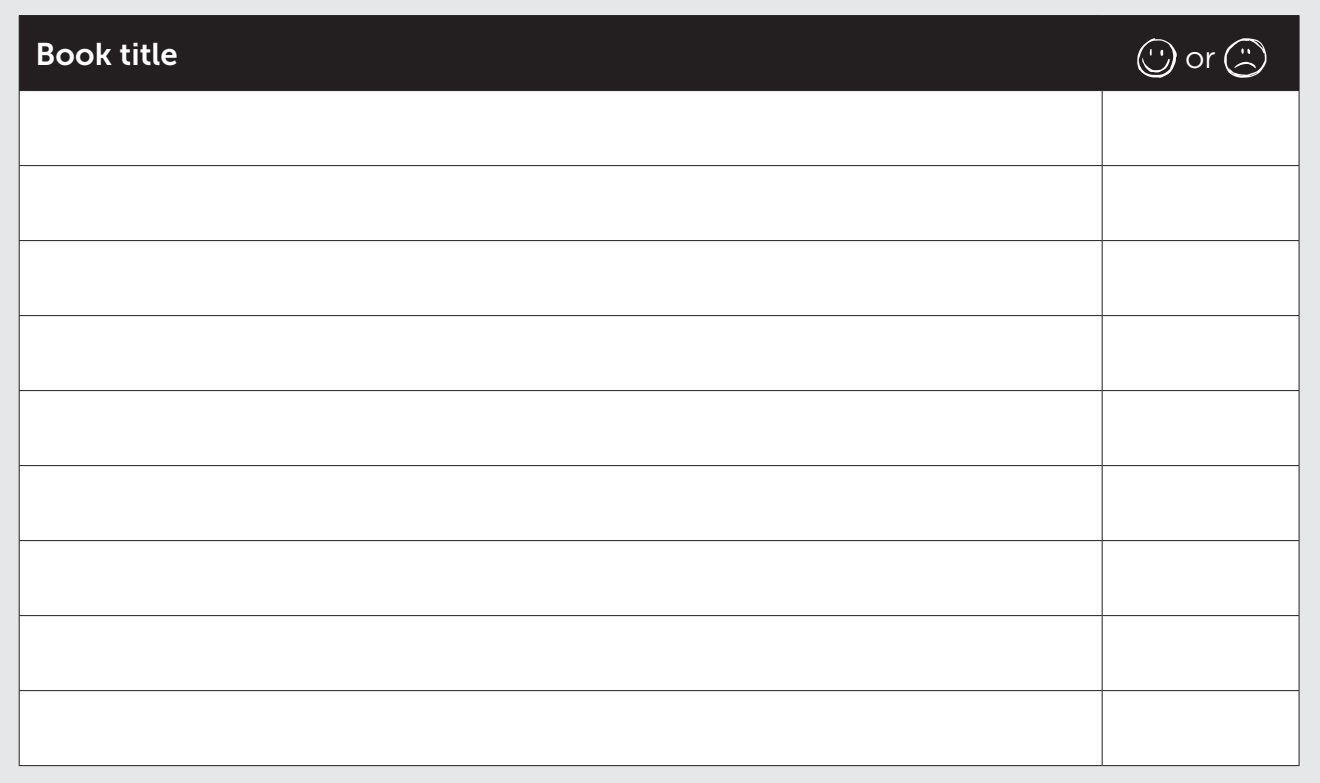




\section{activity 1}

\section{NSHIMA READING, OH! AND AH! BY JEAN MBONYI [15 MINUTES]}

1. Ask: Do we all remember nshima reading? [Let participants respond and describe nshima reading. If they don't remember, remind them that in nshima reading participants trade off reading a story. One person starts reading a story to a point then calls out "nshima" before selecting another person in the group to continue reading. Remind them that they are not allowed to choose a person sitting next to them.]

2. Please open the e-book Oh! and $A h$ ! "Check." [Verify that everyone is on the right book. Help anyone who is not able to find the book.]

3. Ask: Who would like to begin reading? [Choose a volunteer.] Please begin.

4. After reading the book, ask the following questions:

- What did you enjoy about the book?

- Are you satisfied with the ending? Why or why not?

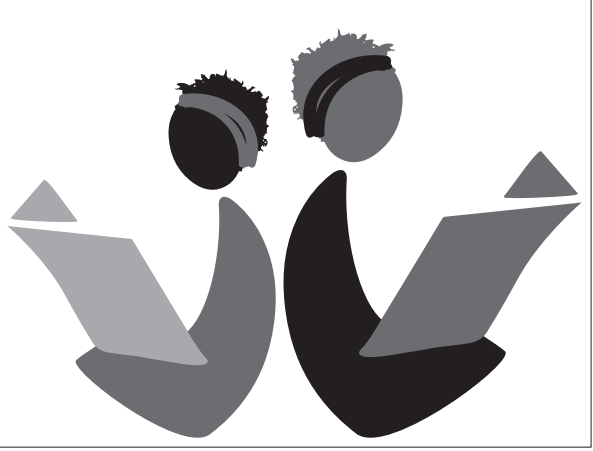




\section{activity 2}

\section{MENTOR READ ALOUD, THE GIRL WITH THE MAGIC HANDS (PART 3) \\ BY NNEDI OKORAFOR, [35 MINUTES]}

1. Note for mentor: As in the previous sessions, you should practice reading the selected book aloud when preparing your session and look up the meaning of potentially unfamiliar words.

2. Explain: I am going to read to you all while you listen and follow along on your e-readers.

3. Say: We are going to read a third segment of the book we read together the last two weeks. Please open the e-book, The Girl with the Magic Hands and go to Chapter 2 around location 309. "Check." [Verify that everyone is on the right book and it is open to location 309. Help anyone who is not able to find the book.]

4. Read the second half of Chapter 2 from around location 309 up through the end of the chapter. While reading, demonstrate good reading by being audible, clear, and expressive.

5. After finishing Chapter 2, ask the participants:

- What do you think will happen next?
6. After discussing, read the first several paragraphs of Chapter 3 to give the girls a sense of the continuing happy ending. [Note if girls are interested to know: The remainder of the book continues on in this upward path for Chidera.] 


\section{wrap-up}

\section{WRAP-UP \\ [5 MINUTES]}

Explain: In next week's session, we will read The Girl Who Got Rich for Activity 1 and

Chapters 1 and 2 of Naomi in Her New School for Activity 2. Please try to read these books in advance of next week's session.

Ask: Are there any other books on the

e-readers that you hope to read between now and our next safe space meeting? [Allow time

for sharing.]

Ask: Is there anything you would like to

discuss about today's session? Did you learn anything new? What are you looking forward to for next week's session?

Thank the group for their participation.

Encourage them to read as much as possible between now and the next session, whether on their own, with a parent/guardian, sibling friend, or neighbor. The more they read, the better readers they will become.

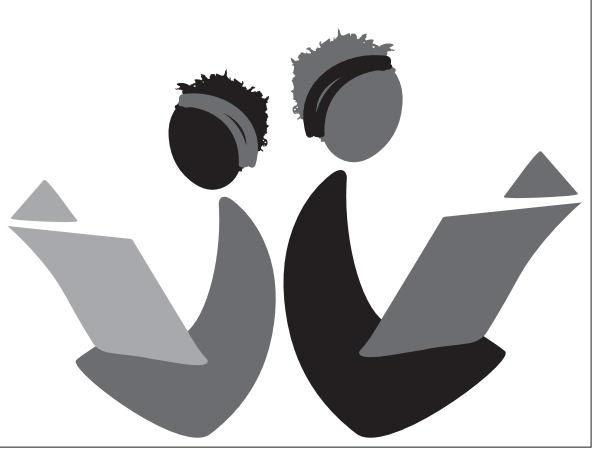




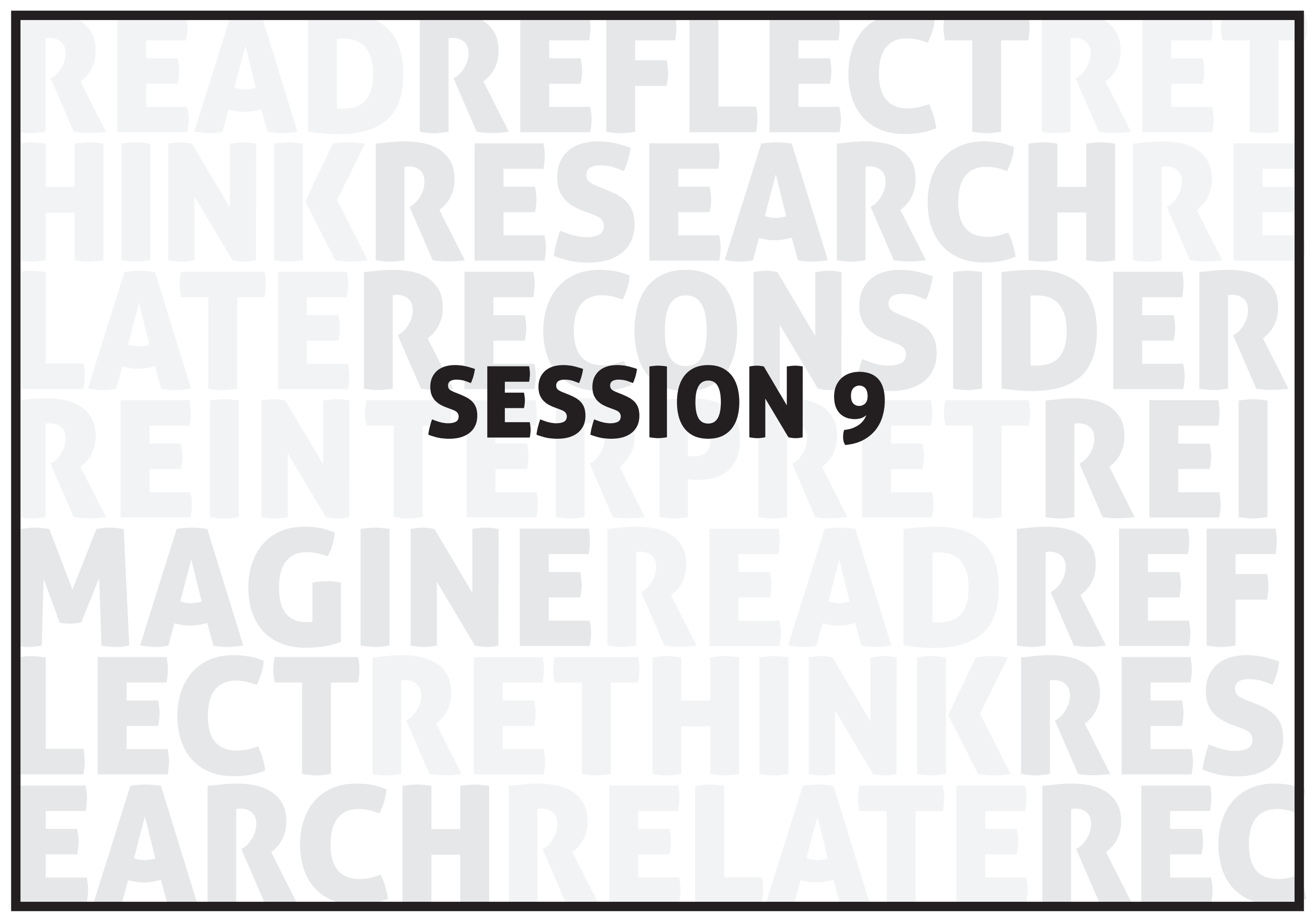




\section{session 9}

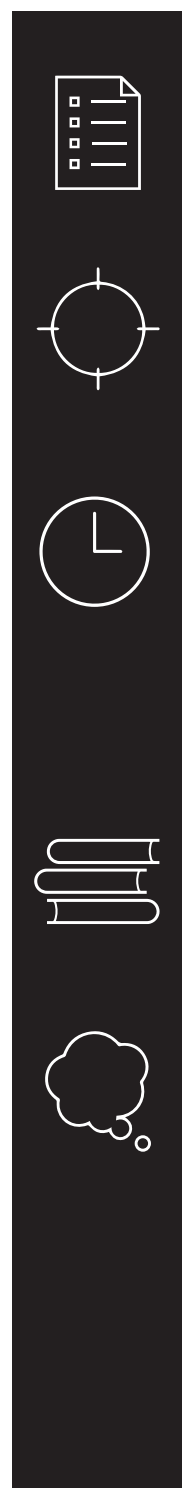

SESSION DESCRIPTION

Share books read the previous week and practice reading as a group.

\section{OBJECTIVES}

In this session, participants will:

Practice reading

Follow along while the mentor reads aloud

SESSION TIME

1 hour

Warm-up: Book board, 5 minutes

Activity 1: Echo reading, The Girl Who Got Rich, 15 minutes

Activity 2: Mentor read aloud, Naomi in Her New School (part 1).

35 minutes

Wrap-up, 5 minutes

\section{REQUIRED MATERIALS}

Devices (e-readers)

Chalkboard, chalk, and eraser

\section{PRE-SESSION PREPARATION}

Read through the entire session and, if necessary, practice presenting the activities. Prepare all materials needed.

Read the e-book for Activities 1 and 2 in advance. 


\section{session 9 (cont.)}

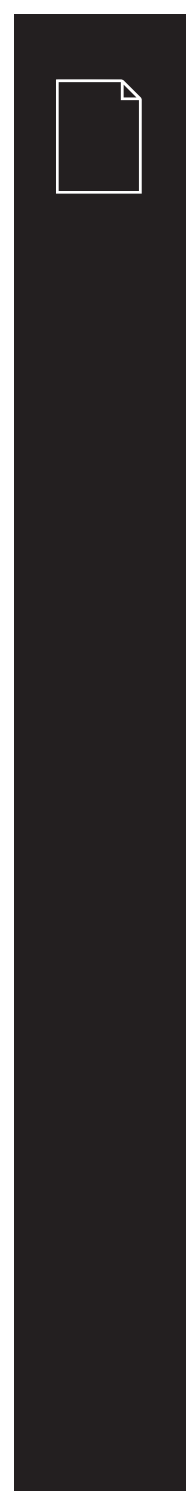

\section{FACILITATOR NOTES}

For Activity 2, here is a summary of the book and instructions for how to break it up over Sessions 9-12:

\section{Naomi in Her New School}

by Joseph Mzee Muleka

Summary, for the mentor's information:

This book is written by a Kenyan author.

Naomi is super excited to go to boarding

school - both for school and to be with her

friend Nilla, who joined Bora Academy earlier.

However, when Naomi starts at Bora, she

makes several social blunders and encounters

teasing and bullies that leave her feeling

ostracized and alone. Nilla and another girl

stand up for her and support her, as does the

head teacher, but it is difficult. Things turn

around when Naomi helps the police find car

thieves and she becomes the hero.

\section{Preview of how you will use this book during} safe spaces:

The main overlapping topics in this book

and the safe spaces curriculum are bullying

and empathy. When you read passages that

portray bullying or unkind behavior, you can

ask participants if they can remember ever

feeling the way Naomi does, and what they

can do to prevent such behavior in their

own school. Here is a preview of how you'll

be breaking up the book over the next four

sessions:
Session 9: You will summarize Chapter 1 and then read Chapter 2.

Do NOT read Chapter 1. Instead, summarize Chapter 1 as follows:

The story opens with Naomi, the main character, very excited about going to boarding school. Naomi lives in a village in Kenya. Her good friend, Nilla, has already started at Bora Academy. Naomi's mother and aunt drive her to Bora Academy. They meet the head teacher, Mrs. Jenida, who is very kind. The head teacher calls Nilla to give Naomi a tour of the school. After Nilla shows Naomi around, Nilla brings her to the dormitory where she will room in the same cubicle as Nilla. Naomi falls asleep quickly, before the other girls have returned from prep.

Then start reading from Chapter 2 and read the entire chapter.

Session 10: Read Chapter 3

Session 11: Read Chapter 4

Session 12: Read Chapters 5 and 6

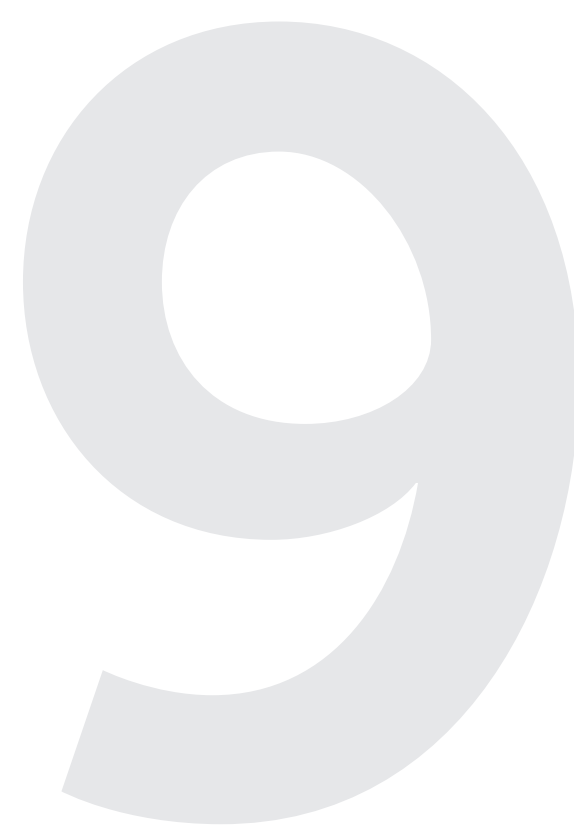




\section{warm-up}

\section{$\mathrm{BOOK} \mathrm{BOARD}$}

[5 MINUTES]

1. As in the previous session, create a simple book board chart on the chalkboard.

2. Before the start of the session, ask participants to write the name of the

book(s) they have read since the last safe space meeting and rate the book(s) with a smiley face (-) if they liked it or a frown face $(1)$ if they did not like it.

3. Point out the books that are listed on the book board and encourage the group to keep sharing book titles they have read each week.

4. Ask if anyone would like to summarize the book they read, and what they liked or didn't like about it. Take one to two volunteers depending on time. The activity should not take more than five minutes.

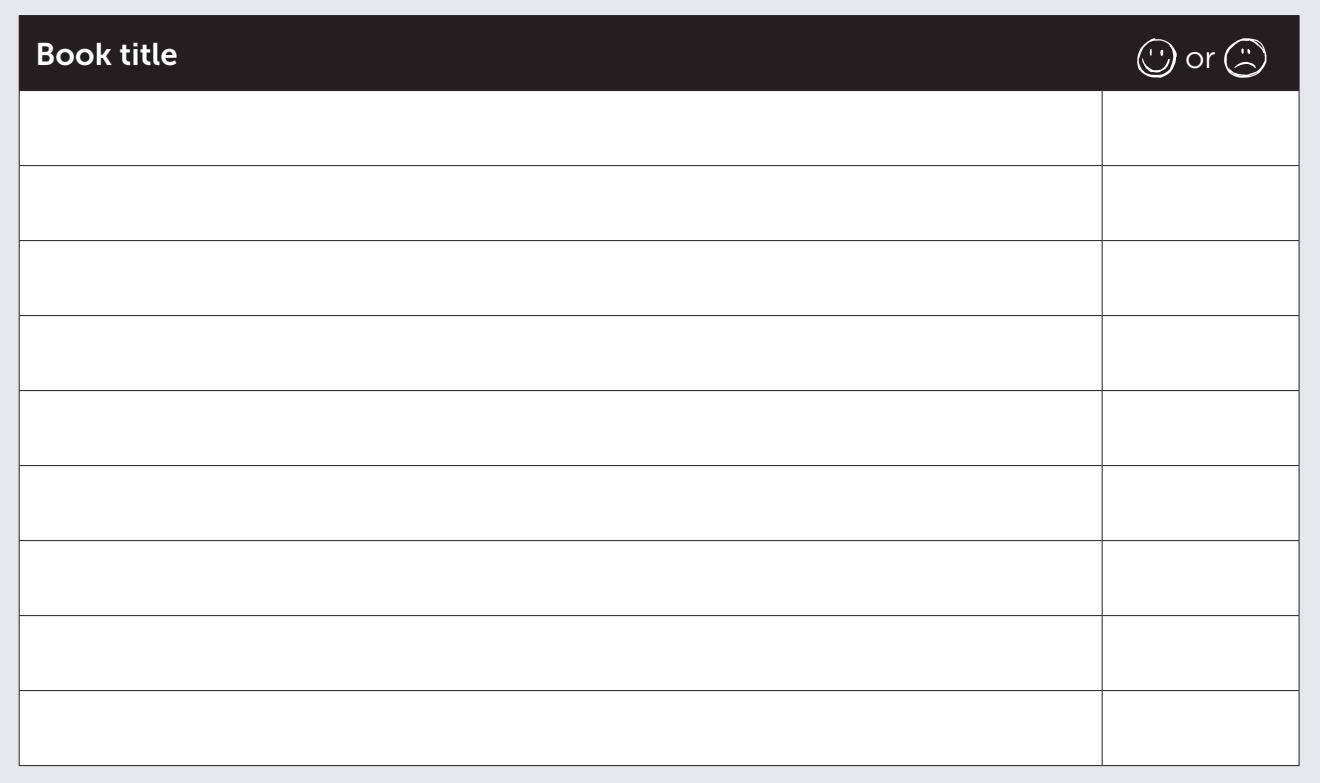




\section{activity 1}

\section{ECHO READING, THE GIRL WHO GOT RICH, BY SALAAMA WANALE [15 MINUTES]}

1. Explain: Now we are going to read a book using echo reading. Could someone remind me what echo reading is? [Let participants answer. Remind them that you will read a sentence, few lines, or a paragraph, then when you stop and point at the group, they will repeat or "echo" what was read.]

2. Say: Please open the e-book The Girl Who Got Rich. "Check." [Verify that everyone is on the right book. Help anyone who is not able to find the book. Begin reading, stopping periodically when it makes sense to stop, and point at the group indicating that it is time for them to repeat (re-read) what you just read.]

3. After reading the book, ask the following questions:

- Which of the characters did you like best? Why?

What do you think are the key lessons from this story?

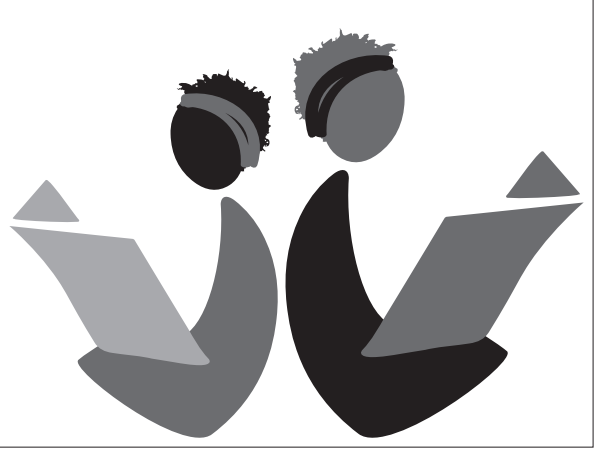




\section{activity 2}

\section{MENTOR READ ALOUD, NAOMI IN HER NEW SCHOOL (PART 1) \\ BY JOSEPH MZEE MULEKA [35 MINUTES]}

1. Note for mentor: As in the previous sessions, you should practice reading the selected book aloud when preparing your session and look up the meaning of potentially unfamiliar words. While reading. demonstrate good reading by being audible, clear, and expressive.

2. Say: Please open the e-book, Naomi in Her New School to Chapter 1. "Check. [Verify that everyone is on the right book and on Chapter 1. Help anyone who is not able to find the book.

3. Explain: This is a longer book so I am NOT going to read Chapter 1 but l'll tell you

what happened in the first chapter:

The story opens with Naomi, the main character, very excited about going to boarding school. Naomi lives in a village in Kenya. Her good friend, Nilla, has already started at Bora Academy. Naomi's mother and aunt drive her to Bora Academy. They meet the head teacher, Mrs. Jenida, who is very kind. The head teacher calls Nilla to give Naomi a tour of the school. After Nilla shows Naomi around, Nilla brings her to the dormitory where she will room in the same cubicle as Nilla. Naomi falls asleep quickly, before the other girls have returned from prep.
4. Say: Now go to Chapter 2 of the same book. I will read Chapter 2 and ask you to follow along.

5. After finishing Chapter 2, ask the participants:

- What do you think will happen next? 


\section{wrap-up}

\section{WRAP-UP \\ [5 MINUTES]}

Explain: In next week's session, we will read Is There Anyone Like Me? for Activity 1 and Chapter 3 of Naomi in Her New School for Activity 2. Please try to read these books in advance of next week's session.

Ask: Are there any other books on the

e-readers that you hope to read between now and our next safe space meeting? [Allow time

for sharing.]

Ask: Is there anything you would like to

discuss about today's session? Did you learn anything new? What are you looking forward to for next week's session?

Thank the group for their participation.

Encourage them to read as much as possible between now and the next session, whether on their own, with a parent/guardian, sibling. friend, or neighbor. The more they read, the better readers they will become.

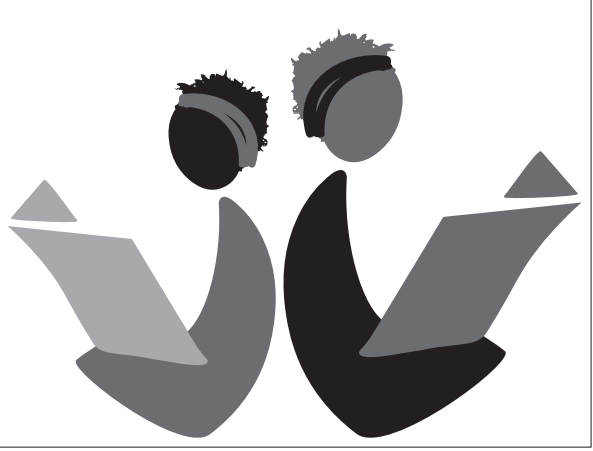




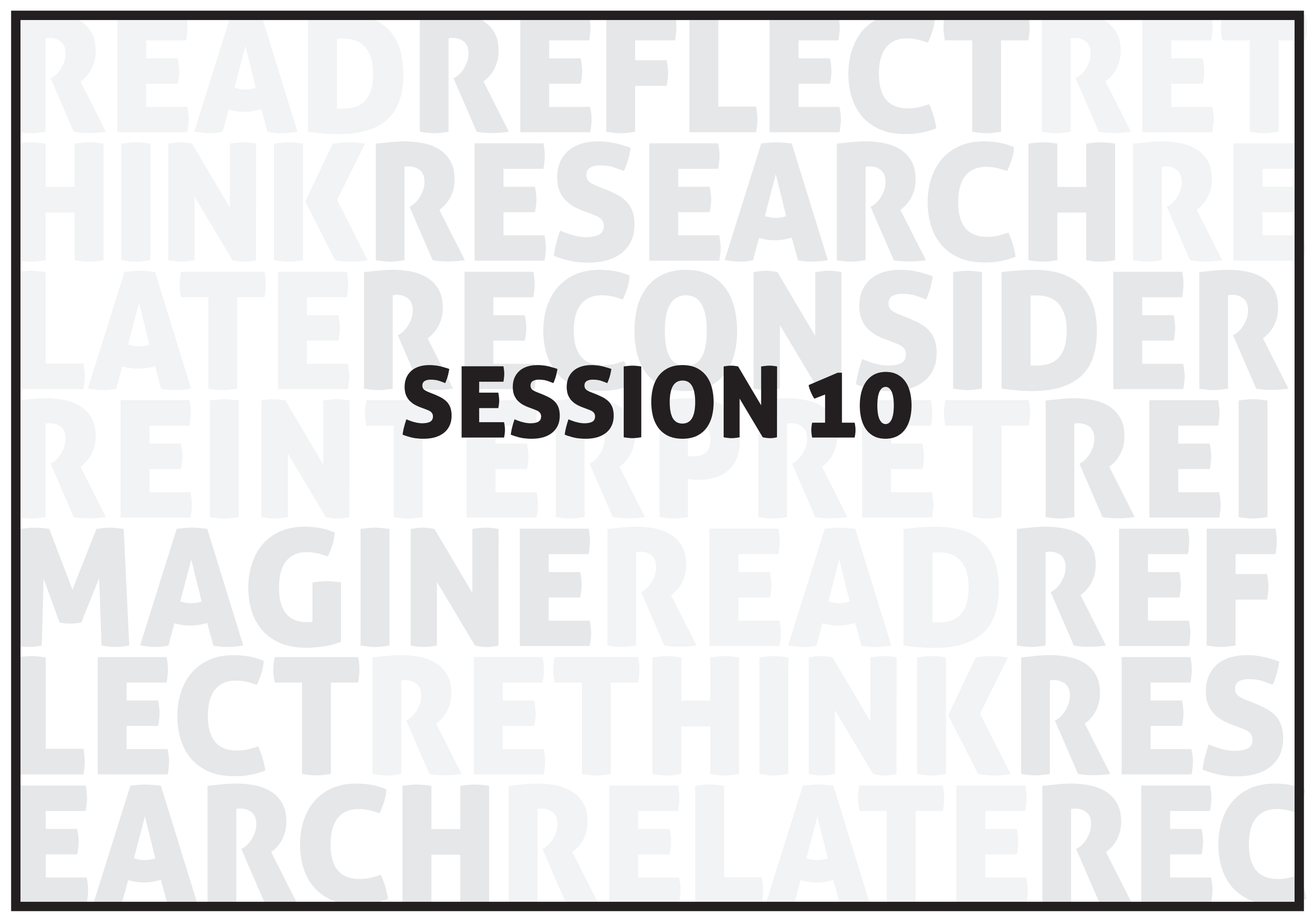




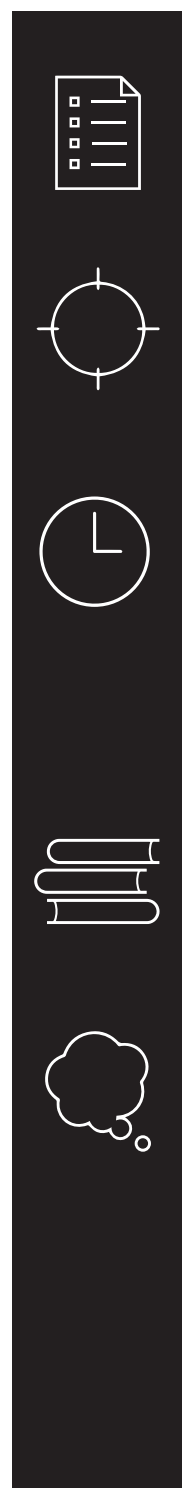

SESSION DESCRIPTION

Share books read the previous week and practice reading as a group.

OBJECTIVES

In this session, participants will:

Practice reading

Follow along while the mentor reads aloud

SESSION TIME

1 hour

Warm-up: Book board, 5 minutes

Activity 1: Paired reading, Is There Anyone Like Me? 15 minutes

Activity 2: Mentor read aloud, Naomi in Her New School (part 2),

35 minutes

Wrap-up, 5 minutes

\section{REQUIRED MATERIALS}

Devices (e-readers)

Chalkboard, chalk, and eraser

PRE-SESSION PREPARATION

Read through the entire session and, if necessary, practice presenting the activities. Prepare all materials needed.

Read the e-book for Activities 1 and 2 in advance. 


\section{warm-up}

\section{$\mathrm{BOOK} \mathrm{BOARD}$}

[5 MINUTES]

1. As in the previous session, create a simple book board chart on the chalkboard.

2. Before the start of the session, ask participants to write the name of the

book(s) they have read since the last safe space meeting and rate the book(s) with a smiley face (-) if they liked it or a frown face 2 if they did not like it.

3. Point out the books that are listed on the book board and encourage the group to keep sharing book titles they have read each week.

4. Ask if anyone would like to summarize the book they read, and what they liked or didn't like about it. Take one to two volunteers depending on time. The activity should not take more than five minutes.

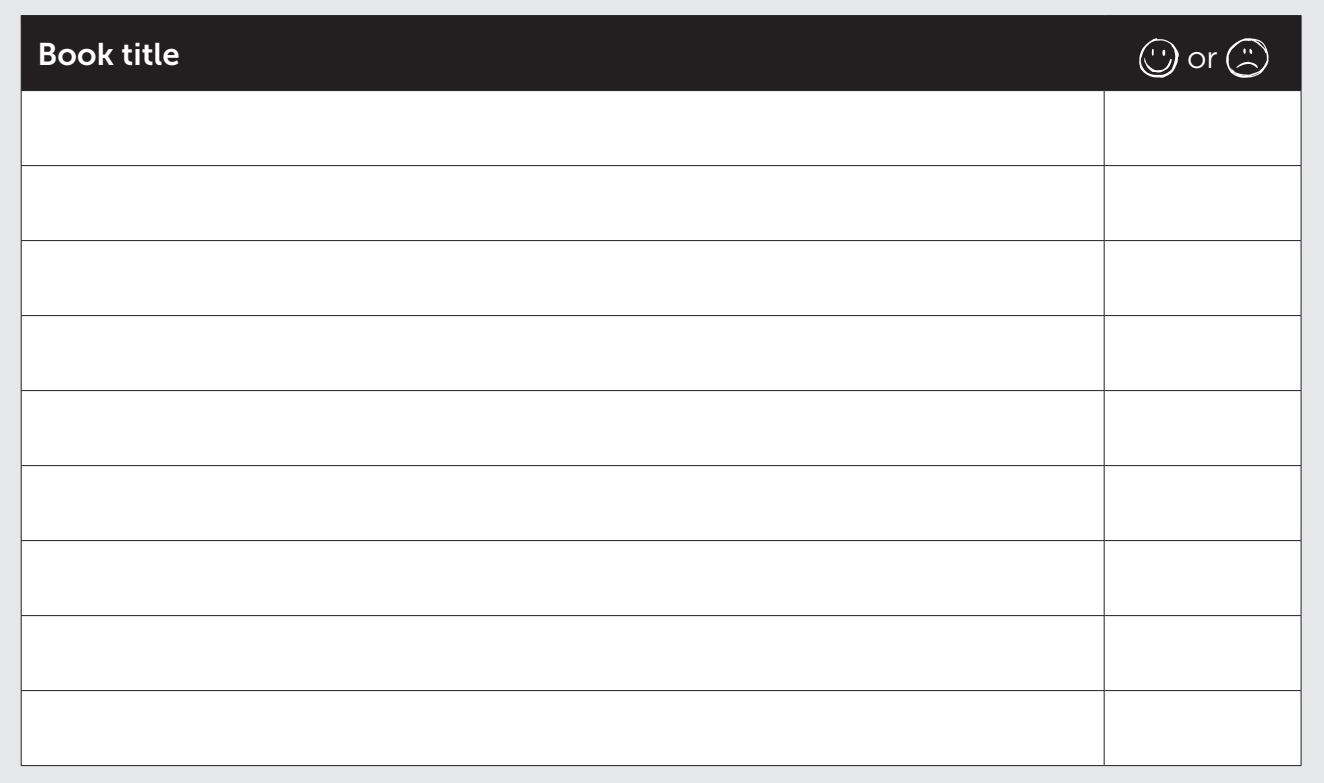




\section{activity 1}

\section{PAIRED READING, IS THERE ANYONE LIKE ME? BY FRED STRYDOM, JESS JARDIM-WEDEPOHL, AND STEPHEN WALLACE [15 MINUTES]}

1. Today we are going to do paired reading. As you may remember, in paired reading you will be paired with another participant and will read aloud to each other, switching on and off so that there

is one person reading at a time. If there is an uneven number, one person will pair with a mentor. Remember to help each other pronounce words correctly. [Note:

Remember to pair the weaker readers with the stronger readers.]

2. Say: Please open the e-book Is There Anyone Like Me? "Check." [Verify that everyone is on the right book. Help anyone who is not able to find the book.]

3. After all pairs have finished reading the story, ask everyone to come back to the main circle.

4. Ask the following questions:

- What is the main message of this book?

What did you like best about the book?

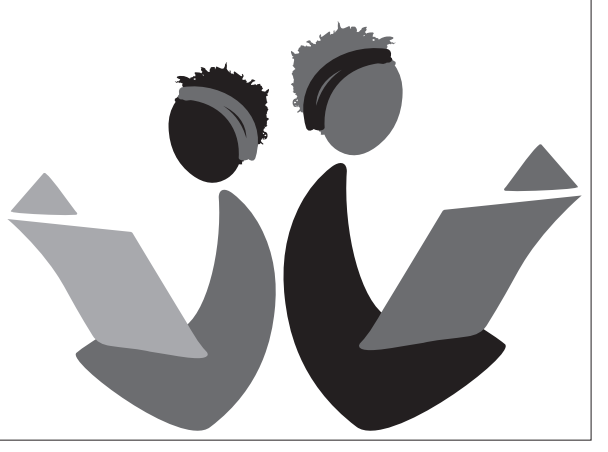




\section{activity 2}

\section{MENTOR READ ALOUD, NAOMI IN HER NEW SCHOOL (PART 2)}

BY JOSEPH MZEE MULEKA [35 MINUTES]

1. Note for mentor: As in the previous sessions, you should practice reading

the selected book aloud when preparing

your session and look up the meaning of

potentially unfamiliar words. While reading

demonstrate good reading by being

audible, clear, and expressive.

2. Say: Please open the e-book, Naomi in

Her New School to Chapter 3. "Check.

[Verify that everyone is on the right book

and at Chapter 3. Help anyone who is not

able to find the book.

3. Explain: Remember that I gave you a summary of Chapter 1 and then I read all of Chapter 2 at our last session. Today I will read Chapter 3 and ask you to follow along.

4. After finishing Chapter 3, ask the participants:

What do you think Naomi will do next?

How is Naomi feeling? Why do you think she is feeling that way?

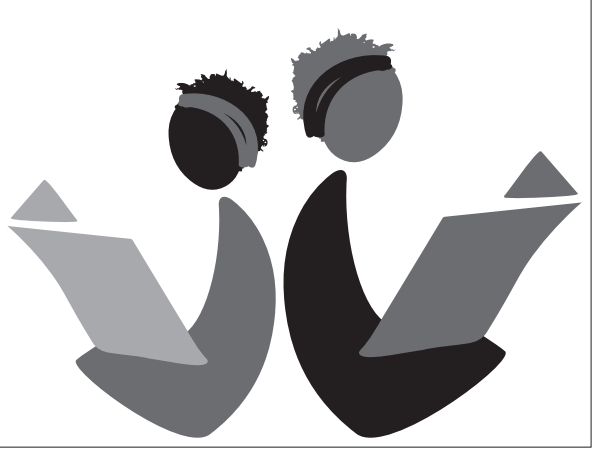




\section{wrap-up}

\section{WRAP-UP \\ [5 MINUTES]}

Explain: In next week's session, we will read Why is Nita Upside Down? for Activity 1 and Chapter 4 of Naomi in Her New School for Activity 2. Please try to read these books in advance of next week's session.

Ask: Are there any other books on the e-readers that you hope to read between now and our next safe space meeting? [Allow time for sharing.]

Ask: Is there anything you would like to discuss about today's session? Did you learn anything new? What are you looking forward to for next week's session?

Thank the group for their participation

Encourage them to read as much as possible

between now and the next session, whether on

their own, with a parent/guardian, sibling, friend,

or neighbor. The more they read, the better

readers they will become. 


\section{SESSION 11}




\section{session 11}

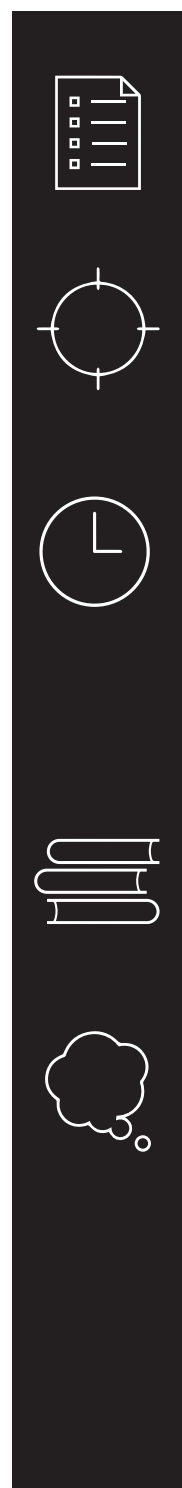

SESSION DESCRIPTION

Share books read the previous week and practice reading as a group.

\section{OBJECTIVES}

In this session, participants will:

Practice reading

Follow along while the mentor reads aloud

SESSION TIME

1 hour

Warm-up: Book board, 5 minutes

Activity 1: Echo reading, Why is Nita Upside Down? 15 minutes

Activity 2: Mentor read aloud, Naomi in Her New School (part 3).

35 minutes

Wrap-up, 5 minutes

\section{REQUIRED MATERIALS}

Devices (e-readers)

Chalkboard, chalk, and eraser

\section{PRE-SESSION PREPARATION}

Read through the entire session and, if necessary, practice presenting the activities. Prepare all materials needed.

Read the e-book for Activities 1 and 2 in advance.

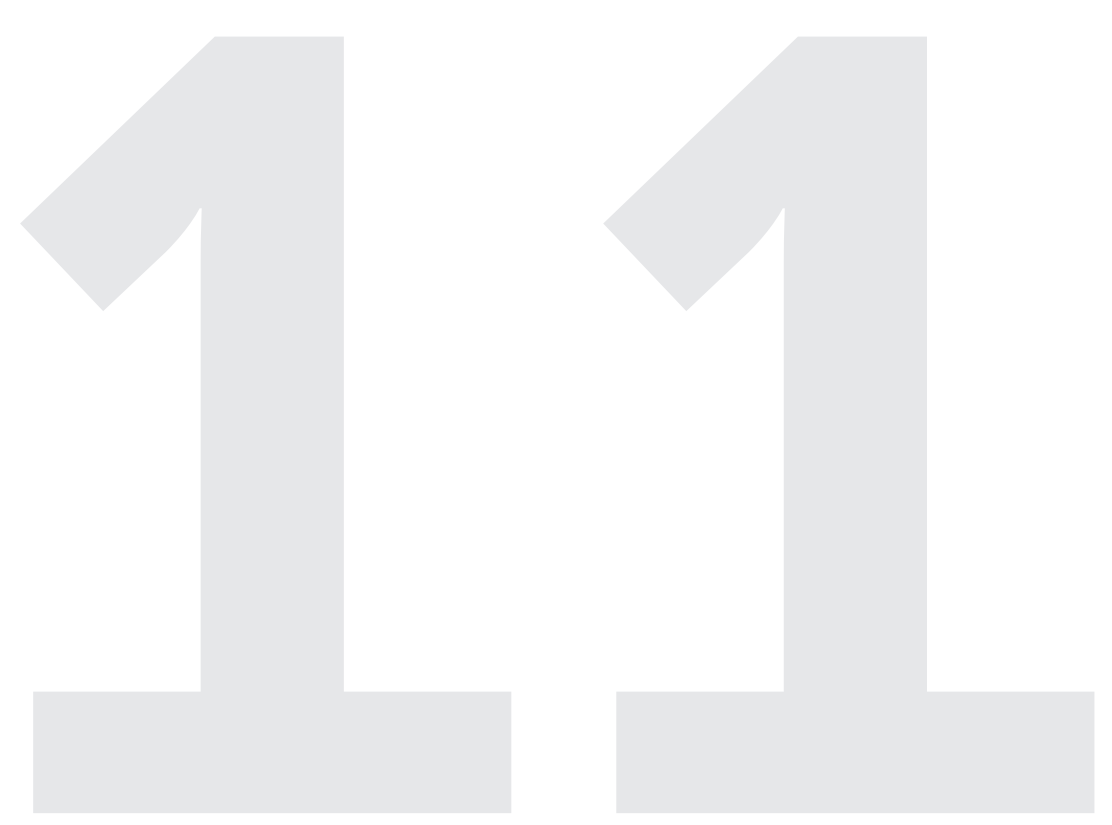




\section{warm-up}

\section{$\mathrm{BOOK} \mathrm{BOARD}$}

[5 MINUTES]

1. As in the previous session, create a simple book board chart on the chalkboard.

2. Before the start of the session, ask participants to write the name of the book(s) they have read since the last safe space meeting and rate the book(s) with a smiley face () if they liked it or a frown face $(-)$ if they did not like it

3. Point out the books that are listed on the book board and encourage the group to keep sharing book titles they have read each week.

4. Ask if anyone would like to summarize the book they read, and what they liked or didn't like about it. Take one to two volunteers depending on time. The activity should not take more than five minutes.

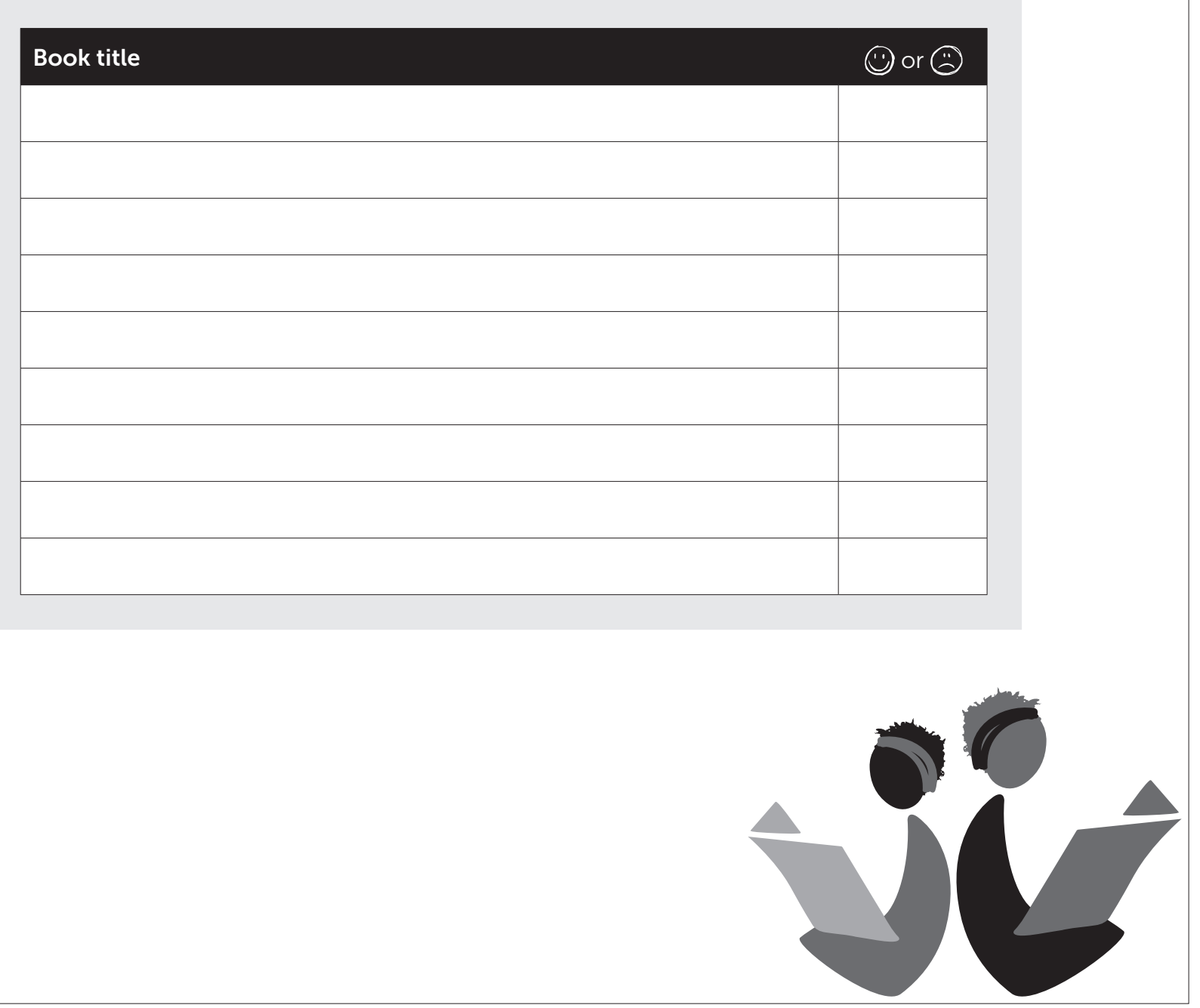




\section{activity 1}

\section{ECHO READING, WHY IS NITA UPSIDE DOWN? BY ROXANA BOUWER, SARAH BOUWER, AND EMMA HEARNE [15 MINUTES]}

1. Explain: Now we are going to read a

book using echo reading. Could someone

remind me what echo reading is? [Let

participants answer. Remind them that

you will read a sentence, few lines, or a

paragraph, then when you stop and point

at the group, they will repeat (re-read) or

"echo" what was read.]

2. Say: Please open the e-book Why is Nita Upside Down? "Check." [Verify that everyone is on the right book. Help anyone who is not able to find the book. Begin reading, stopping periodically when it makes sense to stop, and point at the group indicating that it is time for them to re-read what you just read.]

3. After reading the book, ask the following questions:

- Has anything like this ever happened to you, where you felt alone or too different to play with others?

How did you address this?

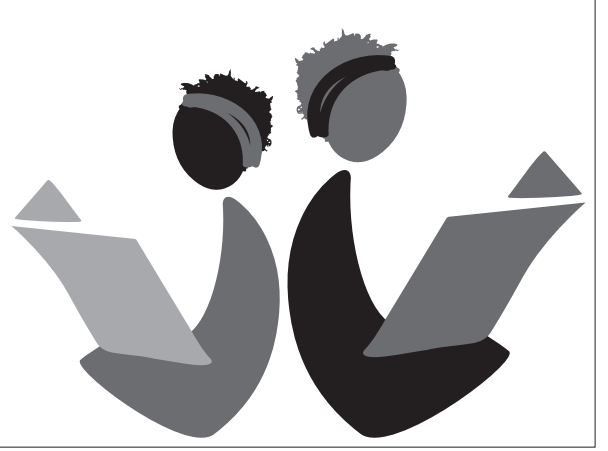




\section{activity 2}

\section{MENTOR READ ALOUD, NAOMI IN HER NEW SCHOOL (PART 3) \\ BY JOSEPH MZEE MULEKA [35 MINUTES]}

1. Note for mentor: As in the previous sessions, you should practice reading

the selected book aloud when preparing

your session and look up the meaning of

potentially unfamiliar words. While reading

demonstrate good reading by being

audible, clear, and expressive.

2. Say: Please open the e-book, Naomi in

Her New School to Chapter 4. "Check.

[Verify that everyone is on the right book

and chapter. Help anyone who is not able

to find the book.

3. Explain: Remember that I read Chapter 3 last session. I will read Chapter 4 and ask you to follow along.

4. After finishing Chapter 4, ask the participants:

- Who is your favorite character so far and why?

If you could give Naomi some advice at this point in the story, what would it be?

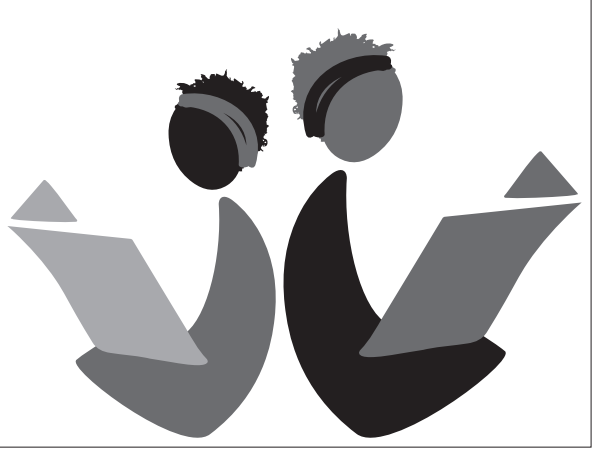




\section{wrap-up}

\section{WRAP-UP \\ [5 MINUTES]}

Explain: In next week's session, we will read Holidays with Grandmother for Activity 1

and Chapters 5 and 6 of Naomi in Her New School for Activity 2. Please try to read these books in advance of next week's session.

Ask: Are there any other books on the

e-readers that you hope to read between now and our next safe space meeting? [Allow time

for sharing.]

Ask: Is there anything you would like to

discuss about today's session? Did you learn anything new? What are you looking forward to for next week's session?

Thank the group for their participation.

Encourage them to read as much as possible between now and the next session, whether on their own, with a parent/guardian, sibling. friend, or neighbor. The more they read, the better readers they will become.

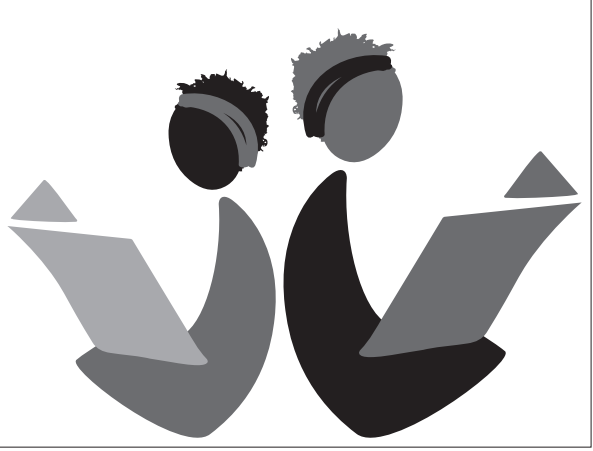




\section{SESSION 12}




\section{session 12}

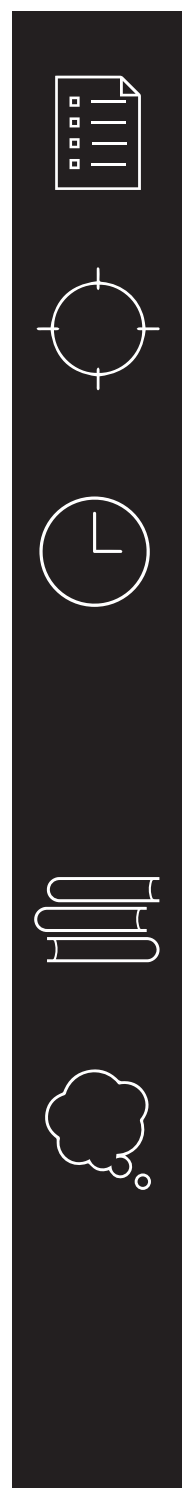

SESSION DESCRIPTION

Share books read the previous week and practice reading as a group.

\section{OBJECTIVES}

In this session, participants will:

Practice reading

Follow along while the mentor reads aloud

SESSION TIME

1 hour

Warm-up: Book board, 5 minutes

Activity 1: Paired reading, Holidays with Grandmother, 15 minutes

Activity 2: Mentor read aloud, Naomi in Her New School (part 4).

35 minutes

Wrap-up, 5 minutes

\section{REQUIRED MATERIALS}

Devices (e-readers)

Chalkboard, chalk, and eraser

\section{PRE-SESSION PREPARATION}

Read through the entire session and, if necessary, practice presenting the activities. Prepare all materials needed.

Read the e-book for Activities 1 and 2 in advance.
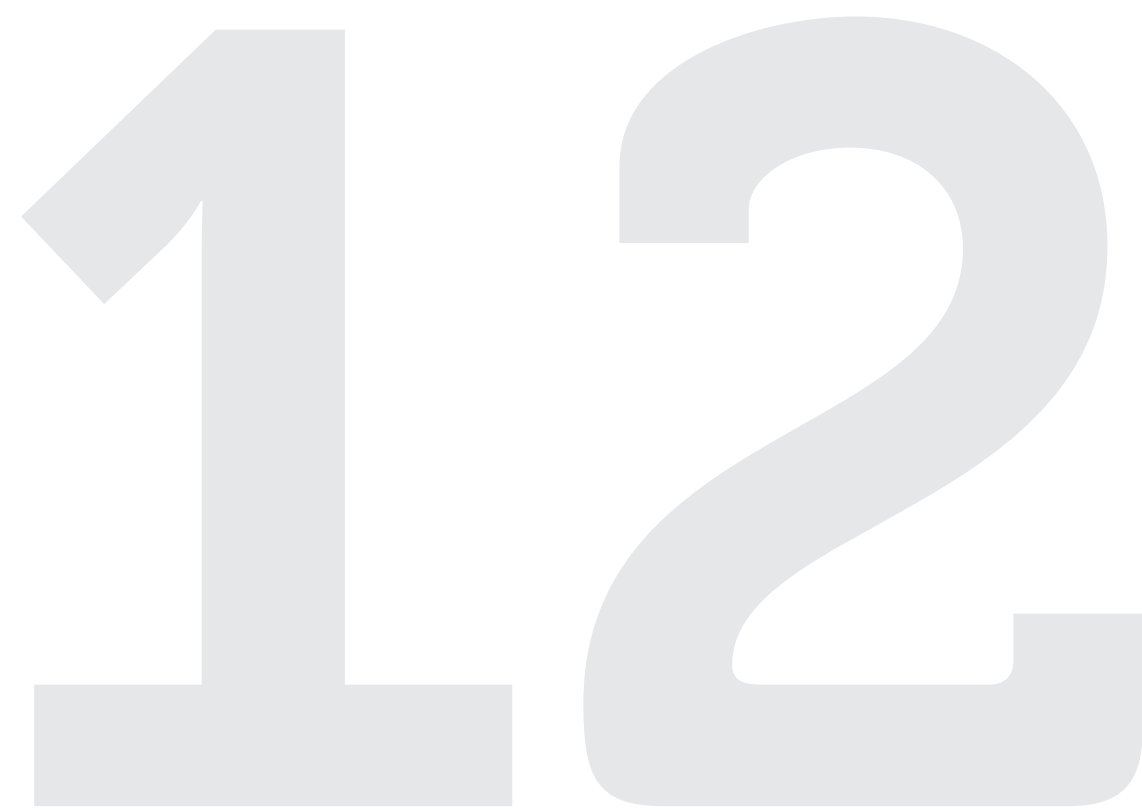


\section{warm-up}

\section{$\mathrm{BOOK} \mathrm{BOARD}$}

[5 MINUTES]

1. As in the previous session, create a simple book board chart on the chalkboard.

2. Before the start of the session, ask participants to write the name of the

book(s) they have read since the last safe space meeting and rate the book(s) with a smiley face (-) if they liked it or a frown face 2 if they did not like it.

3. Point out the books that are listed on the book board and encourage the group to keep sharing book titles they have read each week.

4. Ask if anyone would like to summarize the book they read, and what they liked or didn't like about it. Take one to two volunteers depending on time. The activity should not take more than five minutes.

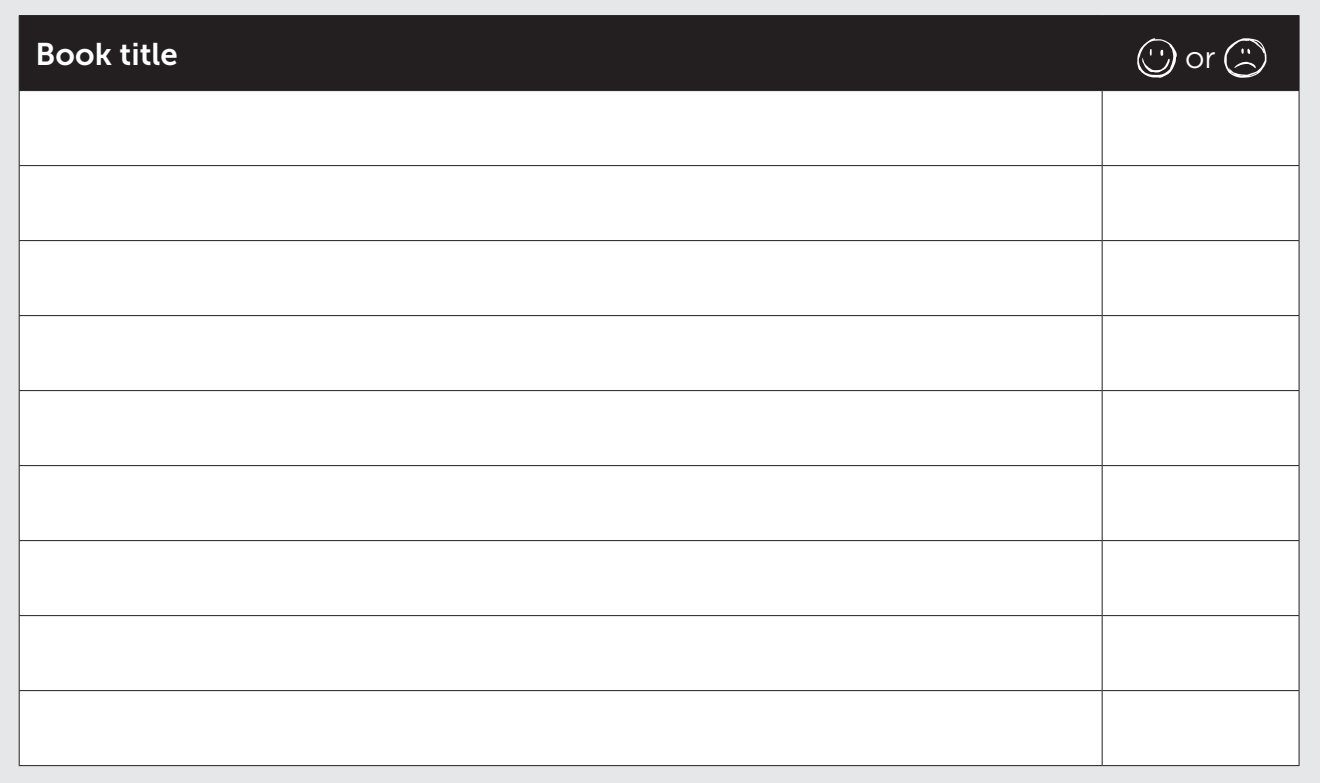




\section{activity 1}

\section{PAIRED READING, HOLIDAYS WITH GRANDMOTHER BY VIOLET OTIENO [15 MINUTES]}

1. Explain: Today we are going to do paired reading. As you may remember from a couple of sessions ago, in paired reading you will be paired with another participant and will read aloud to each

other, switching on and off so that there is one person reading at a time. If there is an uneven number, one person will pair with a mentor. Remember to help each other pronounce words correctly. [Note: Remember to pair the weaker readers with the stronger readers.]

2. Say: Please open the e-book Holidays with Grandmother. "Check." [Verify that everyone is on the right book. Help anyone who is not able to find the book.]

3. After all pairs have finished reading the story, ask everyone to come back to the main circle.

4. Ask the following questions:

- What did you enjoy about the book?

Would anyone like to share what they like about going to their grandmother or any other relative's house? 


\section{activity 2}

\section{MENTOR READ ALOUD, NAOMI IN HER NEW SCHOOL (PART 4)}

BY JOSEPH MZEE MULEKA [35 MINUTES]

1. Note for mentor: As in the previous sessions, you should practice reading

the selected book aloud when preparing

your session and look up the meaning of

potentially unfamiliar words. While reading

demonstrate good reading by being

audible, clear, and expressive.

2. Say: Please open the e-book, Naomi in

Her New School to Chapter 5. "Check.

[Verify that everyone is on the right book

and chapter. Help anyone who is not able

to find the book.

3. Explain: Remember that I read Chapter 4 last session. Today I will read Chapters 5

and 6; please follow along.

4. After finishing Chapters 5 and 6, ask the participants:

- Are you satisfied with the ending? Why or why not?

What have you learned from the story?

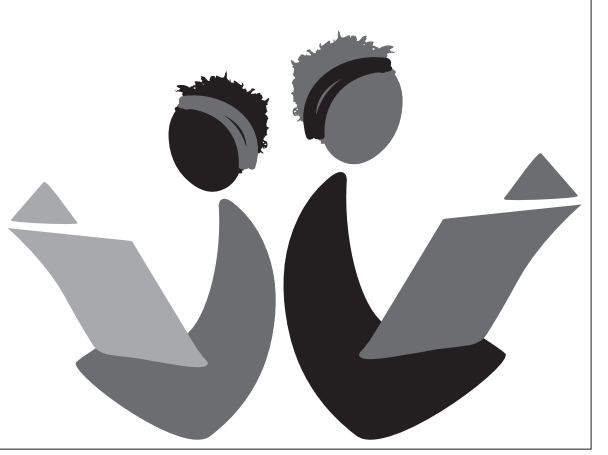




\section{wrap-up}

\section{WRAP-UP \\ [5 MINUTES]}

Explain: In next week's session, we will read Searching for the Spirit of Spring for Activity

1 and a summary of Chapters 1-9 and the full Chapter 10 of Broken Promises for Activity 2. Please try to read these books in advance of

next week's session.

Ask: Are there any other books on the

e-readers that you hope to read between now

and our next safe space meeting? [Allow time

for sharing.]

Ask: Is there anything you would like to

discuss about today's session? Did you learn anything new? What are you looking forward to for next week's session?

Thank the group for their participation.

Encourage them to read as much as possible between now and the next session, whether on their own, with a parent/guardian, sibling friend, or neighbor. The more they read, the better readers they will become.

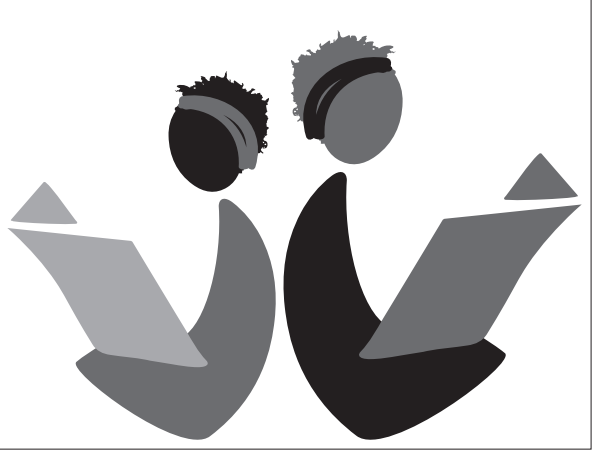




\section{SESSION 13}




\section{session 13}

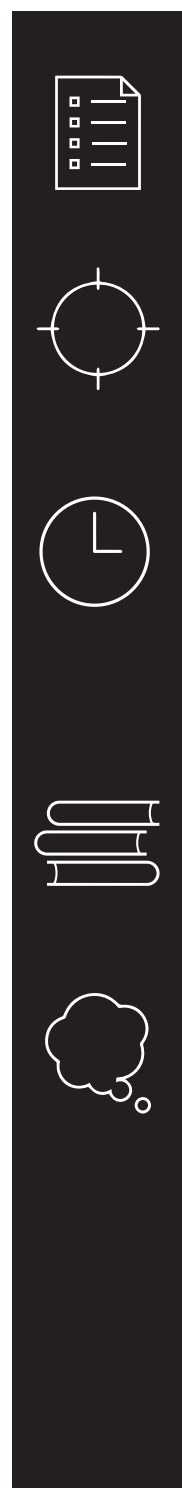

SESSION DESCRIPTION

Share books read the previous week and practice reading as a group.

\section{OBJECTIVES}

In this session, participants will:

Practice reading

Follow along while the mentor reads aloud

SESSION TIME

1 hour

Warm-up: Book board, 5 minutes

Activity 1: Nshima reading, Searching for the Spirit of Spring, 15 minutes

Activity 2: Mentor read aloud, Broken Promises (part 1), 35 minutes

Wrap-up, 5 minutes

REQUIRED MATERIALS

Devices (e-readers)

Chalkboard, chalk, and eraser

PRE-SESSION PREPARATION

Read through the entire session and, if necessary, practice presenting

the activities. Prepare all materials needed.

Read the e-book for Activities 1 and 2 in advance.

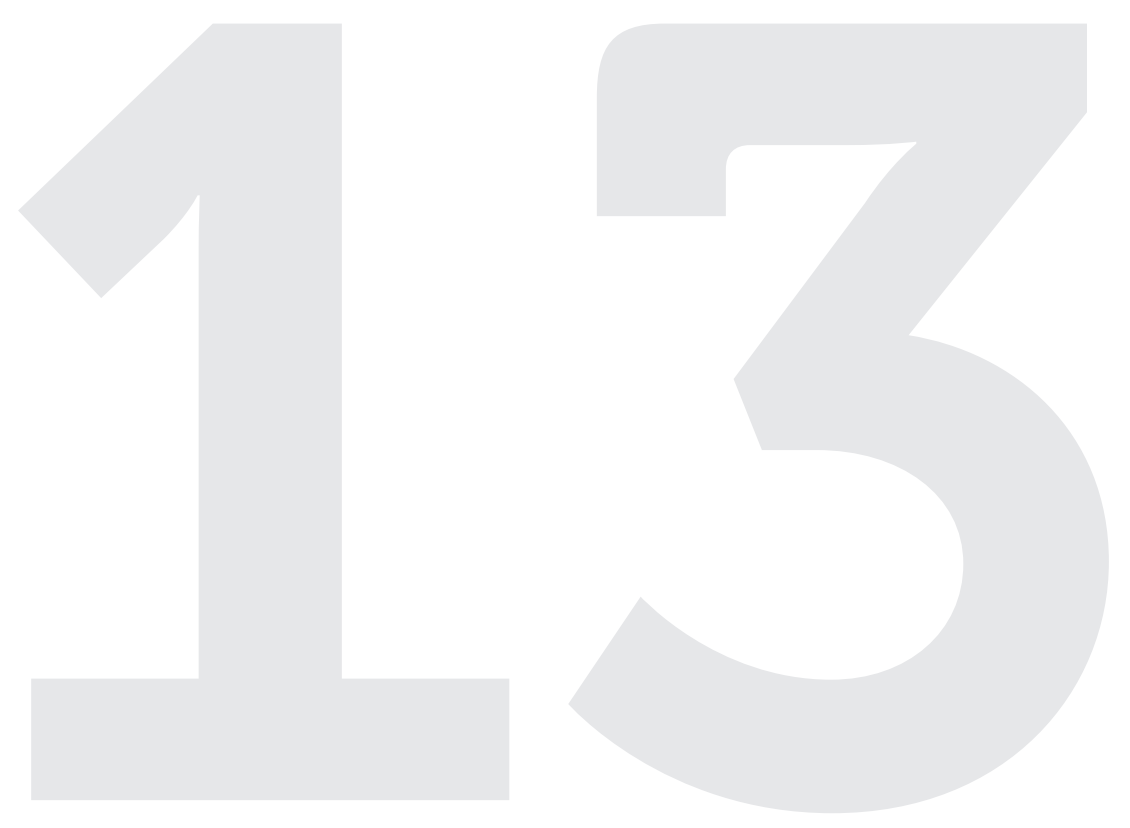




\section{session 13 (cont.)}

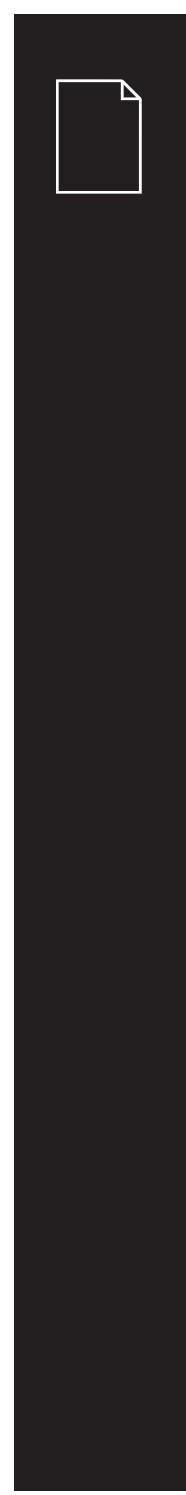

FACILITATOR NOTES

For Activity 2, here is a summary of the book and instructions for how to break it up over Sessions 13-15:

\section{Broken Promises \\ by Ros Haden}

Summary, for the mentor's information:

Ntombi, the main character, is a 15-year-old

high school student who lives with her mother

and younger sister. Ntombi is a talented

singer and dreams of winning Teen Voice, a

singing competition for high school students.

Ntombi falls for a handsome older student,

$\mathrm{Mzi}$, who is alternatingly sweet and coercive.

Ntombi's emotions and how she processes

her conflicting feelings are relatable and

touching. Her girlfriends are there for her, as is

another male student, Olwethu, who Ntombi

becomes friends with. As the story progresses

it is increasingly clear that Mzi is "bad news"

(he is disrespectful of Ntombi, controlling,

drinks, drives too fast, etc.). As Ntombi finds

out more about Mzi, she learns that he is

mixed up with car thieves. Ntombi winds up

in several dangerous situations, including one

where Mzi is about to force Ntombi to have

sex with him, but Ntombi, with Olwethu's help

escapes, and helps the police capture the car

thieves, including Mzi. In the course of the

story Olwethu and Ntombi have grown closer

- he treats her well, and they are honest and

caring with each other. At the end, Olwethu and

Ntombi get together, and Ntombi does get to compete in the Teen Voice auditions. There are other subplots and dynamics in the story as well, including between Ntombi and her mom, but

this is the main idea. The author is South African.

\section{Preview of how you will use this book during}

\section{safe spaces:}

Topics from the safe spaces curriculum that are covered in this book include healthy relationships and sexual coercion, as well as general growing up, responsibility, and being true to yourself. Broken Promises is a great read - very relatable characters, well-written, and an engaging plot. Unfortunately, it is too long a book (19 chapters plus an epilogue) to read aloud with the group in its entirety, but you can encourage the participants to finish reading it on their own. The selected Chapters - 10-12, from the middle of the book - get at the heart of the issues that Ntombi faces in her relationship, including sexual pressure. Here is how you'll engage the participants in the book and read it with them over the course of the next three sessions:

Continued on next page

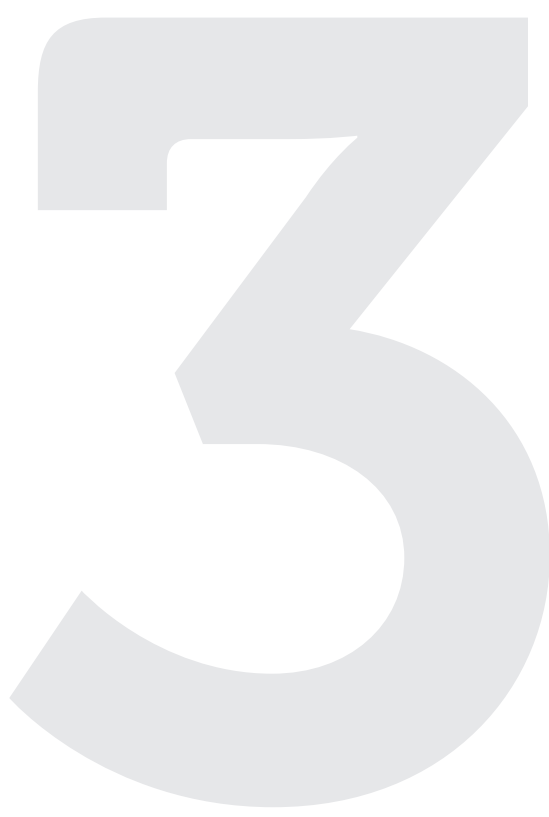




\section{session 13 (cont.)}

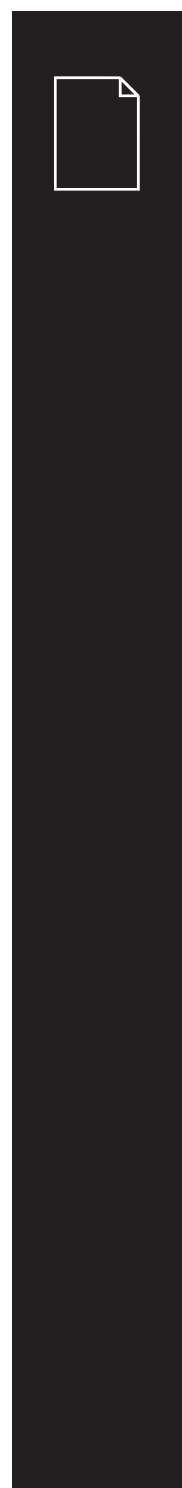

Session 13: Before starting to read Chapter 10, you will orient the participants to the characters and catch them up on the main things happening in the book. You might even want to write the characters' names, and who they are, on the board to make it easier for everyone to remember who is who. This is the summary of Chapters 1-9.

This book is about a 15-year-old high school student named Ntombi. Ntombi lives with her mother and younger sister, Zinzi, in South Africa. Her father abandoned them a year ago and Ntombi's mom is now dating a man named Zakes. Ntombi is suspicious of Zakes and doesn't trust him

Ntombi has three great girlfriends, Busi, Asanda, and Lettie (Zinzi calls them the "giraffes" because they are all tall). Ntombie dreams of winning Teen Voice, a singing competition for high school students and she has been practicing for the upcoming auditions. As the story unfolds she starts to become friends with a male student who lives nearby. His name is Olwethu. Olwethu lives with his grandmother and younger sister.

On her way to school one day, one of the best looking boys at their high school starts to flirt with Ntombi. His name is Mzi. Ntombi starts to fall for Mzi - he is charming and tells her nice things like she is gorgeous. But then small warning signs start coming up. Sometimes Mzi loses his temper with Ntombi and frightens her, but then becomes sweet again. He pressures her to drink alcohol when she would rather not, and she thinks she sees him flirting with another girl named Thumi. Ntombi's feelings get very confused.

We are going to start reading at a point in the story where Ntombi is at a party with Mzi. She is outside on her own thinking that the relationship with Mzi has gotten very complicated, very fast. She thinks, "Love wasn't meant to be like this with all this insecurity and jealousy. Why couldn't it be like the words of those songs where it's all happy ever after, always."

Then you'll start reading from Chapter 10 and read the entire chapter. [Note: This chapter, about half-way through, includes a scene where Mzi tries to have sex with Ntombi but she resists.]

\section{Session 14: Read Chapter 11}

Session 15: Read Chapter 12. You can ask girls to predict what they think happens. Encourage them to read the book on their own.

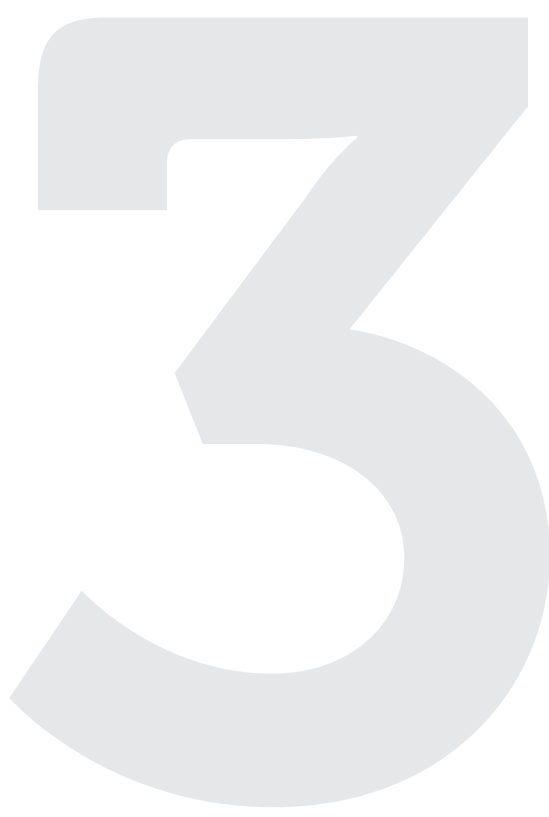




\section{warm-up}

\section{$\mathrm{BOOK} \mathrm{BOARD}$}

[5 MINUTES]

1. As in the previous session, create a simple book board chart on the chalkboard.

2. Before the start of the session, ask participants to write the name of the

book(s) they have read since the last safe space meeting and rate the book(s) with a smiley face (-) if they liked it or a frown face $(1)$ if they did not like it.

3. Point out the books that are listed on the book board and encourage the group to keep sharing book titles they have read each week.

4. Ask if anyone would like to summarize the book they read, and what they liked or didn't like about it. Take one to two volunteers depending on time. The activity should not take more than five minutes.

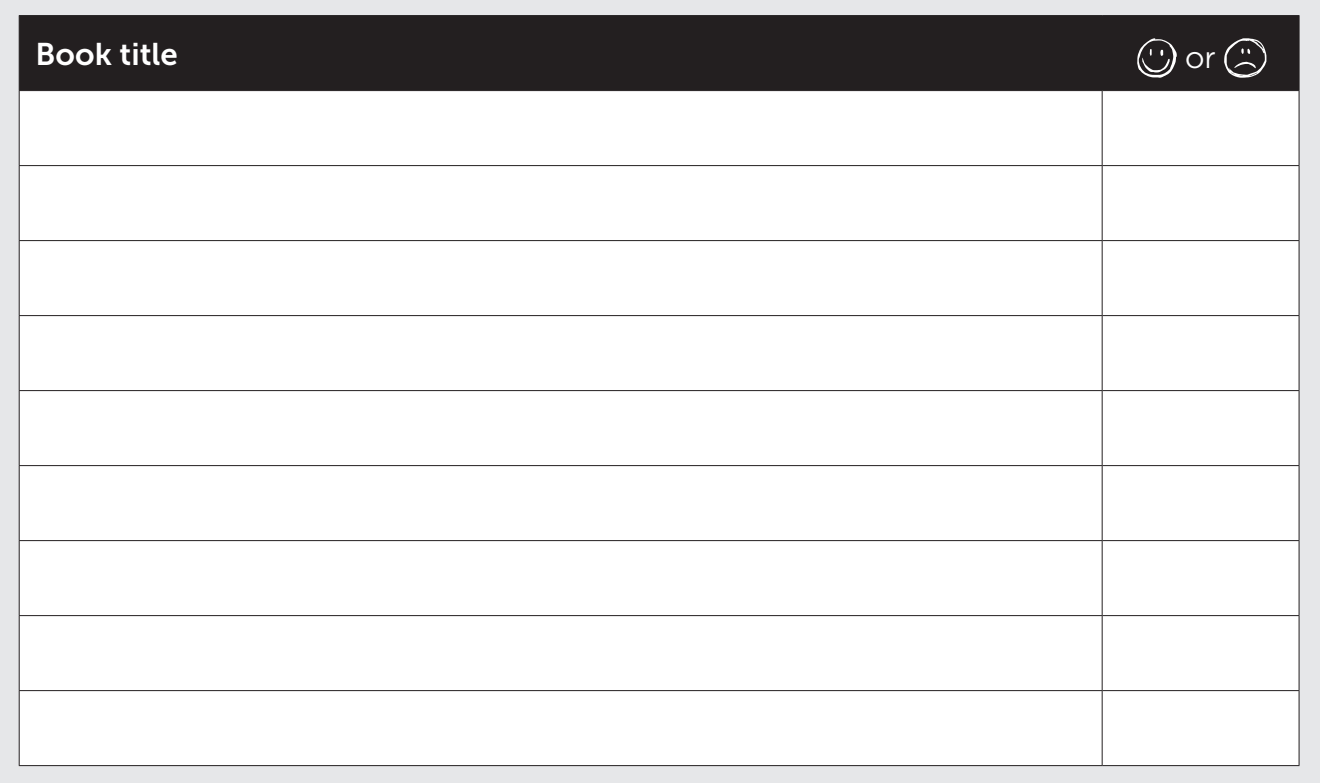




\section{activity 1}

\section{NSHIMA READING, SEARCHING FOR THE SPIRIT OF SPRING BY MOSA MAHLABA, SELINA MORULANE, AND SIBUSISO MKHWANAZI [15 MINUTES]}

1. Ask: Do we all remember nshima reading? [Let participants respond and describe nshima reading. If they don't remember, remind them that in nshima reading participants trade off reading a story. One person starts reading a story to a point then calls out "nshima" before selecting another person in the group to continue reading. Remind them that they are not allowed to choose a person sitting next to them.]

2. Please open the e-book Searching for the Spirit of Spring. "Check." [Verify that everyone is on the right book. Help anyone who is not able to find the book.]

3. Ask: Who would like to begin reading? [Choose a volunteer.] Please begin.

4. After reading the book, ask the following questions:

-What questions would you like to ask the authors if you could talk to them?

- What did you like best about this story?

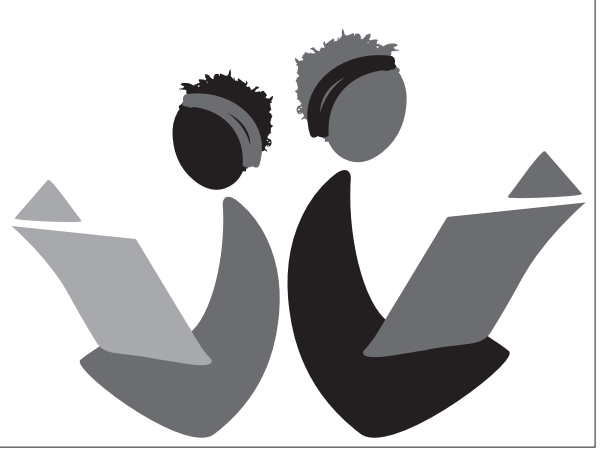




\section{activity 2}

\section{MENTOR READ ALOUD, BROKEN PROMISES (PART 1) BY ROS HADEN \\ [35 MINUTES]}

1. Note for mentor: As in the previous sessions, you should practice reading the selected book aloud when preparing your session and look up the meaning of potentially unfamiliar words. While reading demonstrate good reading by being audible, clear, and expressive.

2. Say: Please open the e-book Broken Promises. "Check." [Verify that everyone is on the right book. Help anyone who is not able to find the book.

3. Explain: First, I am going to summarize the first 9 chapters of the book as we will not be able to read the whole book here in our safe space. Here is what is happening in the book. [You may want to write the characters' names and who they are on the board so it's easier for the girls to remember who is who.]

- This book is about a 15-year old high school student named Ntombi. Ntombi lives with her mother and younger sister, Zinzi, in South Africa. Her father abandoned them a year ago and Ntombi's mom is now dating a man named Zakes. Ntombi is suspicious of Zakes and doesn't trust him.
Ntombi has three great girlfriends, Busi, Asanda, and Lettie (Zinzi calls them the "giraffes" because they are all tall). Ntombie dreams of winning Teen Voice, a singing competition for high school students and she has been practicing for the upcoming auditions. As the story unfolds she starts to become friends with a male student who lives nearby. His name is Olwethu Olwethu lives with his grandmother and younger sister

On her way to school one day, one of the best looking boys at their high school starts to flirt with Ntombi. His name is Mzi. Ntombi starts to fall for Mzi - he is charming and tells her nice things like she is gorgeous. But then small warning signs start coming up. Sometimes Mzi loses his temper with Ntombi and frightens her, but then becomes sweet again. He pressures her to drink alcohol when she would rather not, and she thinks she sees him flirting with another girl named Thumi. Ntombi's feelings get very confused.

We are going to start reading at a point in the story where Ntombi is at a party with Mzi. She is outside on her own thinking that the relationship with Mzi has gotten very complicated, very fast. She thinks, "Love wasn't meant to be like this with all this insecurity and jealousy. Why couldn't it be like the words of those songs where it's all happy ever after, always."

4. Say: Please go to Chapter 10 of Broken Promises. "Check." [Verify that everyone is on Chapter 10.]

5. Explain: Today I will read Chapter 10 please follow along in your e-readers as read.

6. After finishing Chapter 10, ask the participants:

How do you think Ntombi is feeling?

-What do you think will happen next? Why?

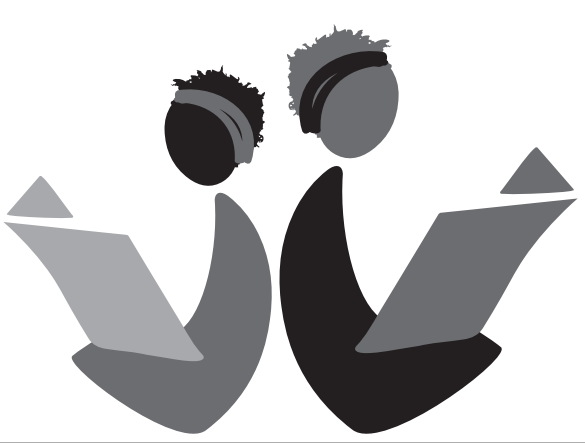




\section{wrap-up}

\section{WRAP-UP \\ [5 MINUTES]}

Explain: In next week's session, we will read Dad Goes to School for Activity 1 and Chapter 11 of Broken Promises for Activity 2. Please try to read these books in advance of next week's session.

Ask: Are there any other books on the

e-readers that you hope to read between now and our next safe space meeting? [Allow time

for sharing.]

Ask: Is there anything you would like to

discuss about today's session? Did you learn anything new? What are you looking forward to for next week's session?

Thank the group for their participation.

Encourage them to read as much as possible between now and the next session, whether on their own, with a parent/guardian, sibling friend, or neighbor. The more they read, the better readers they will become.

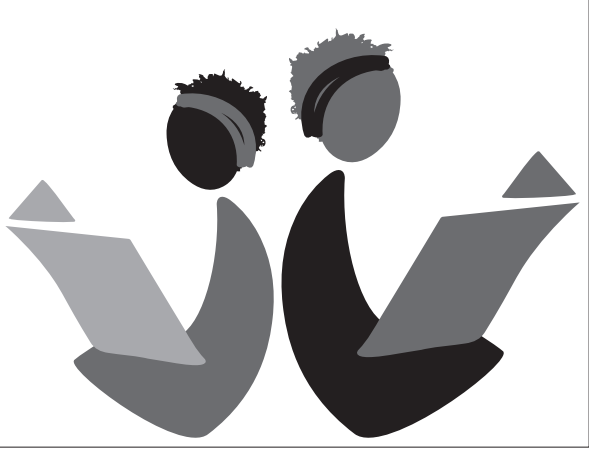




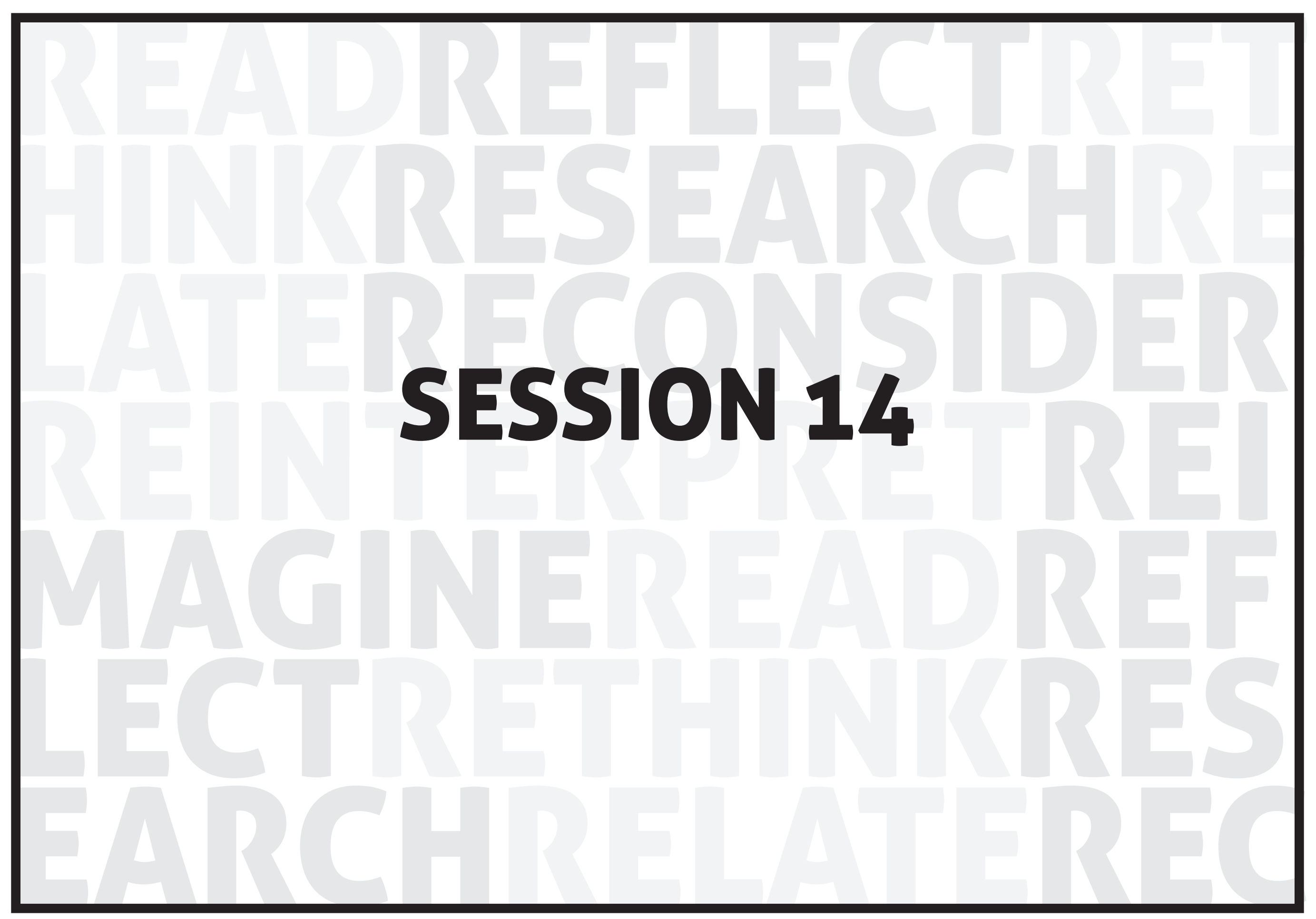




\section{session 14}

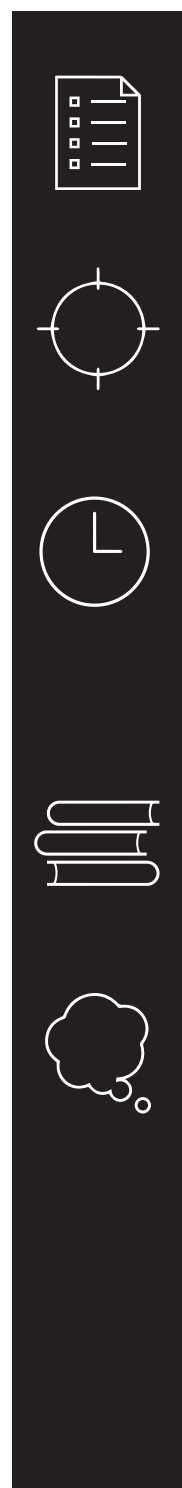

SESSION DESCRIPTION

Share books read the previous week and practice reading as a group.

\section{OBJECTIVES}

In this session, participants will:

Practice reading

Follow along while the mentor reads aloud

SESSION TIME

1 hour

Warm-up: Book board, 5 minutes

Activity 1: Nshima reading, Dad Goes to School, 15 minutes

Activity 2: Mentor read aloud, Broken Promises (part 2), 35 minutes

Wrap-up, 5 minutes

REQUIRED MATERIALS

Devices (e-readers)

Chalkboard, chalk, and eraser

PRE-SESSION PREPARATION

Read through the entire session and, if necessary, practice presenting the activities. Prepare all materials needed.

Read the e-book for Activities 1 and 2 in advance.

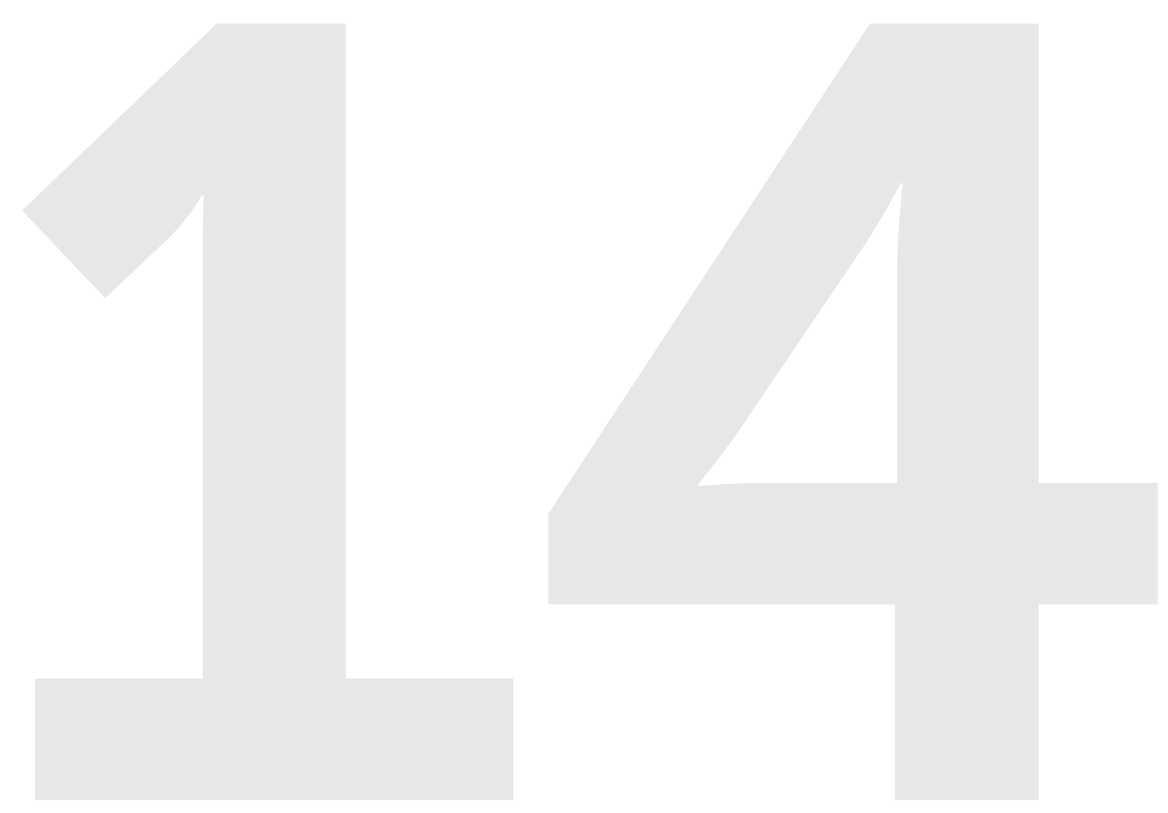




\section{warm-up}

\section{$\mathrm{BOOK} \mathrm{BOARD}$}

[5 MINUTES]

1. As in the previous session, create a simple book board chart on the chalkboard.

2. Before the start of the session, ask participants to write the name of the

book(s) they have read since the last safe space meeting and rate the book(s) with a smiley face (-) if they liked it or a frown face $(1)$ if they did not like it.

3. Point out the books that are listed on the book board and encourage the group to keep sharing book titles they have read each week.

4. Ask if anyone would like to summarize the book they read, and what they liked or didn't like about it. Take one to two volunteers depending on time. The activity should not take more than five minutes.

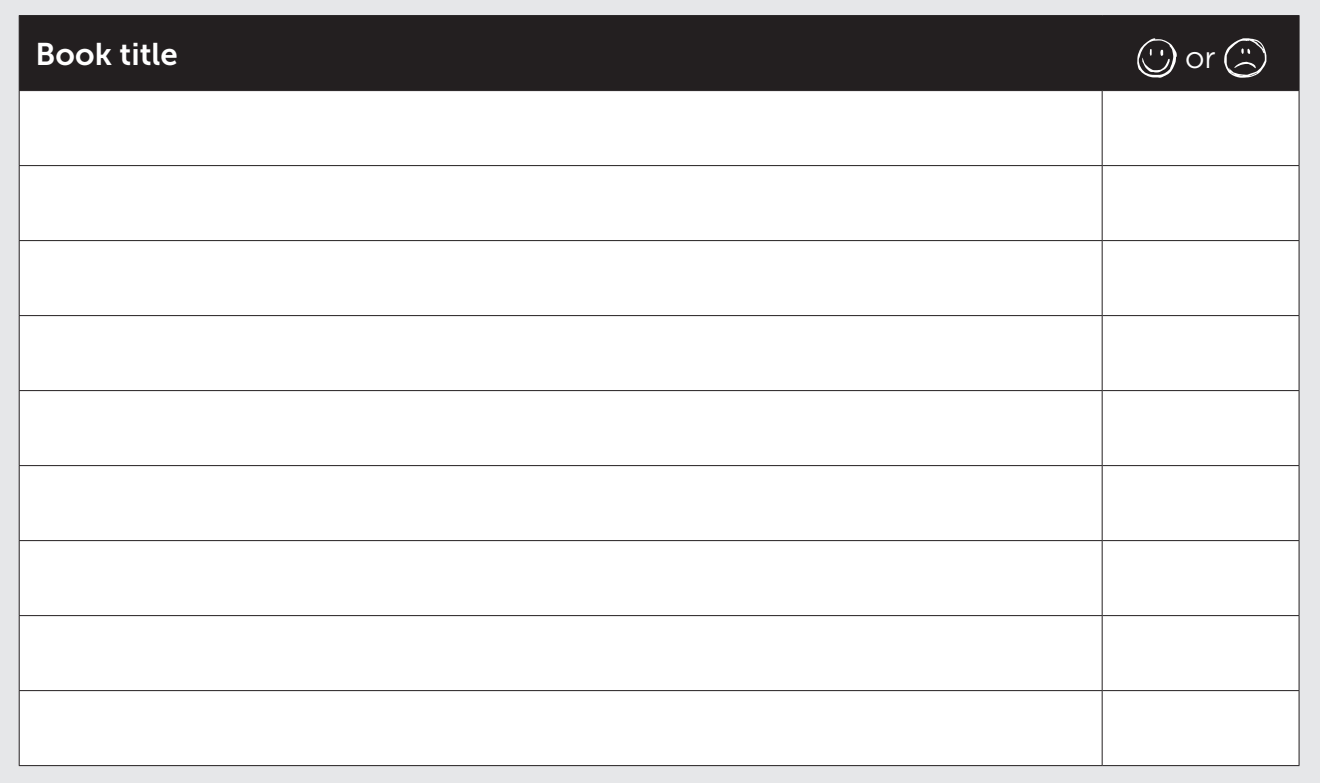




\section{activity 1}

\section{NSHIMA READING, DAD GOES TO SCHOOL BY MANDY COLLINS [15 MINUTES]}

1. Explain: Today we are going to do nshima reading like we did last session.

2. Ask: Do we all remember what nshima reading is? [Let participants respond and describe nshima reading. If they don't remember, remind them that in nshima reading participants trade off reading a story. One person starts reading a story to a point then calls out "nshima" before selecting another person in the group to continue reading. Remind them that they are not allowed to choose a person sitting next to them.

3. Please open the e-book Dad Goes to School. "Check." [Verify that everyone is on the right book. Help anyone who is not able to find the book.

4. Ask: Who would like to begin reading? [Choose a volunteer.] Please begin.
5. After reading the book, ask the following questions:

- Are you happy with the ending? Why or why not?

Could one of you volunteer to retell your favorite part of the story in your own words? 


\section{activity 2}

\section{MENTOR READ ALOUD, BROKEN PROMISES (PART 2) BY ROS HADEN [35 MINUTES]}

1. Note for mentor: As in the previous sessions, you should practice reading the selected book aloud when preparing your session and look up the meaning of potentially unfamiliar words. While reading

demonstrate good reading by being audible, clear, and expressive.

2. Say: Please open the e-book Broken Promises to Chapter 11. "Check." [Verify that everyone is on the right book and chapter. Help anyone who is not able to find the book.]

3. Explain: Today I will read Chapter 11, continuing from last session; please follow along in your e-readers as I read. [You might want to write the names of the characters on the board and who they are to remind the girls who is who.]

4. After finishing Chapter 11, ask the participants:

- How is Ntombi's mother feeling?

What do you think you would do next if you were Ntombi?

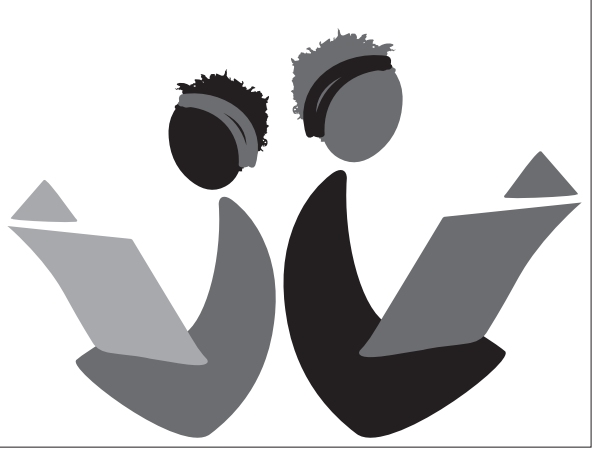




\section{wrap-up}

\section{WRAP-UP \\ [5 MINUTES]}

Explain: In next week's session, we will read Sindi and the Moon for Activity 1 and Chapter

12 of Broken Promises for Activity 2. Please try to read these books in advance of next week's session.

Ask: Are there any other books on the

e-readers that you hope to read between now and our next safe space meeting? [Allow time

for sharing.]

Ask: Is there anything you would like to

discuss about today's session? Did you learn anything new? What are you looking forward to for next week's session?

Thank the group for their participation.

Encourage them to read as much as possible between now and the next session, whether on their own, with a parent/guardian, sibling friend, or neighbor. The more they read, the better readers they will become.

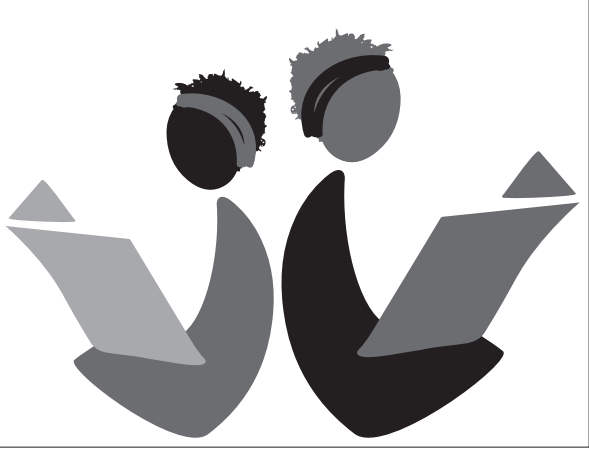




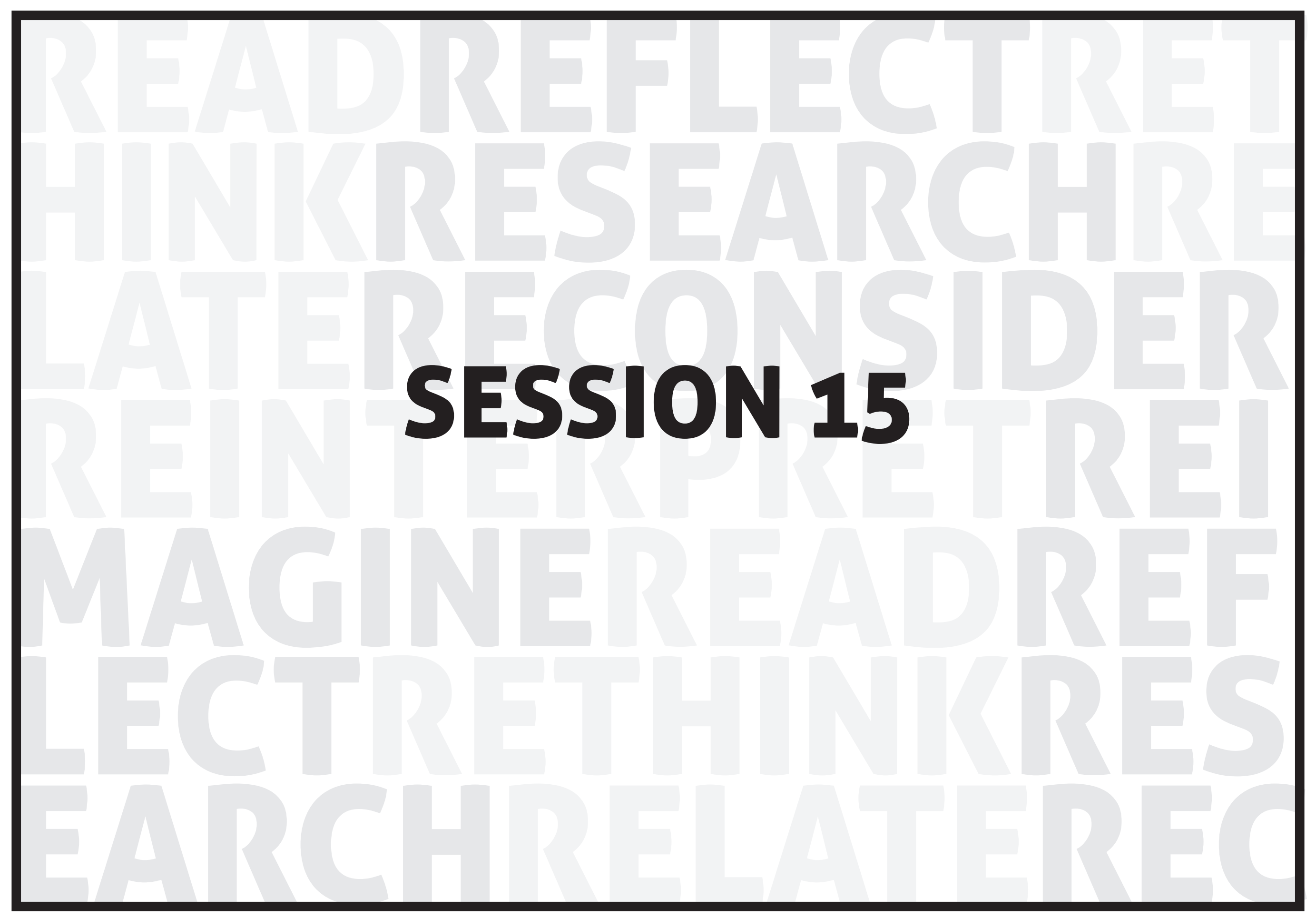




\section{session 15}

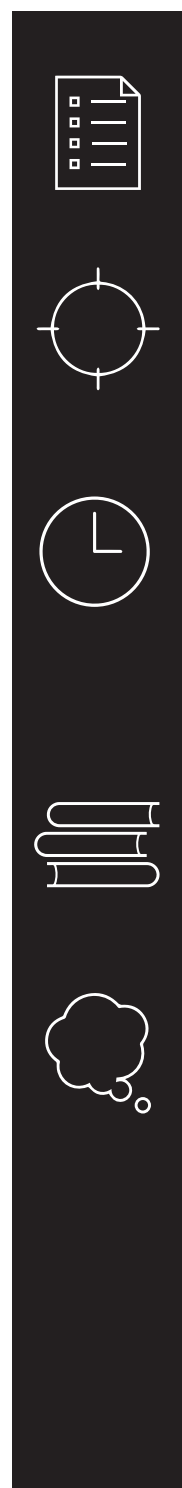

SESSION DESCRIPTION

Share books read the previous week and practice reading as a group.

\section{OBJECTIVES}

In this session, participants will:

Practice reading

Follow along while the mentor reads aloud

SESSION TIME

1 hour

Warm-up: Book board, 5 minutes

Activity 1: Paired reading, Sindi and the Moon, 15 minutes

Activity 2: Mentor read aloud, Broken Promises (part 3), 35 minutes

Wrap-up, 5 minutes

REQUIRED MATERIALS

Devices (e-readers)

Chalkboard, chalk, and eraser

PRE-SESSION PREPARATION

Read through the entire session and, if necessary, practice presenting the activities. Prepare all materials needed.

Read the e-book for Activities 1 and 2 in advance.
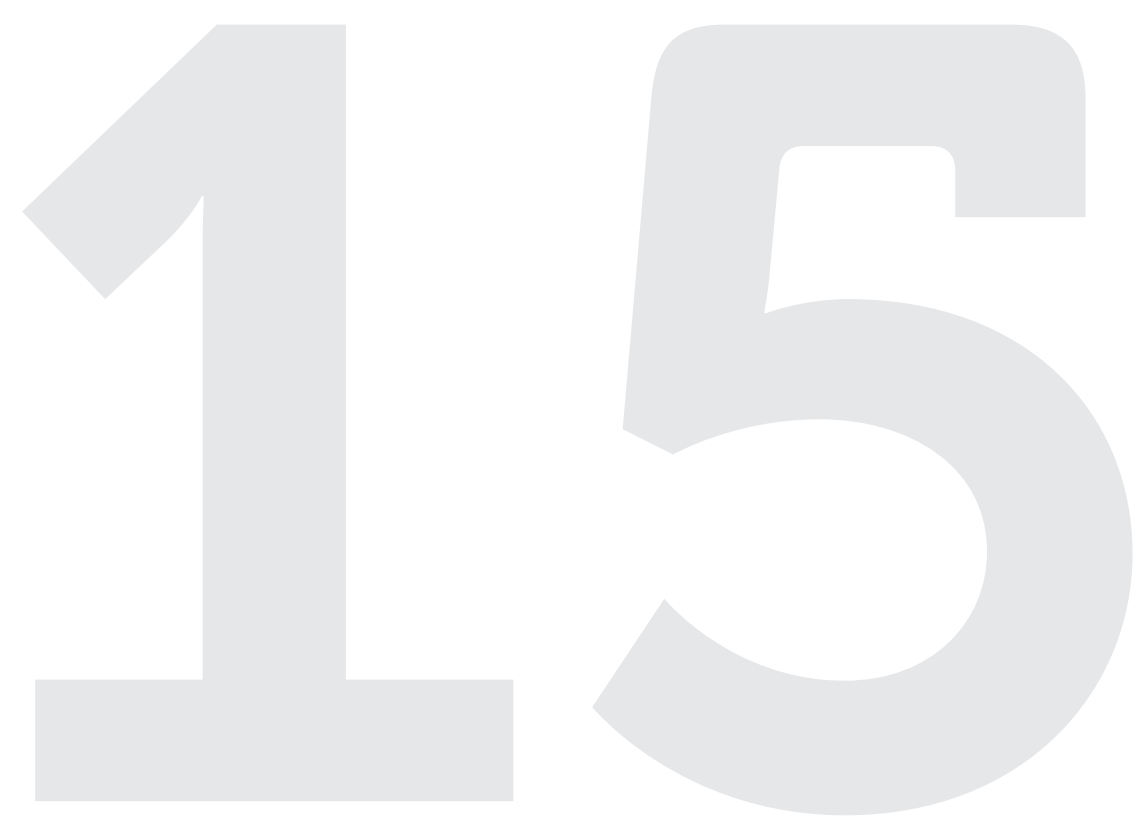


\section{warm-up}

\section{$\mathrm{BOOK} \mathrm{BOARD}$ \\ [5 MINUTES]}

1. As in the previous session, create a simple book board chart on the chalkboard.

2. Before the start of the session, ask participants to write the name of the

book(s) they have read since the last safe space meeting and rate the book(s) with a smiley face (-) if they liked it or a frown face 1 if they did not like it.

3. Point out the books that are listed on the book board and encourage the group to keep sharing book titles they have read each week.

4. Ask if anyone would like to summarize the book they read and what they liked or didn't like about it. Take one to two volunteers depending on time. The activity should not take more than five minutes.

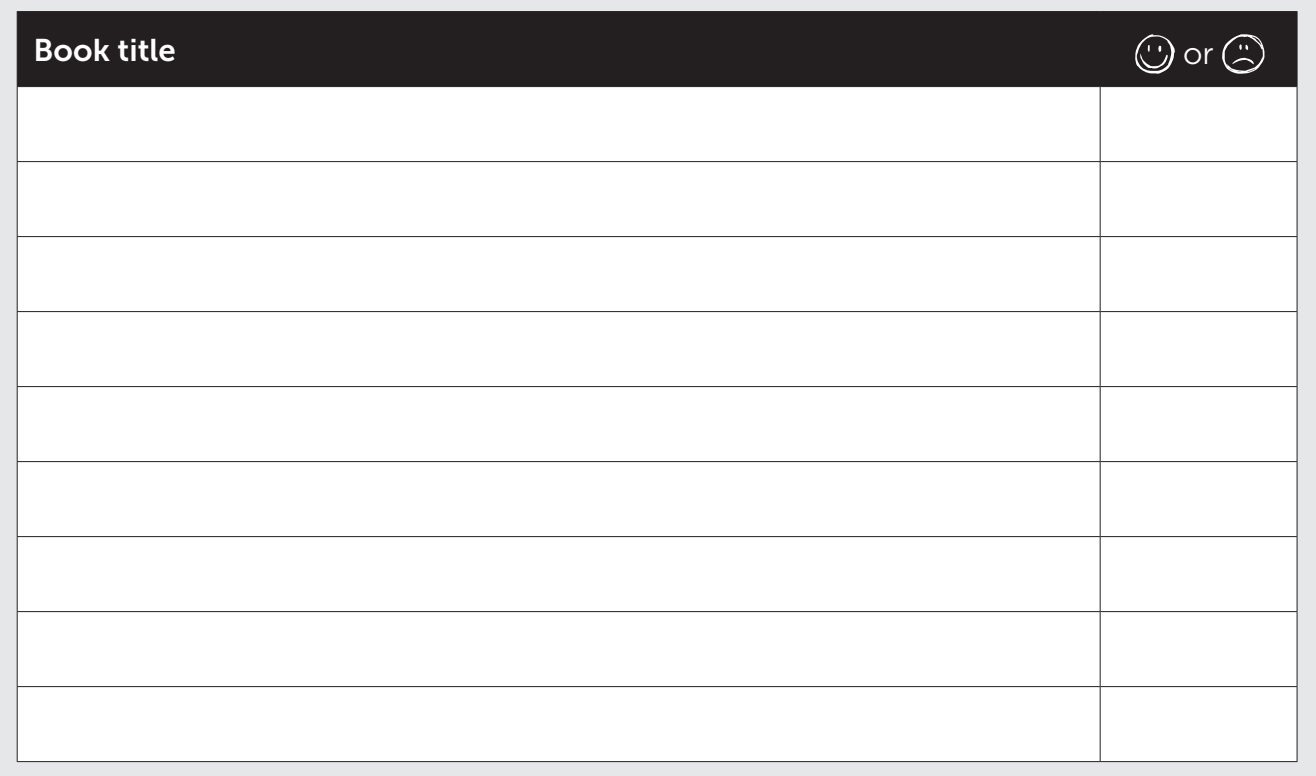

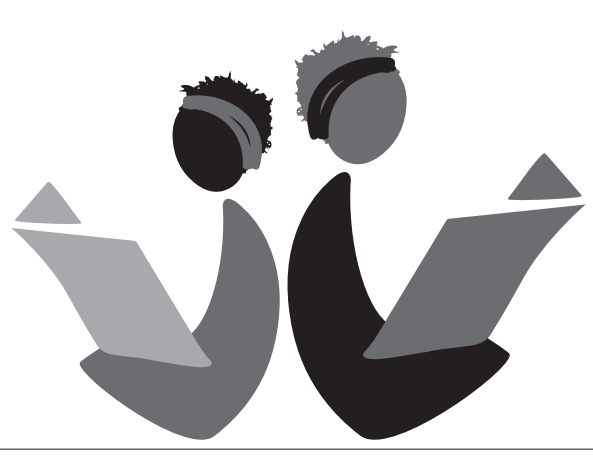




\section{activity 1}

\section{PAIRED READING, SINDI AND THE MOON, BY ZANELE DLAMINI, THOKOZANI MKHIZE, WESLEY VAN EEDEN [15 MINUTES]}

1. Explain: Today we are going to do paired reading. As you may remember, in paired reading you will be paired with another participant and will read aloud to each other, switching on and off so that there is one person reading at a time. If there is an uneven number, one person will pair with a mentor. Remember to help each other pronounce words correctly. [Note:

Remember to pair the weaker readers with the stronger readers.]

2. Say: Please open the e-book Sindi and the Moon. "Check." [Verify that everyone is on the right book. Help anyone who is not able to find the book.

3. After all pairs have finished reading the story, ask everyone to come back to the main circle.

4. Ask the following questions:

- How is Sindi feeling? Why do you think she is feeling that way?

-What do you think Sindi's parents and grandmother/gogo are feeling? Why?

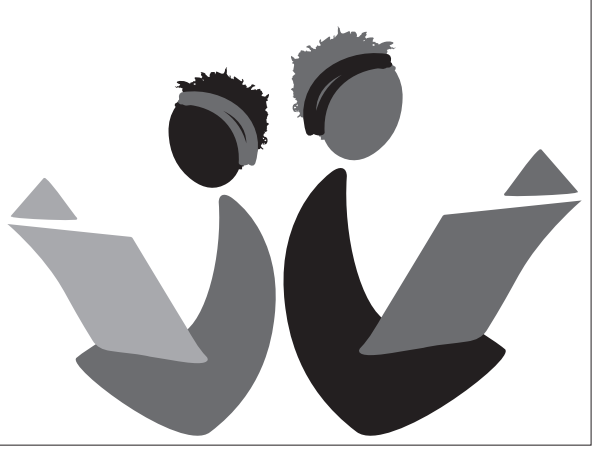




\section{activity 2}

\section{MENTOR READ ALOUD, BROKEN PROMISES (PART 3) BY ROS HADEN}

[35 MINUTES]

1. Note for mentor: As in the previous sessions, you should practice reading the selected book aloud when preparing your session and look up the meaning of potentially unfamiliar words. While reading,

demonstrate good reading by being audible, clear, and expressive.

2. Say: Please open the e-book Broken Promises to Chapter 12. "Check." [Verify that everyone is on the right book and chapter. Help anyone who is not able to find the book.]

3. Explain: Today I will read Chapter 12, continuing from last session; please follow along in your e-readers as I read.

4. After finishing Chapter 12, ask the participants:

How do you think Ntombi is feeling and why?

- What do you think will happen next?

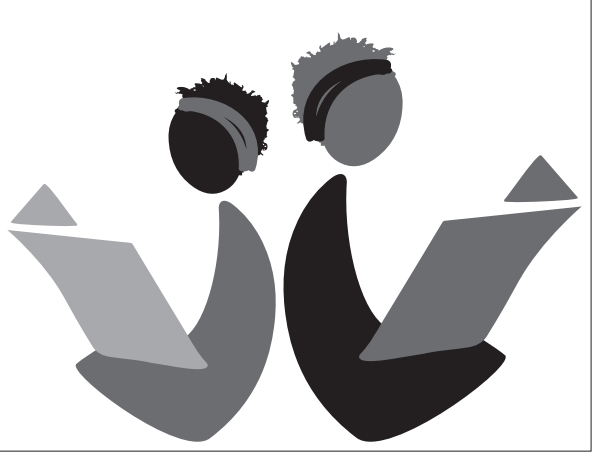




\section{wrap-up}

\section{WRAP-UP \\ [5 MINUTES]}

Explain: In next week's session, we will read

There Must be a Rainbow for Activity 1 and all of

Citronella for Activity 2. Please try to read these

books in advance of next week's session.

Ask: Are there any other books on the e-readers

that you hope to read between now and our

next safe space meeting? [Allow time for

sharing.]

Ask: Is there anything you would like to discuss about today's session? Did you learn anything

new? What are you looking forward to for next

week's session?

Thank the group for their participation.

Encourage them to read as much as possible

between now and the next session, whether on

their own, with a parent/guardian, sibling, friend,

or neighbor. The more they read, the better

readers they will become. 


\section{SESSION 16}




\section{session 16}

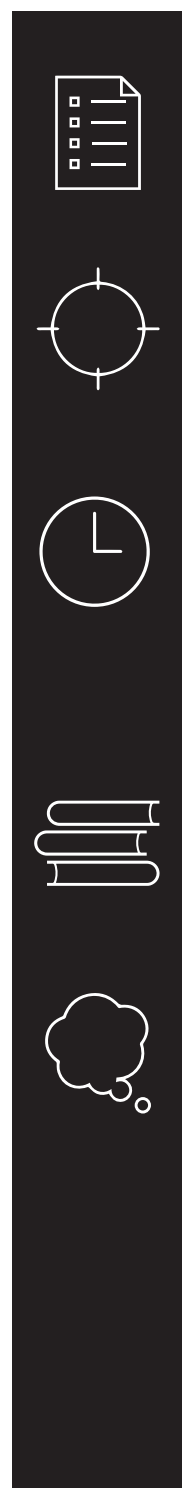

SESSION DESCRIPTION

Share books read the previous week and practice reading as a group.

\section{OBJECTIVES}

In this session, participants will:

Practice reading

Follow along while the mentor reads aloud

\section{SESSION TIME}

1 hour

Warm-up: Book board, 5 minutes

Activity 1: Nshima reading, There Must be a Rainbow, 15 minutes

Activity 2: Mentor read aloud, Citronella 35 minutes

Wrap-up, 5 minutes

\section{REQUIRED MATERIALS}

Devices (e-readers)

Chalkboard, chalk, and eraser

\section{PRE-SESSION PREPARATION}

Read through the entire session and, if necessary, practice presenting the activities. Prepare all materials needed.

Read the e-book for Activities 1 and 2 in advance.
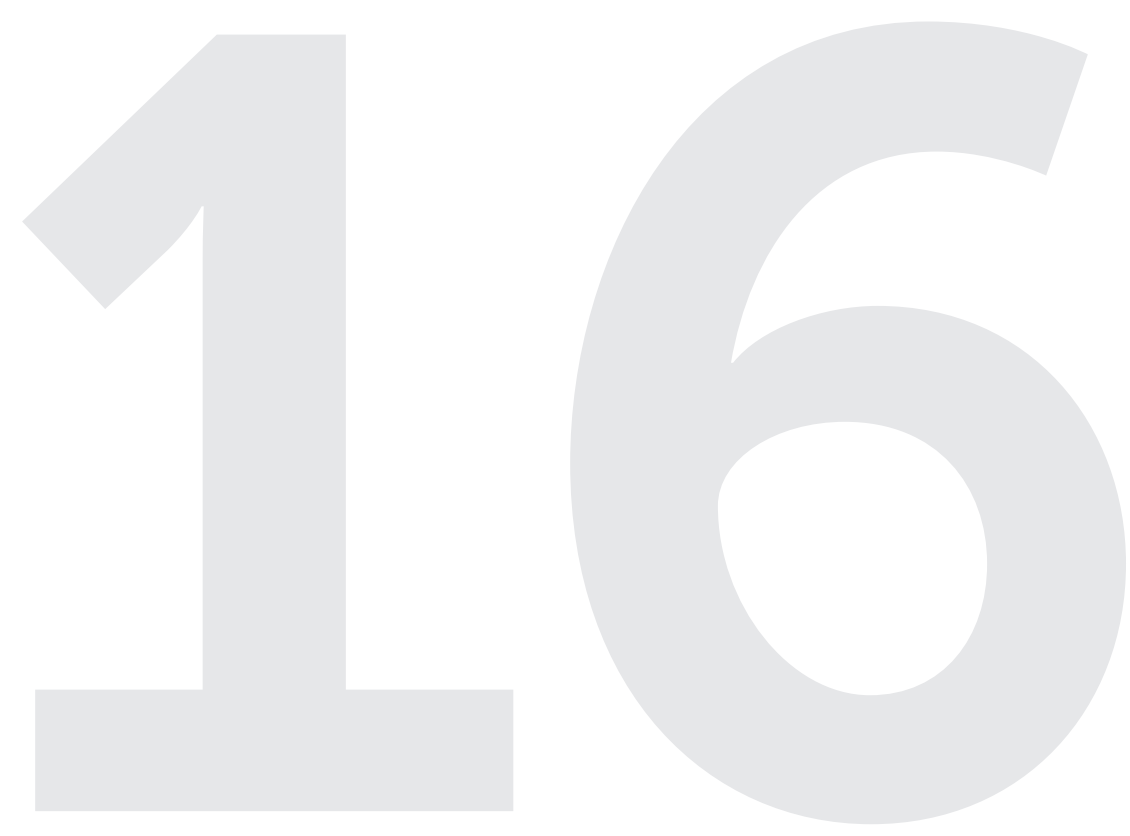


\section{session 16 (cont.)}

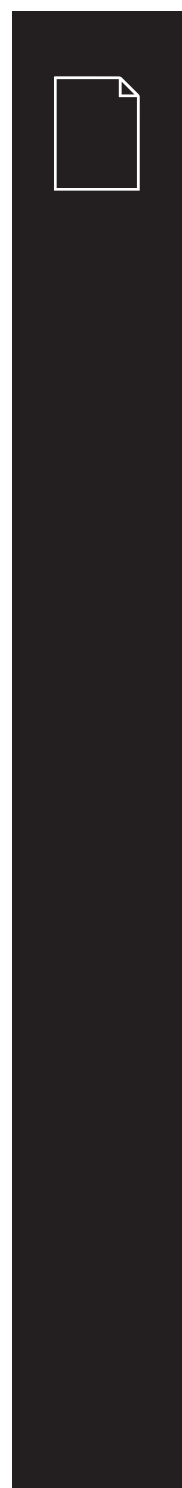

FACILITATOR NOTES

For Activity 2, here is a summary of the book and instructions:

\section{Citronella}

by Carl de Souza

Summary, for the mentor's information:

This story is about Citronella, a little girl who

cannot hear and no one can cure her. Her

family sends her to Grandpa Tambala, who

takes her far away, to a place where you don't

only hear with your ears. Reading closely, one

also wonders whether people were listening to

Citronella.

Preview of how you'll read the book in the

session:

This is a short book, you will finish the entire

book in one session.

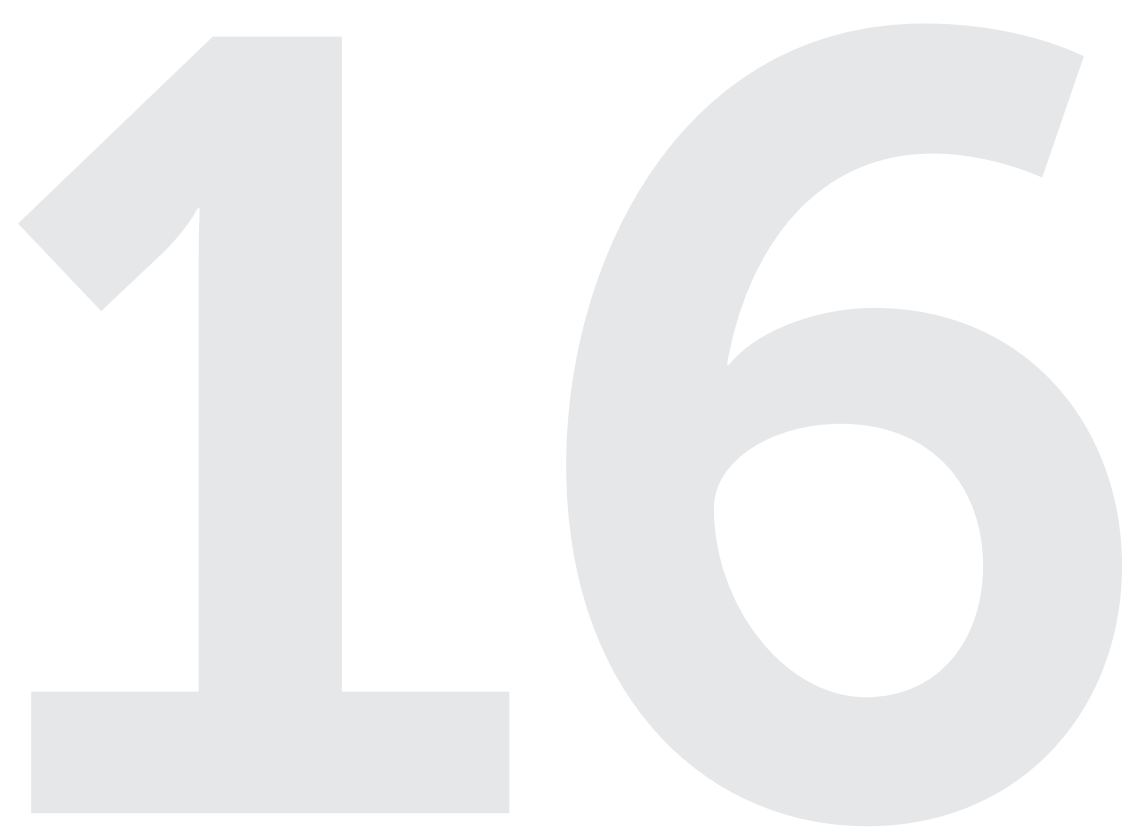




\section{warm-up}

\section{$\mathrm{BOOK} \mathrm{BOARD}$}

[5 MINUTES]

1. As in the previous session, create a simple book board chart on the chalkboard.

2. Before the start of the session, ask participants to write the name of the

book(s) they have read since the last safe space meeting and rate the book(s) with a smiley face (-) if they liked it or a frown face $(1)$ if they did not like it.

3. Point out the books that are listed on the book board and encourage the group to keep sharing book titles they have read each week.

4. Ask if anyone would like to summarize the book they read, and what they liked or didn't like about it. Take one to two volunteers depending on time. The activity should not take more than five minutes.

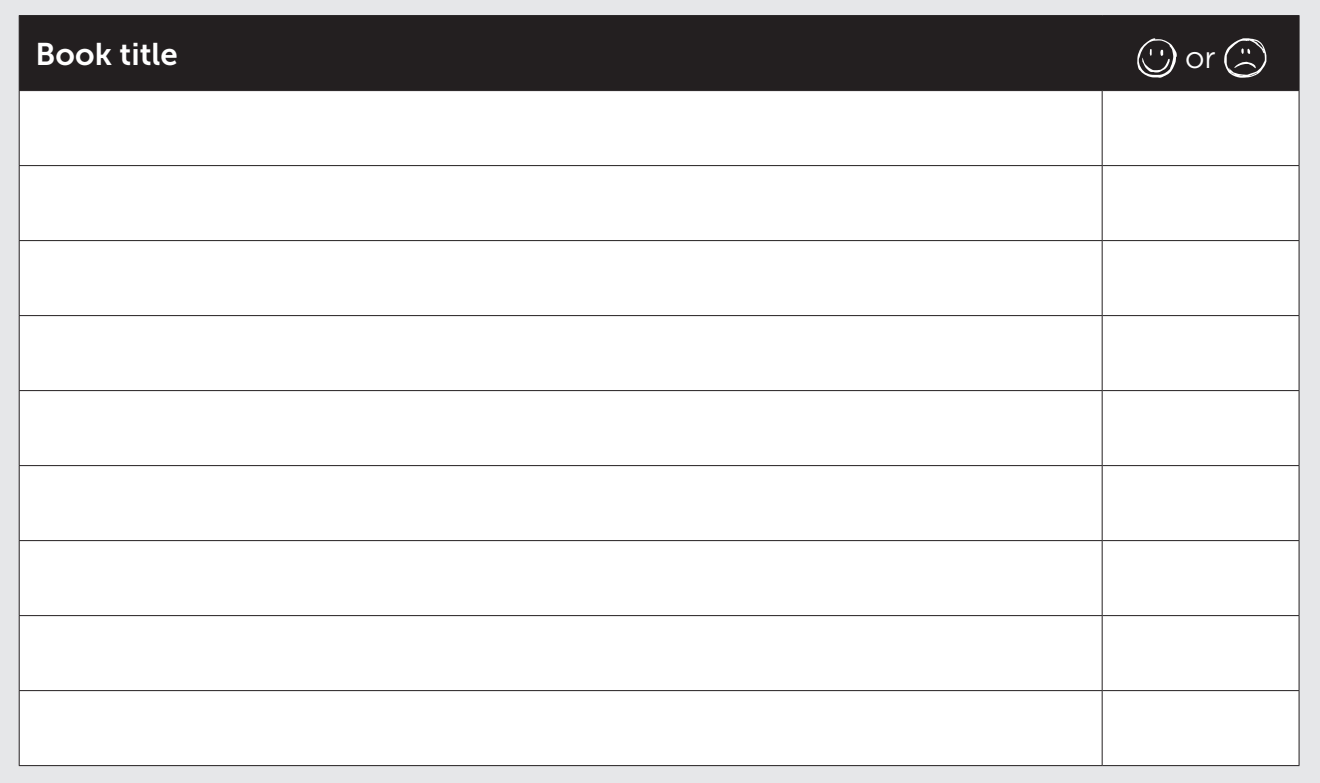




\section{activity 1}

\section{NSHIMA READING, THERE MUST BE A RAINBOW BY SINOMONDE NGWANE, NERISSA GOVENDER, AND THULISIZWE MAMBA [15 MINUTES]}

1. Explain: Today we are going to do nshima reading.

2. Ask: Do we all remember what nshima reading is? [Let participants respond and describe nshima reading. If they don't remember, remind them that in nshima reading participants trade off reading a story. One person starts reading a story to a point then calls out "nshima" before selecting another person in the group to continue reading. Remind them that they are not allowed to choose a person sitting next to them.]

3. Please open the e-book There Must be a Rainbow. "Check." [Verify that everyone is on the right book. Help anyone who is not able to find the book.

4. Ask: Who would like to begin reading? [Choose a volunteer.] Please begin.

5. After reading the book, ask the following questions:

What is your favorite part of the story? Why?

- What is the main message of the book?

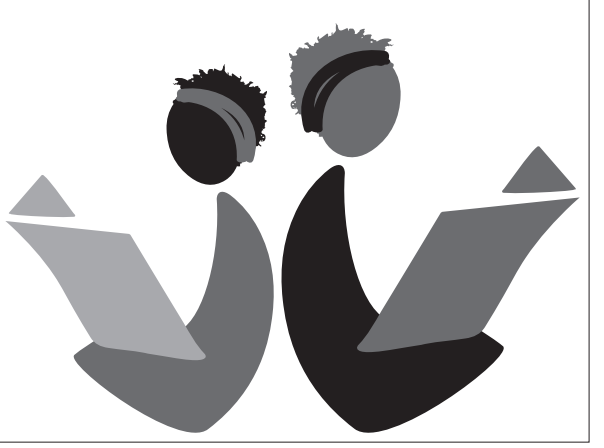




\section{activity 2}

\section{MENTOR READ ALOUD, CITRONELLA BY CARL DE SOUZA [35 MINUTES]}

1. Note for mentor: As in the previous sessions, you should practice reading the selected book aloud when preparing your session and look up the meaning of potentially unfamiliar words. While reading

demonstrate good reading by being audible, clear, and expressive.

2. Say: Please open the e-book Citronella. "Check." [Verify that everyone is on the right book. Help anyone who is not able to find the book.]

3. Explain: Today I will I will read the whole book. Please follow along in your e-readers as I read.

4. After finishing the book, ask the participants:

- What have you learned from the story?

- Which of the characters did you like best?

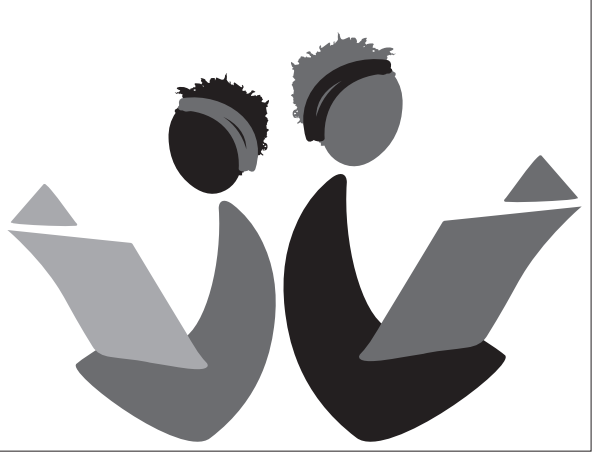




\section{wrap-up}

\section{WRAP-UP \\ [5 MINUTES]}

Explain: In next week's session, we will read Londi the Dreaming Girl for Activity 1 and

Chapter 1 and a summary of Chapters 2-6

of $A$ Shining Star for Activity 2. Please try to read these books in advance of next week's

session.

Ask: Are there any other books on the

e-readers that you hope to read between now

and our next safe space meeting? [Allow time

for sharing.]

Ask: Is there anything you would like to

discuss about today's session? Did you learn

anything new? What are you looking forward

to for next week's session?

Thank the group for their participation.

Encourage them to read as much as possible

between now and the next session, whether

on their own, with a parent/guardian, sibling

friend, or neighbor. The more they read, the

better readers they will become.

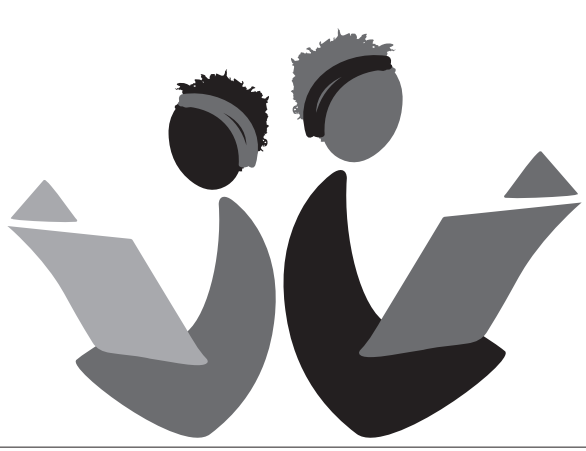




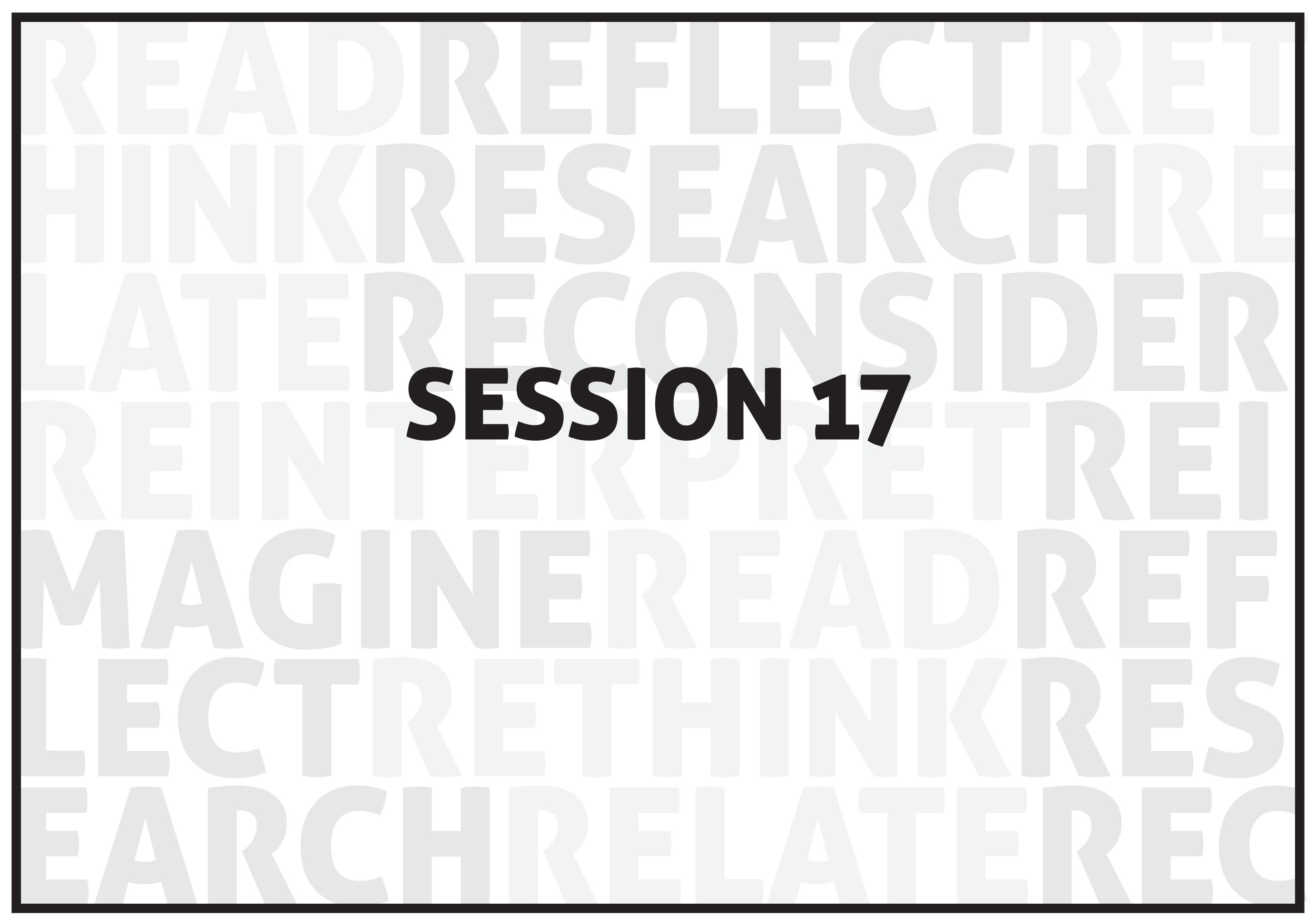




\section{session 17}

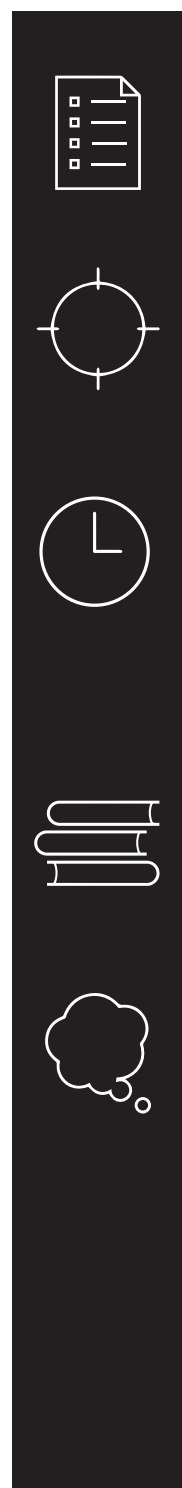

SESSION DESCRIPTION

Share books read the previous week and practice reading as a group.

\section{OBJECTIVES}

In this session, participants will:

Practice reading

Follow along while the mentor reads aloud

SESSION TIME

1 hour

Warm-up: Book board, 5 minutes

Activity 1: Choral reading, Londi the Dreaming Girl, 15 minutes

Activity 2: Mentor read aloud, A Shining Star (part 1), 35 minutes

Wrap-up, 5 minutes

REQUIRED MATERIALS

Devices (e-readers)

Chalkboard, chalk, and eraser

PRE-SESSION PREPARATION

Read through the entire session and, if necessary, practice presenting the activities. Prepare all materials needed.

Read the e-book for Activities 1 and 2 in advance.
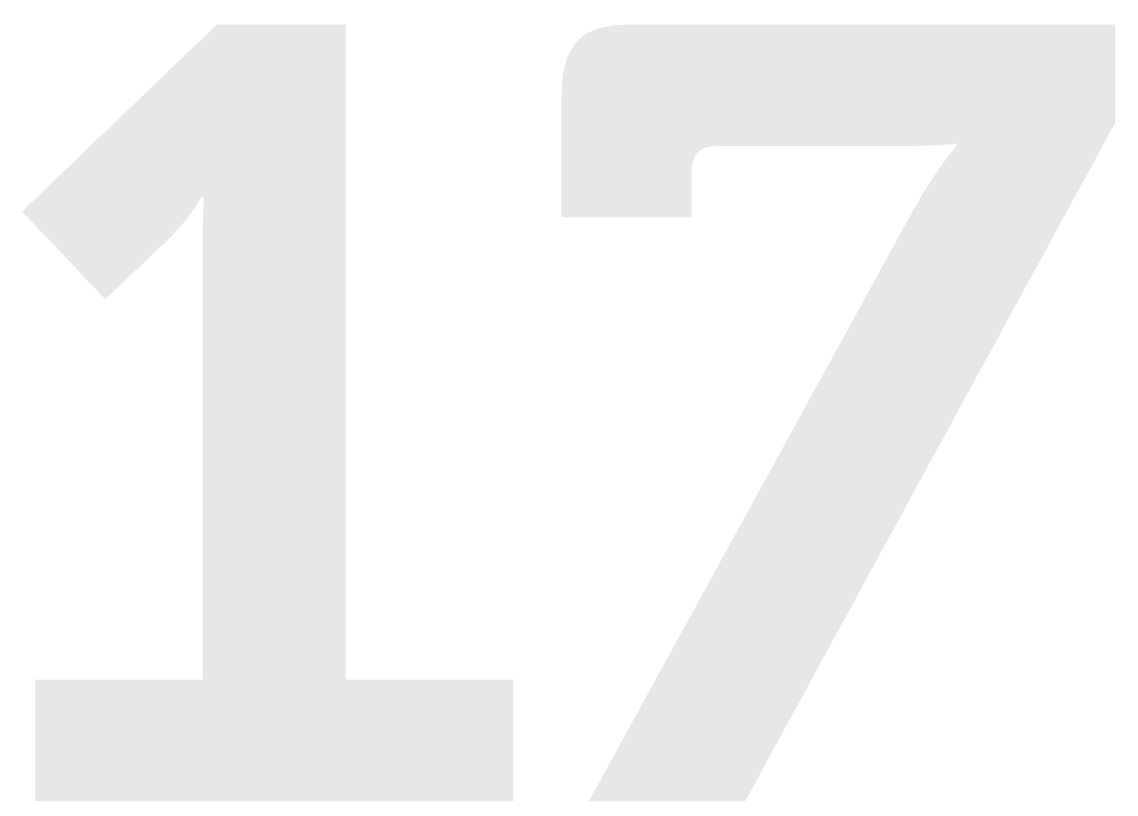


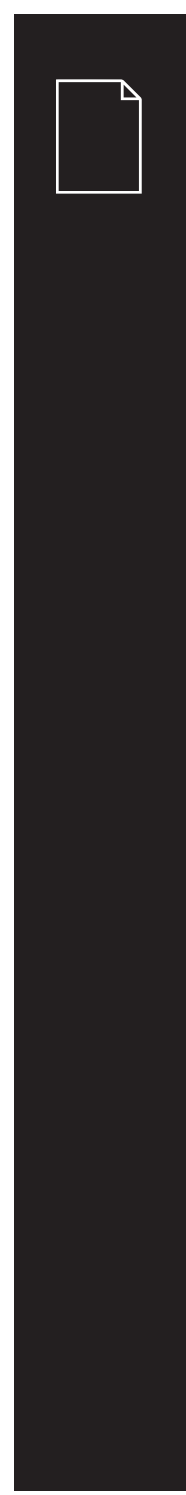

\section{FACILITATOR NOTES}

For Activity 2, here is a summary of the book and a preview of instructions for how you will break it up over the next few sessions:

\section{A Shining Star \\ by Julie Baker}

Summary, for the mentor's information: The narrator - the person telling the story - is the main character, Duduzile (Dudu for short). Dudu is an adolescent girl living in Alexandra township (called "Alex" for short) in South Africa. She and her best friend S'bu share an interest in astronomy. Astronomy is the science that studies the stars and everything else outside of earth's atmosphere. They go to a school in nearby Sandton, where Dudu gets teased because she is mixed race. Dudu's mother is black, and all Dudu knows about her father is that he is German. Her mother refuses to talk about him, but S'bu helps Dudu trace him. At the same time, there is trouble developing in Alex. People in Alex are angry that foreigners who have come to make a life in South Africa are getting houses in Alex. During a protest about housing a local gangster picks on Dudu, asking why she has light brown skin and lives in one of the newer houses. The crowd gets agitated and violent. In the chaos, Dudu's mother tries to protect Dudu, and is badly hurt. S'bu is also with Dudu but he is too busy protecting his new telescope from the violence and does not help them. In the end, Dudu is proud as her mother speaks up at a community meeting about how there should be no prejudice against anybody; and how everyone has a right to live in Alex. Dudu also forgives S'bu, who realized that he should have stood up for Dudu, and begins to do so at school. Dudu's future is now shining bright: her dad is planning a visit; she has reconciled with her mom; and S'bu is by her side.

The book is well-written, in an informal style, with great descriptions (for example, "It is a dark city: no lights and no law.") and very relatable characters. There is a glossary at the end for local terms.

\section{Preview of how you'll read and discuss this}

\section{book during safe spaces:}

Topics from the safe spaces curriculum that are covered in this book include prejudice, being different from other people, teasing/bullying, and standing up for what is right. It's a great book, but it is too long to read all of it. You will read the first chapter to introduce the characters, then read some chapters and skip others. Do encourage the girls to read the whole book - there's lots of other exciting parts. Before you start reading, remind the girls that the narrator - Dudu - is not real, she is a character created by the writer Here's how you'll read the book:

Session 17: Read Chapter 1. After you read Chapter 1, you will summarize what happens in Chapters 2-6 as follows:

In the next several chapters, some of the main things that happens are that Dudu writes to her father, but when her mother finds out that Dudu did this, she is furious with Dudu and they have an argument. At school, Alison teases Dudu again and they get into a physical fight. And, in the community, tensions are picking up. People in Alex are angry that foreigners who have come to make a life in South Africa are getting houses in Alex. Some "tsotsi" (gangsters) harass those who they consider different from them, including refugees. For example, one day when Dudu and S'bu are at a friend's father's store, two tsotsi throw a rock through an open window and hit the owner in the head. He is okay, but is bleeding

Session 18: Read Chapter 7. [Note: if you want, you can quickly re-read the summary of Chapters 2-6 to remind the girls of what is happening in the story.]

Session 19: Read Chapters 9 and 10 [Yes, you will skip Chapter 8; that is okay.] 


\section{warm-up}

\section{$\mathrm{BOOK} \mathrm{BOARD}$}

[5 MINUTES]

1. As in the previous session, create a simple book board chart on the chalkboard.

2. Before the start of the session, ask participants to write the name of the

book(s) they have read since the last safe space meeting and rate the book(s) with a smiley face (-) if they liked it or a frown face $(1)$ if they did not like it.

3. Point out the books that are listed on the book board and encourage the group to keep sharing book titles they have read each week.

4. Ask if anyone would like to summarize the book they read, and what they liked or didn't like about it. Take one to two volunteers depending on time. The activity should not take more than five minutes.

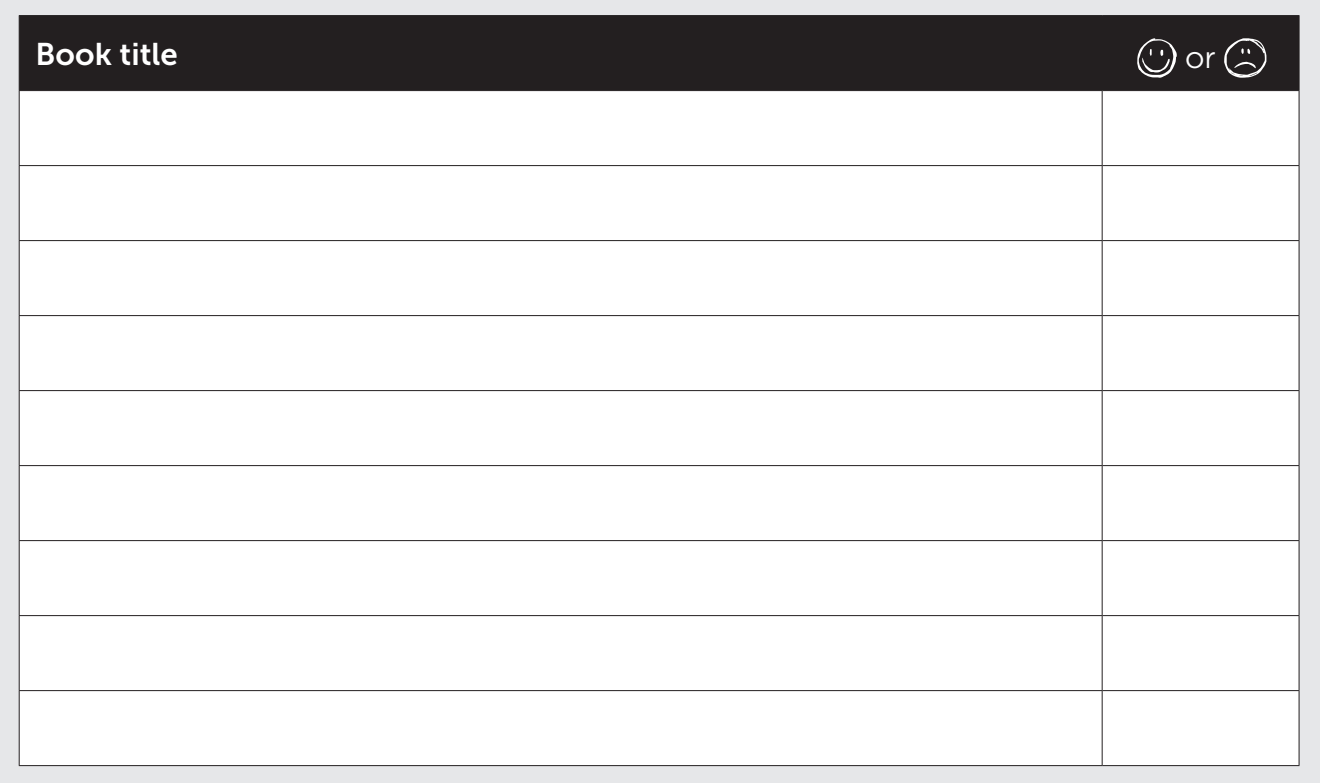




\section{activity 1}

\section{CHORAL READING, LONDI THE DREAMING GIRL BY NATHALIE KOENIG AND LAUREN HOLLIDAY [15 MINUTES]}

1. Explain: Today we are going to use a technique called choral reading. With choral reading, we read all together out loud as a group.

2. Say: Please open the e-book, Londi the Dreaming Girl to location 1 where the title and opening text, "Londi was a dreaming girl," is found. "Check." [Verify that

everyone is on the right book and on the first page of text. Help anyone who is not able to find the book.]

3. Let's begin reading together, "Londi was a dreaming girl..."

4. After finishing the book, ask:

- What did you enjoy about the book?

If you could give the book another title, what would it be?

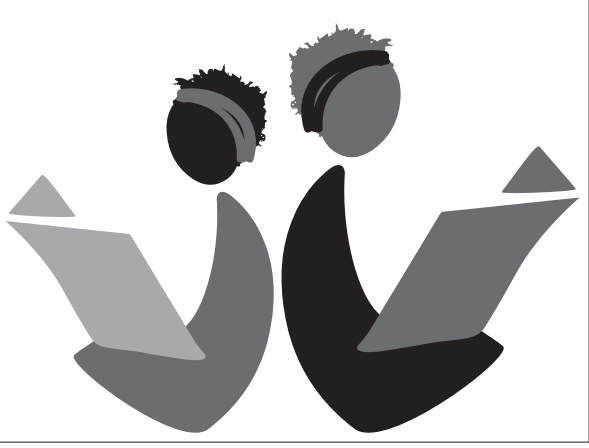




\section{activity 2}

\section{MENTOR READ ALOUD, A SHINING STAR (PART 1) BY JULIE BAKER [35 MINUTES]}

1. Note for mentor: As in the previous sessions, you should practice reading the selected book aloud when preparing your session and look up the meaning of potentially unfamiliar words. While reading demonstrate good reading by being audible, clear, and expressive.

2. Say: Please open the e-book A Shining Star to Chapter 1. "Check." [Verify that everyone is on the right book and chapter. Help anyone who is not able to find the book.]

3. Explain: I will read Chapter 1 out loud. Please follow along in your e-readers as I read.

4. After reading Chapter 1 , explain that you will not be reading Chapters 2-6, but instead you'll give them a summary of the highlights:

Say: In the next several chapters, some of the main things that happen are that Dudu writes to her father, but when her mother finds out that Dudu did this, she is furious with Dudu and they have an argument.

At school, Alison teases Dudu again and they get into a physical fight. And, in the community, tensions are picking up.
People in Alex are angry that foreigners who have come to make a life in South Africa are getting houses in Alex. Some "tsotsi" (gangsters) harass those who they consider different from them, including refugees. For example, one day when Dudu and S'bu are at a friend's father's store, two tsotsi throw a rock through an open window and hit the owner in the head. He is okay, but is bleeding.

5. After reading the summary, ask the participants:

- What has happened so far in the story?

As you have been reading, what pictures have been in your mind of the people and places in the story? 


\section{wrap-up}

\section{WRAP-UP \\ [5 MINUTES]}

Explain: In next week's session, we will read Singing the Truth: The Story of Miriam Makeba

for Activity 1 and Chapter 7 of $A$ Shining Star

for Activity 2. Please try to read these books in

advance of next week's session.

Ask: Are there any other books on the e-readers that you hope to read between now and our next safe space meeting? [Allow time for

sharing.]

Ask: Is there anything you would like to discuss about today's session? Did you learn anything new? What are you looking forward to for next week's session?

Thank the group for their participation.

Encourage them to read as much as possible

between now and the next session, whether on

their own, with a parent/guardian, sibling, friend,

or neighbor. The more they read, the better

readers they will become. 


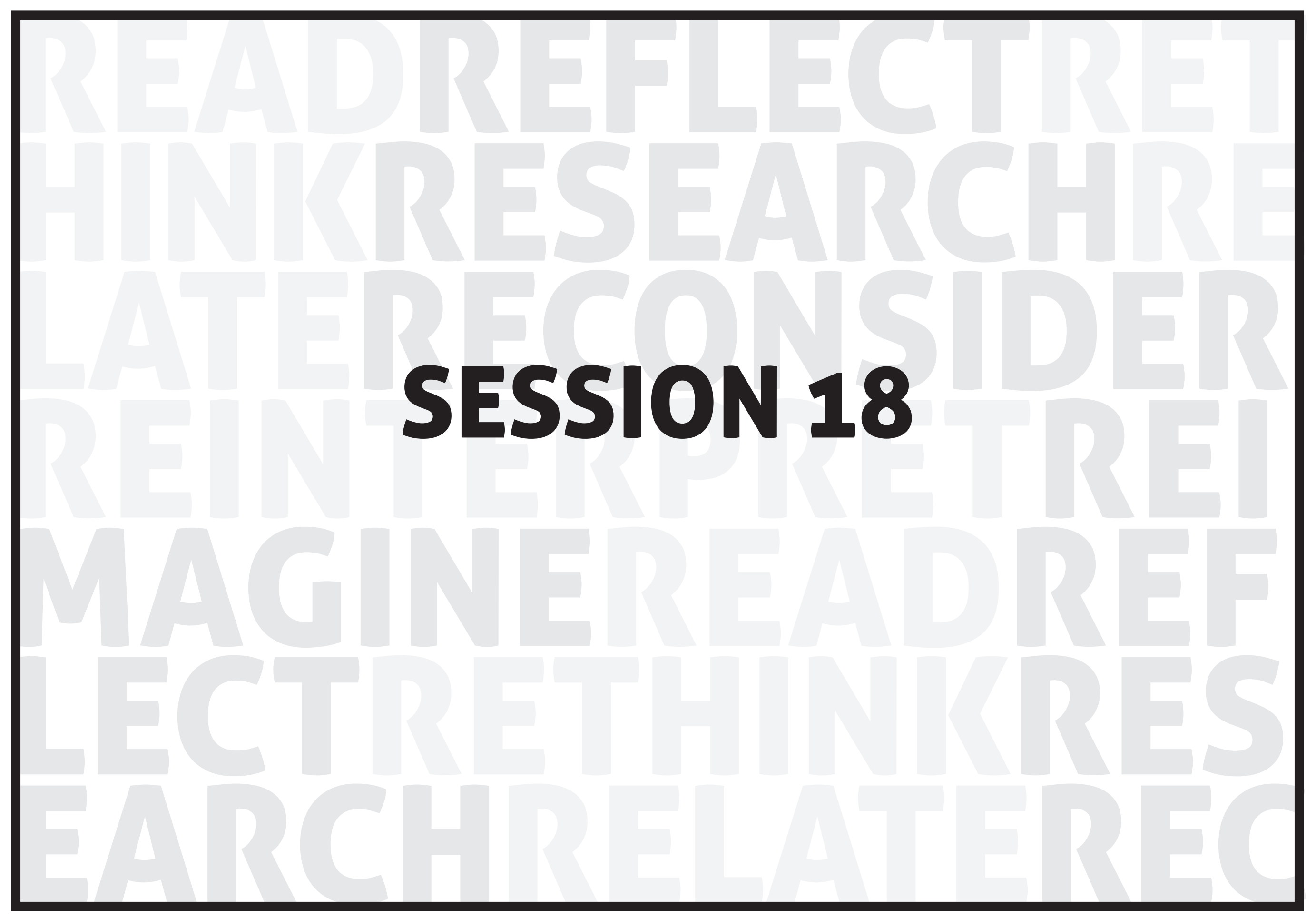




\section{session 18}

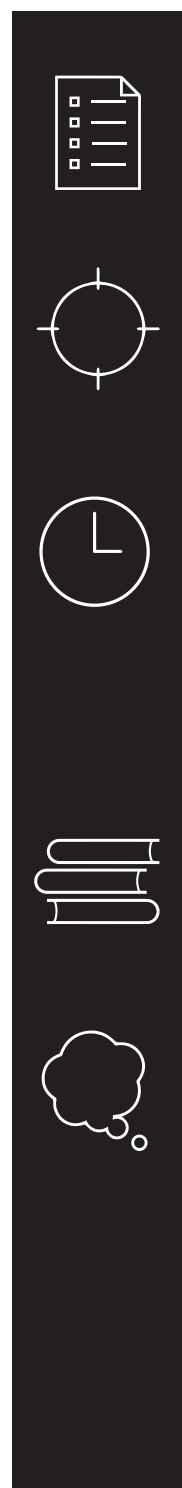

SESSION DESCRIPTION

Share books read the previous week and practice reading as a group.

\section{OBJECTIVES}

In this session, participants will:

Practice reading

Follow along while the mentor reads aloud

SESSION TIME

1 hour

Warm-up: Book board, 5 minutes

Activity 1: Paired reading, Singing the Truth: The Story of Miriam

Makeba, 15 minutes

Activity 2: Mentor read aloud, A Shining Star (part 2), 35 minutes

Wrap-up, 5 minutes

\section{REQUIRED MATERIALS}

Devices (e-readers)

Chalkboard, chalk, and eraser

\section{PRE-SESSION PREPARATION}

Read through the entire session and, if necessary, practice presenting the activities. Prepare all materials needed.

Read the e-book for Activities 1 and 2 in advance.

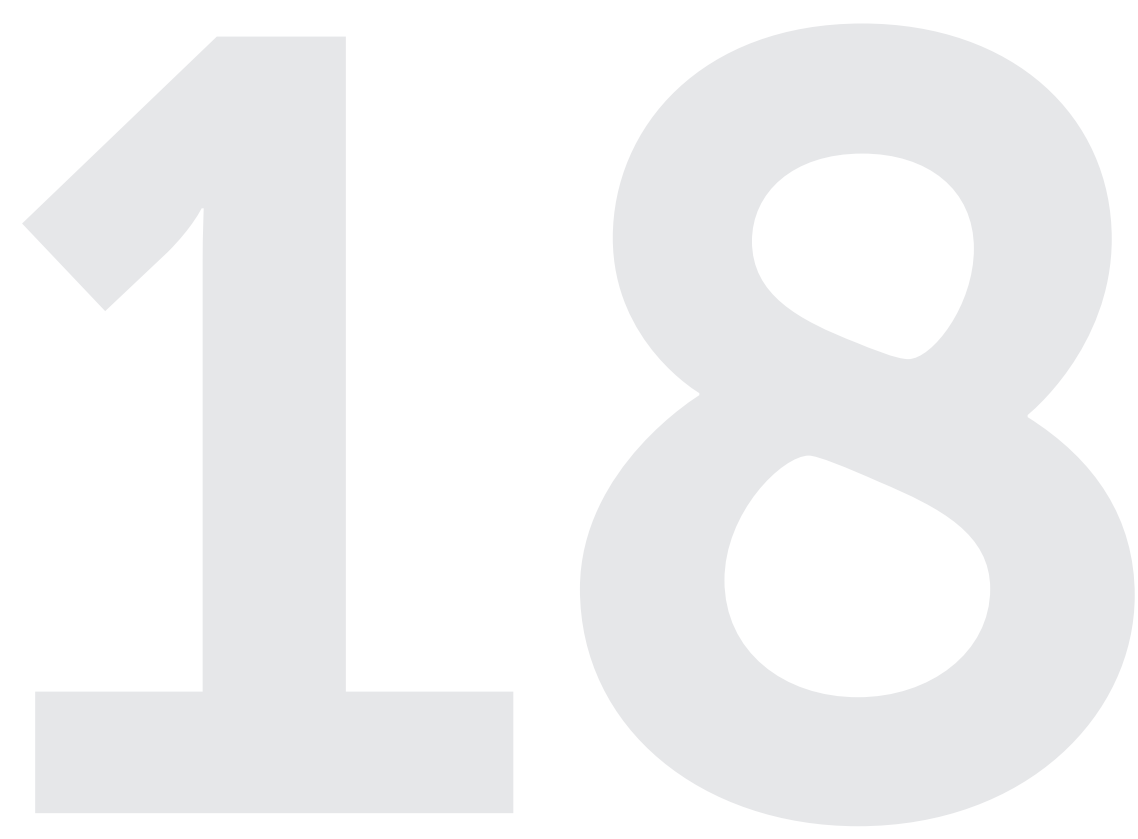




\section{warm-up}

\section{$\mathrm{BOOK} \mathrm{BOARD}$}

[5 MINUTES]

1. As in the previous session, create a simple book board chart on the chalkboard.

2. Before the start of the session, ask participants to write the name of the

book(s) they have read since the last safe space meeting and rate the book(s) with a smiley face (-) if they liked it or a frown face 2 if they did not like it.

3. Point out the books that are listed on the book board and encourage the group to keep sharing book titles they have read each week.

4. Ask if anyone would like to summarize the book they read, and what they liked or didn't like about it. Take one to two volunteers depending on time. The activity should not take more than five minutes.

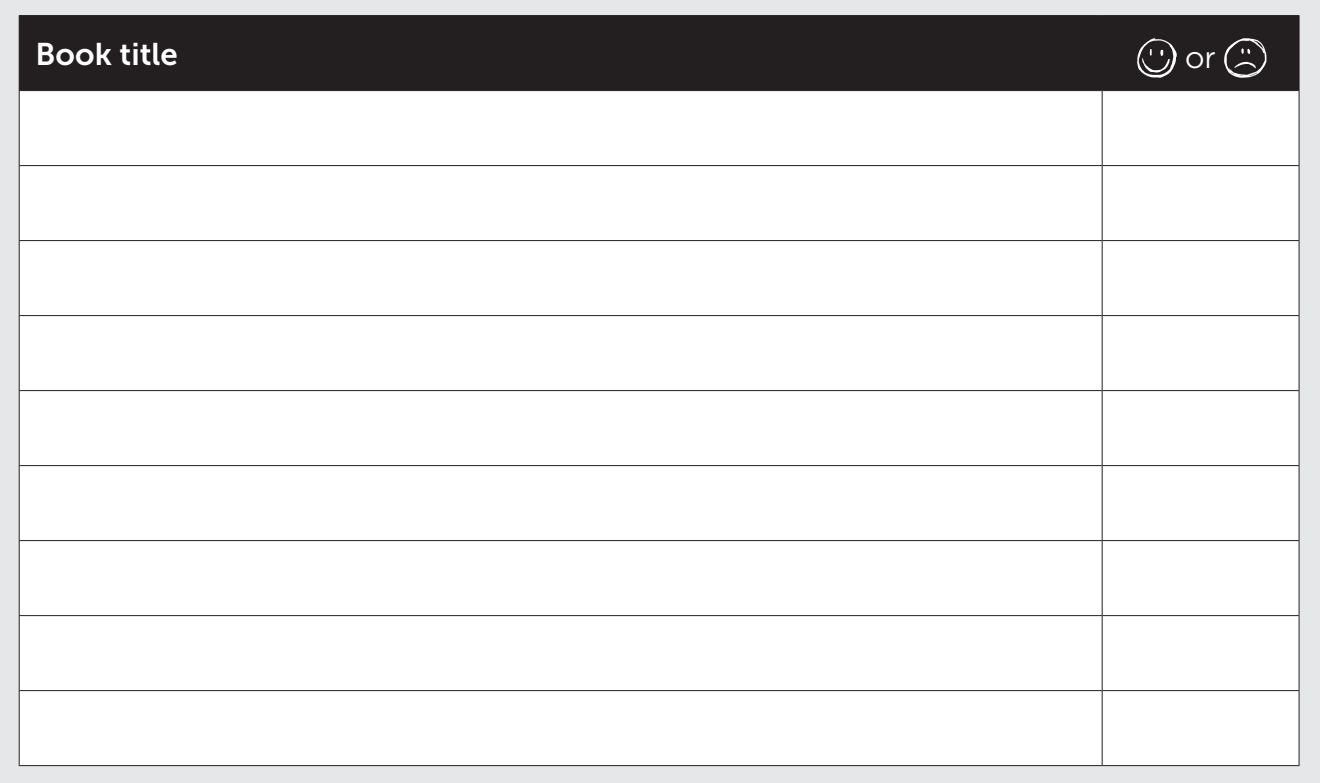




\section{activity 1}

\section{PAIRED READING, SINGING THE TRUTH: THE STORY OF MIRIAM MAKEBA BY LOUWRISA BLAAUW, BIANCA DE JONG, AND JADE MATHIESON [15 MINUTES]}

1. Explain: Today we are going to do paired reading. As you may remember, in paired reading you will be paired with another participant and will read aloud to each other, switching on and off so that there is one person reading at a time. If there is an uneven number, one person will pair with a mentor. Remember to help each other pronounce words correctly. [Note: Remember to pair the weaker readers with the stronger readers.]

2. Say: Please open the e-book Singing the Truth: The Story of Miriam Makeba. "Check." [Verify that everyone is on the right book. Help anyone who is not able to find the book.]

3. After all pairs have finished reading the story, ask everyone to come back to the main circle.
4. Ask the following questions:

How many people have heard of Miriam Makeba or any of her songs? [If no one knows her or any of her songs, see if

they know "Pata Pata (The Click Song),"

"Malaika," or "Soweto Blues" - all famous

Miriam Makeba songs.]

What have you learned about Miriam Makeba's life from this story? 


\section{activity 2}

\section{MENTOR READ ALOUD, A SHINING STAR (PART 2) BY JULIE BAKER [35 MINUTES]}

1. Note for mentor: As in the previous sessions, you should practice reading the selected book aloud when preparing your session and look up the meaning of potentially unfamiliar words. While reading demonstrate good reading by being audible, clear, and expressive.

2. Say: Please open the e-book $A$ Shining Star to Chapter 7 (location 365). "Check." [Verify that everyone is on the right book and chapter. Help anyone who is not able to find the book.]

3. Explain: Before I read Chapter 7, I want to remind you of what happened in Chapters 2-6:

- In Chapters 2-6, some of the main things that happen are that Dudu writes to her father, but when her mother finds out that Dudu did this, she is furious with Dudu and they have an argument. At school Alison teases Dudu again and they get into a physical fight, and in the community, tensions are picking up. People in Alex are angry that foreigners who have come to make a life in South Africa are getting houses in Alex. Some "tsotsi" (gangsters) harass those who they consider different from them, including refugees. For example, one day when Dudu and S'bu are at a friend's father's store, two tsotsi throw a rock through an open window and hit the owner in the head. He is okay, but is bleeding.

4. Explain: Now I will read Chapter 7 out loud. Please follow along in your e-readers as I read.

5. After reading Chapter 7, ask the participants:

How do you think S'bu is feeling? And Dudu?

- What do you think of the book so far? 


\section{wrap-up}

\section{WRAP-UP \\ [5 MINUTES]}

Explain: In next week's session, we will read $A$ Tiny Seed: The Story of Wangari Maathai for

Activity 1 and Chapters 9-10 of $A$ Shining Star

for Activity 2. Please try to read these books in advance of next week's session.

Ask: Are there any other books on the

e-readers that you hope to read between now and our next safe space meeting? [Allow time

for sharing.]

Ask: Is there anything you would like to

discuss about today's session? Did you learn anything new? What are you looking forward to for next week's session?

Thank the group for their participation.

Encourage them to read as much as possible between now and the next session, whether on their own, with a parent/guardian, sibling friend, or neighbor. The more they read, the better readers they will become.

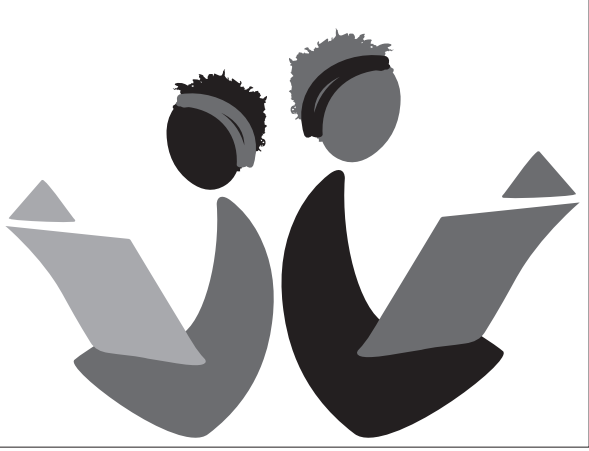




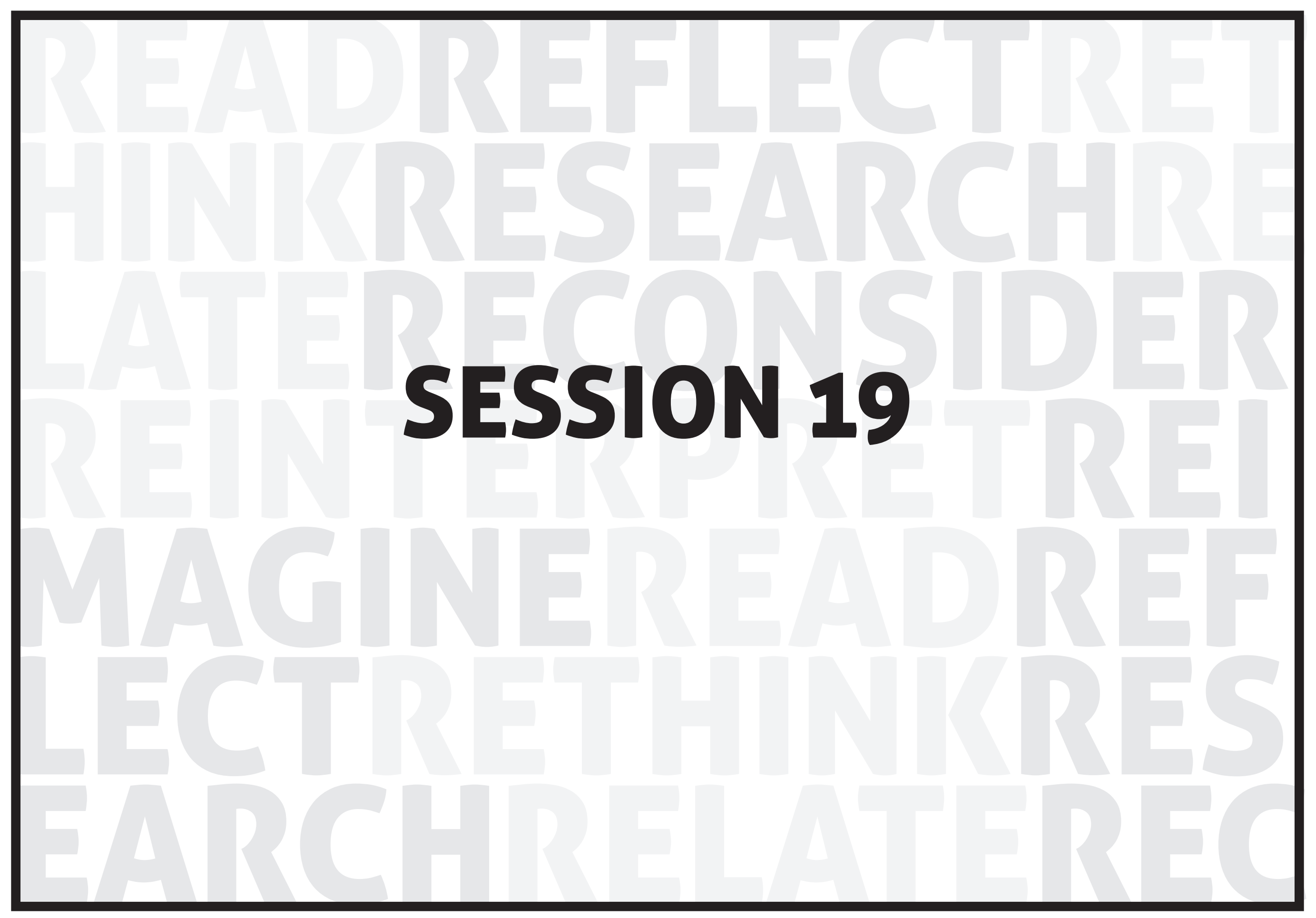




\section{session 19}

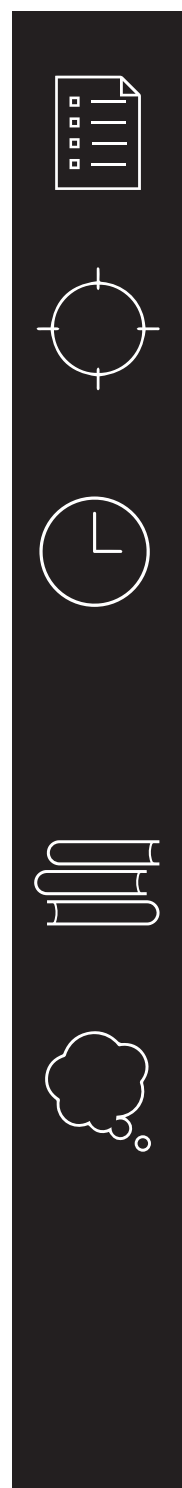

SESSION DESCRIPTION

Share books read the previous week and practice reading as a group.

\section{OBJECTIVES}

In this session, participants will:

Practice reading

Follow along while the mentor reads aloud

SESSION TIME

1 hour

Warm-up: Book board, 5 minutes

Activity 1: Paired reading, A Tiny Seed: The Story of Wangari Maathai,

15 minutes

Activity 2: Mentor read aloud, A Shining Star (part 3), 35 minutes

Wrap-up, 5 minutes

\section{REQUIRED MATERIALS}

Devices (e-readers)

Chalkboard, chalk, and eraser

\section{PRE-SESSION PREPARATION}

Read through the entire session and, if necessary, practice presenting the activities. Prepare all materials needed.

Read the e-book for Activities 1 and 2 in advance.

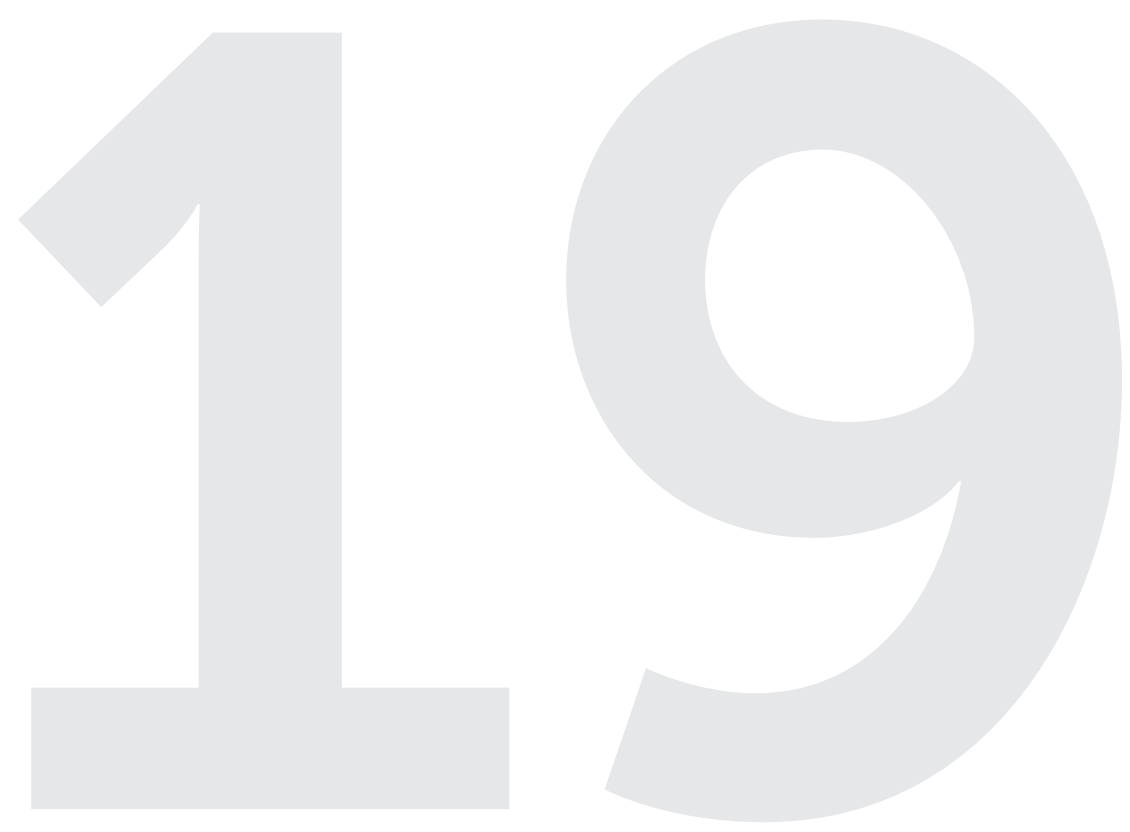




\section{warm-up}

\section{$\mathrm{BOOK} \mathrm{BOARD}$}

[5 MINUTES]

1. As in the previous session, create a simple book board chart on the chalkboard.

2. Before the start of the session, ask participants to write the name of the

book(s) they have read since the last safe space meeting and rate the book(s) with a smiley face (-) if they liked it or a frown face $(1)$ if they did not like it.

3. Point out the books that are listed on the book board and encourage the group to keep sharing book titles they have read each week.

4. Ask if anyone would like to summarize the book they read, and what they liked or didn't like about it. Take one to two volunteers depending on time. The activity should not take more than five minutes.

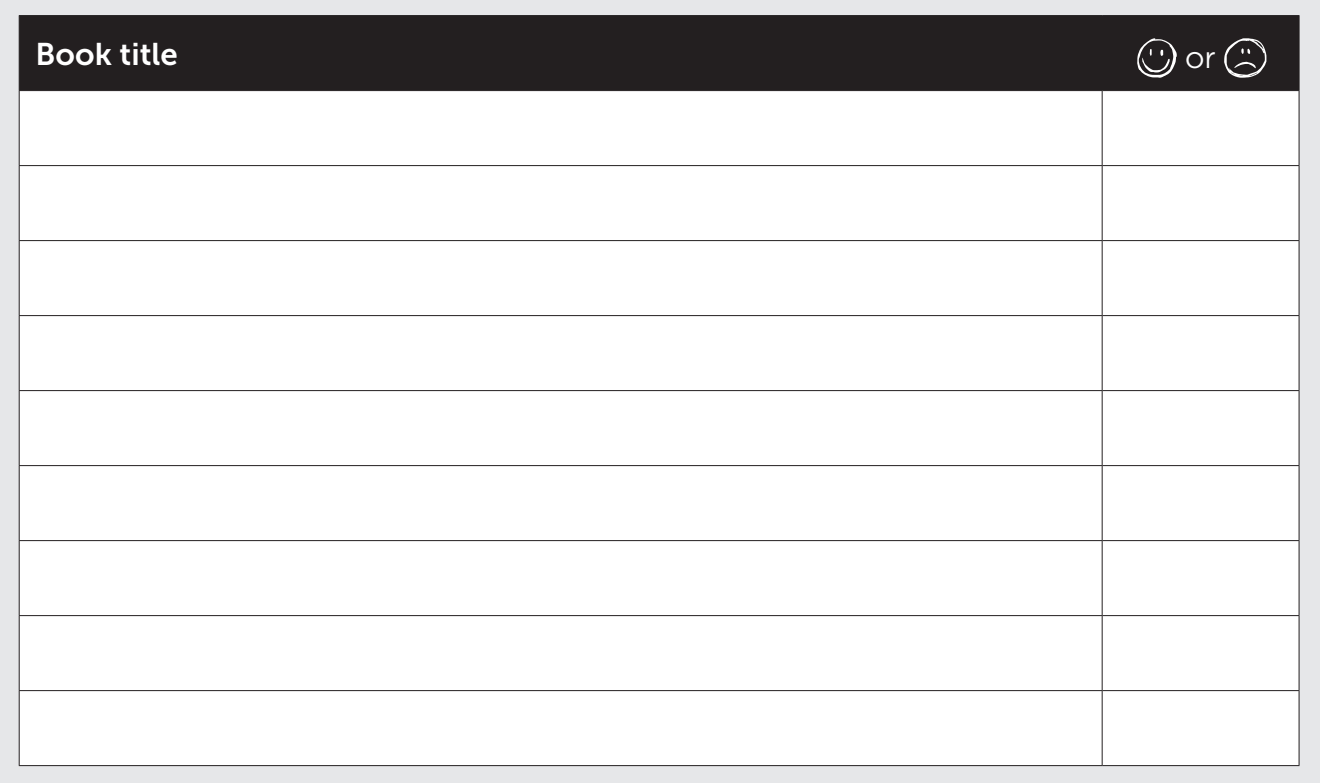




\section{activity 1}

\section{ECHO READING, A TINY SEED: THE STORY OF WANGARI MAATHAI BY \\ NICOLA RIJSDIJK [15 MINUTES]}

1. Explain: Now we are going to read a

book using echo reading. Could someone

remind me what echo reading is? [Let

participants answer. Remind them that

you will read a sentence, few lines, or a

paragraph, then when you stop and point

at the group, they will repeat (re-read) or

"echo" what was read.]

2. Say: Please open the e-book A Tiny Seed: The Story of Wangari Maathai "Check."

[Verify that everyone is on the right book.

Help anyone who is not able to find the

book. Begin reading, stopping periodically

when it makes sense to stop and point at

the group indicating that it is time for them

to re-read what you just read.]

3. After reading the book, ask the following questions:

-What did you learn from this book?

-What do you think about Wangari Maathai? Does her story inspire you? If so, how/ why?

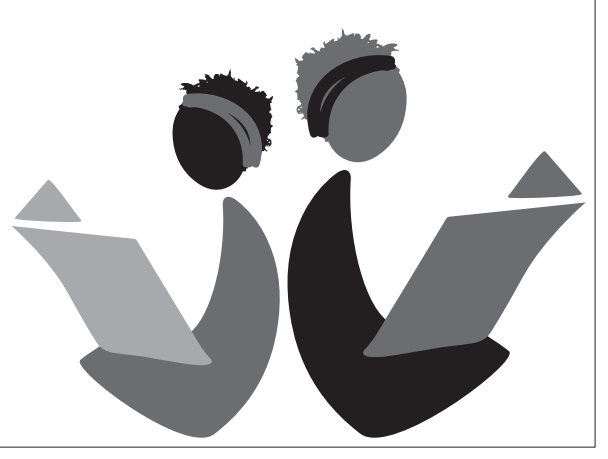




\section{activity 2}

\section{MENTOR READ ALOUD, A SHINING STAR BY JULIE BAKER (PART 3) [35 MINUTES]}

1. Note for mentor: As in the previous sessions, you should practice reading the selected book aloud when preparing your session and look up the meaning of potentially unfamiliar words. While reading demonstrate good reading by being audible, clear, and expressive.

2. Say: Please open the e-book $A$ Shining Star to Chapter 9 (location 471). "Check. [Verify that everyone is on the right book and chapter. Help anyone who is not able to find the book.]

3. Explain: Remember that we read Chapter 7 last week; we are skipping Chapter 8. Now I will read Chapters 9-10 out loud. Please follow along in your e-readers as I read.

4. After reading Chapters $9-10$, ask the participants:

What do you all think happens next? [Give the group some time to share what they think will happen next.]
5. Explain what happens in the rest of the book: There is a community meeting called at the library and Dudu and her mom go. Dudu's mom stands and speaks at the meeting, saying, "We all belong here, every one of us. Not just bona fides...l almost died. Beaten and left for dead by my own people because my daughter is only half Zulu. I have a right to live here, so does Dudu. She can go to school where she likes and I will grow red, pink and orange lettuce if I want to." Dudu is proud of her mother.

6. Ask: What about Dudu and S'bu? What do you think happens to their friendship? [Explain that although for a while Dudu avoided S'bu and ignored him if she saw him, S'bu stands up for Dudu at school when Allison tries to bully her and Dudu forgives him for not standing up for her during the protest. They become friends again and declare their love for each other.]

How does the end of the story make you feel?

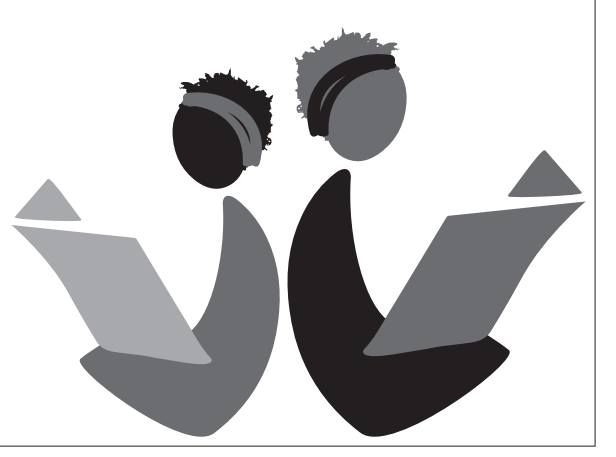




\section{wrap-up}

\section{WRAP-UP \\ [5 MINUTES]}

Explain: This is the last e-reader session for GirlsRead! I hope that you have enjoyed

this time as we read books together on the

e-readers. It has been very special for us as mentors to spend this time with you, discuss

new topics, and improve our reading skills. As

we wrap up the last session, I would love to ask

you a few questions:

-What was your favorite book you read

from all of the e-reader sessions? [Allow

many participants to answer.]

- Is there anything you would like to

discuss about any of the books we read throughout the program? Did you learn anything new?

What was your favorite part of being a part of GirlsRead!?

Say: Thank you for your great participation over the previous months. Please keep reading as

much as possible, even though the program is ending. Although you will graduate from the program next week, I hope that the lessons and skills learned during GirlsRead! will carry on.

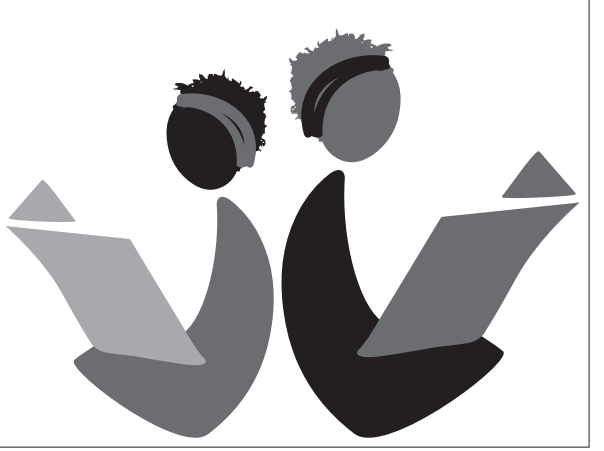




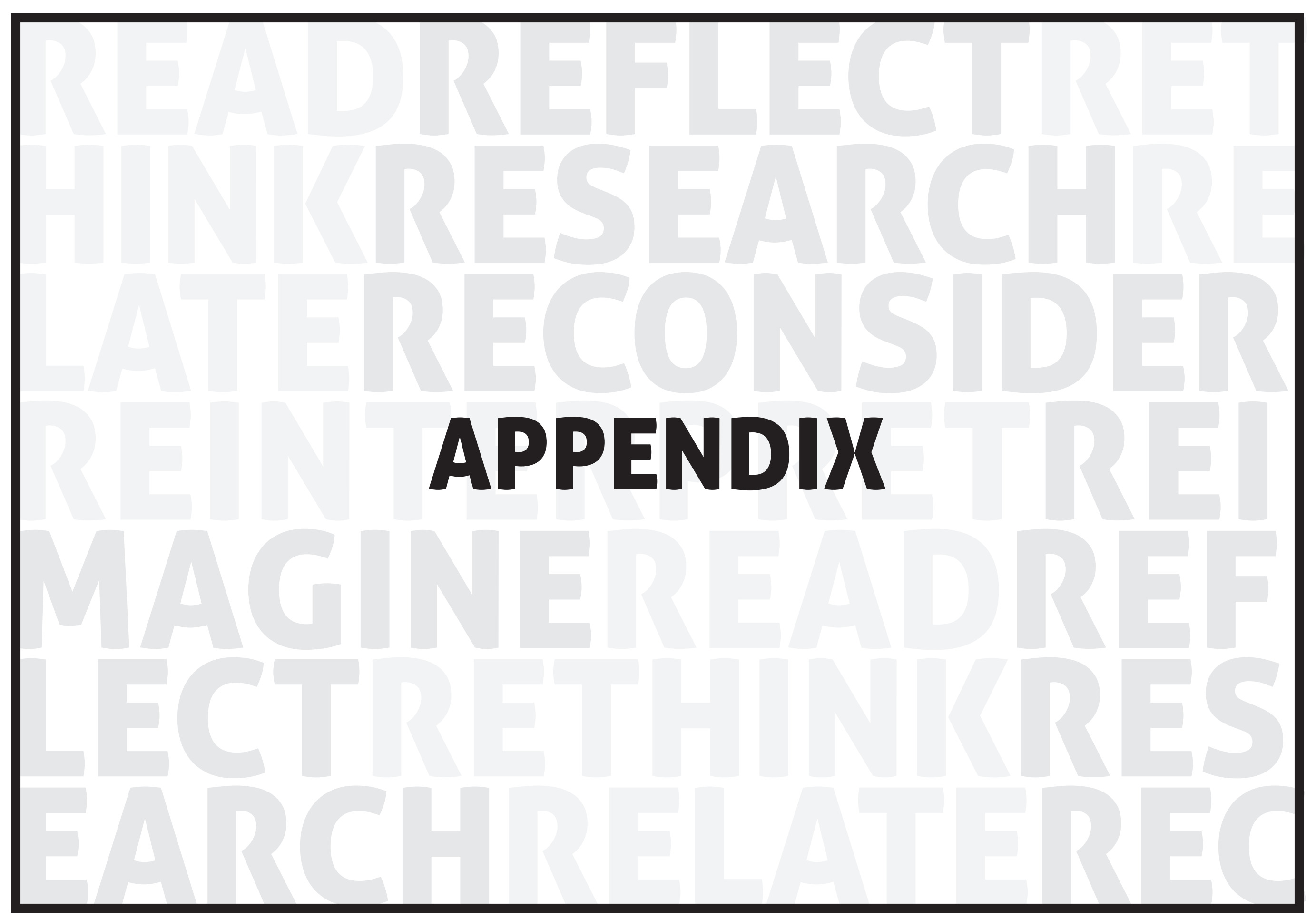




\section{top zone}

TAP THIS AREA TO DISPLAY THE TOOLBAR

\section{right zone}

\section{TAP THIS AREA TO GO}

TO THE NEXT PAGE

\section{left zone}

4 tap this area to go to

THE PREVIOUS PAGE 


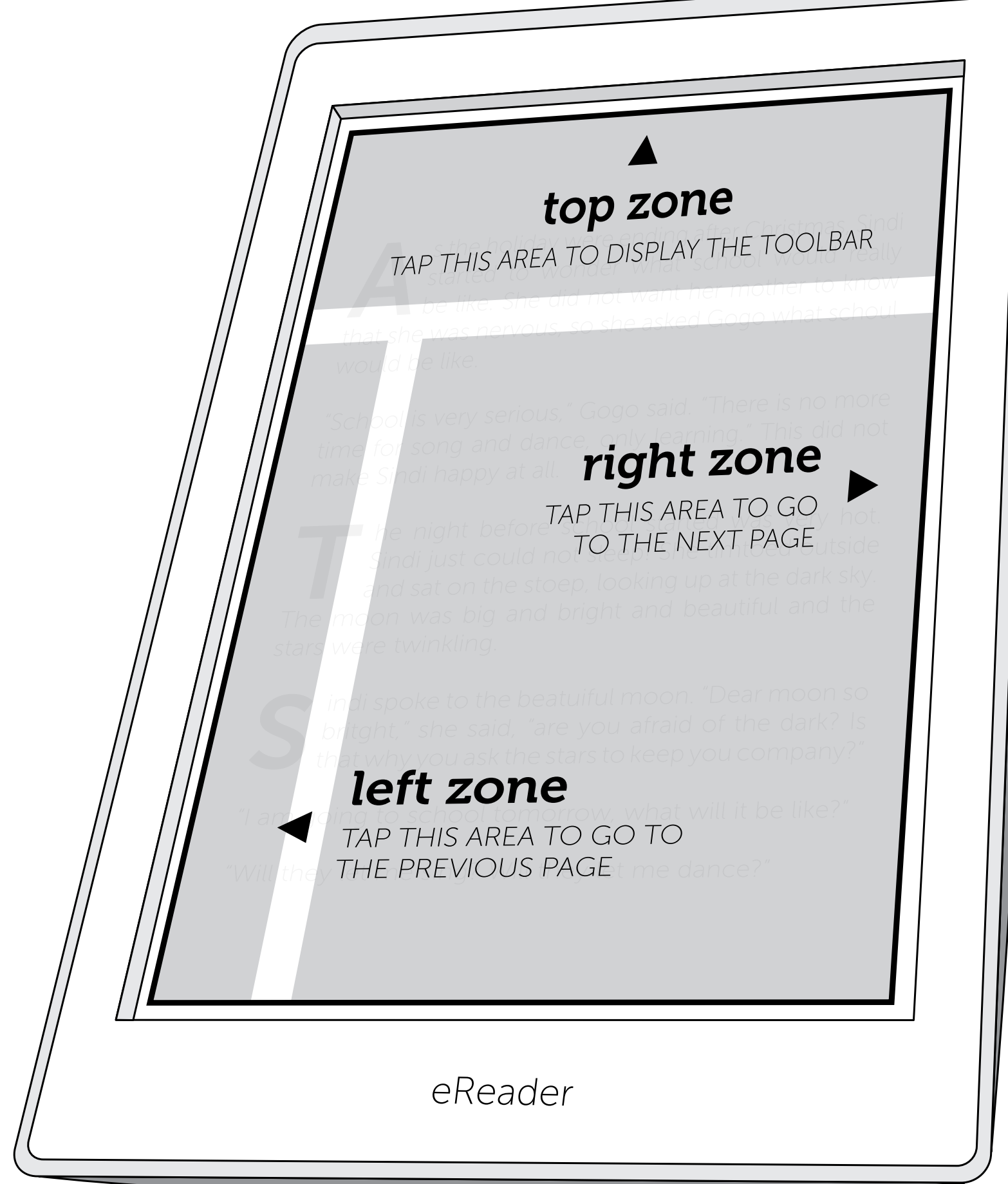




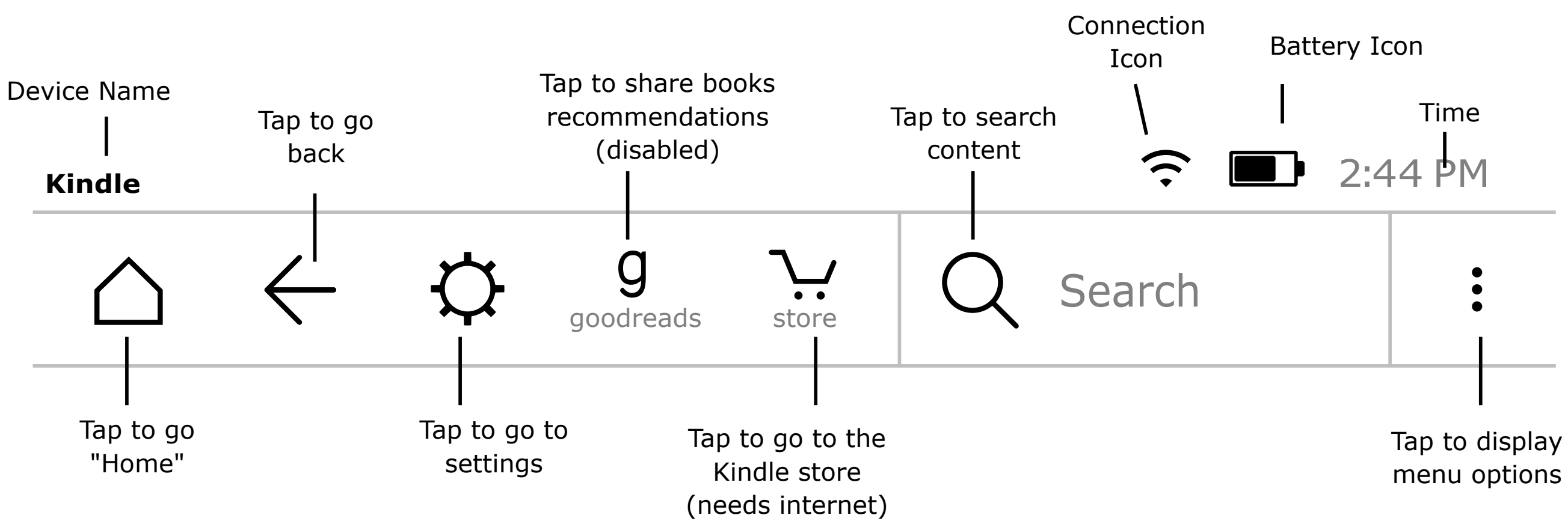




\section{references}

International Sexuality and HIV Curriculum Working Group. 2009, updated 2011. It's All One Curriculum: Guidelines and Activities

for a Unified Approach to Sexuality, Gender, HIV and Human Rights Education. New York: Population Council.

www.popcouncil.org/publications/

books/2010_ItsAllOne.asp

Population Council. 2013. Life Skills and

Health Curriculum for the Adolescent Girls

Empowerment Program (AGEP).

www. popcouncil.org/uploads/pdfs/2013PGY

HealthLifeSkills_AGEP.pdf

Worldreader. 2017. GirlsRead! Zambia

E-reader Training Guide: Kindle Paperwhite

Model.

Worldreader. 2017. GirlsRead! Zambia

E-reading Integration Guide. 


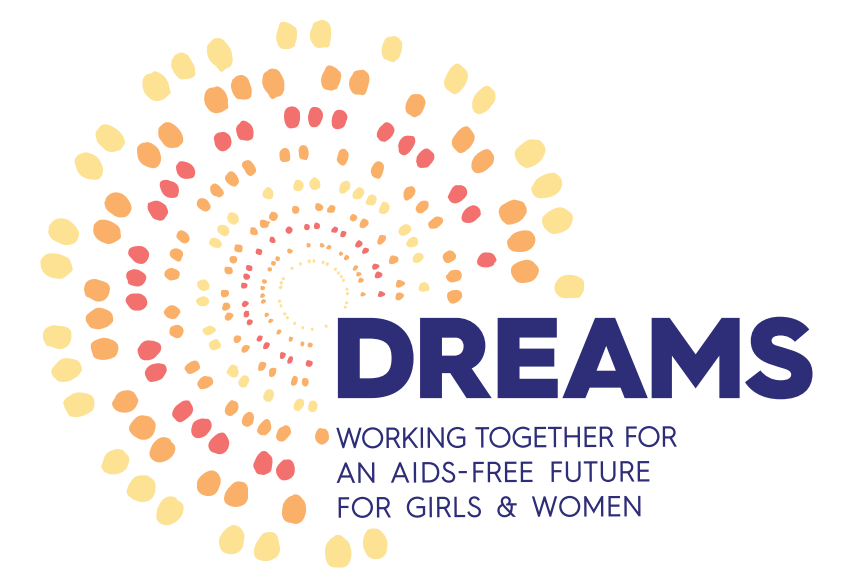

Determined Resilient Empowered AlDS-Free Mentored Safe

